\title{
RELAÇÃO DO ESTADO NUTRICIONAL, NIVEIS SÉRICOS DE COLESTEROL, FRAÇÕES E TRIGLICÉRIDES COM O CONSUMO ALIMENTAR DE GORDURAS E FIBRAS EM IDOSOS.
}

VERA LÜCIA SAMPAR DE SOUZA NOVAES

Tese apresentada ao Departamento de Prática de Saúde Pública da Faculdade de Saúde Pública da Universidade de São Paulo para obtenção do titulo de Doutor em Saúde Pública

Área de concentração: Prática de Saúde pública

ORIENTADOR: Prof. Dr. Luiz Eugênio Garcez Leme

São Paulo

2003

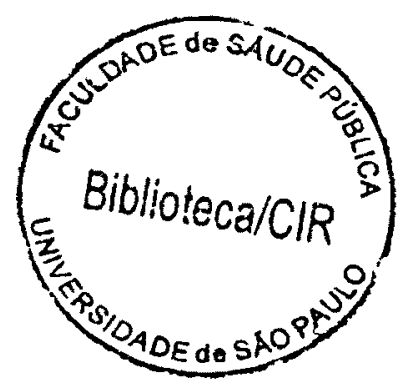




\section{Errata}

Na página 21, Tabela 2, linha "Normal", coluna "feminino \%", onde se lê 64,2 leia-se $34,2$. 
"Porque o Senhor dá sabedoria, da sua boca vem a inteligência e o entendimento"

Provérbios 2:6

"Toda substância, inteligência, sabedoria, existência, imortalidade, causa e efeito, pertencem a Deus"

Mary Baker Eddy 
Dedicado

À memória da minha mãe, Magdalena $\mathbf{e}$

Aos meus amores: Vicente, Taís, Lívia e Júlia 


\section{AGRADECIMENTOS}

Ao Prof. Dr. Luiz Eugênio Garcez Leme, pela orientação, confiança e importante contribuição no encaminhamento deste trabalho.

À Profa. Dra. Yolanda Maria Garcia, pela disponibilidade em atender minhas solicitações, pelas sugestões e por compartilhar o banco de dados que possibilitou a elaboração deste trabalho.

À Profa. Titular Maria José Roncada, pelo carinho e pela importante contribuição no desenvolvimento e finalização deste trabalho.

Ao Prof. Dr. Matheus Papaléo Netto, pela especial atenção e importante contribuição na conclusão deste trabalho.

Á Prof. Dra. Sônia Tucunduva Philippi, pelas importantes sugestões na fase final deste trabalho.

Ao Eng. Antônio Vicente Novaes Jr pela dedicação, incentivo, companheirismo e colaboração, fundamentais na execução deste trabalho

A minha filha Lívia Lais de Souza Novaes pela colaboração na digitação dos dados.

À Prof. Silvia Suini Sanchez pelas sugestões, pela amizade e pelo apoio. 
À nutricionista Mônica Inez Elias Jorge pela colaboração e interesse demonstrado.

Ao Dr. Hermes Sanchez Cruz pela colaboração e empenho na revisão do texto.

A todos os colaboradores diretos e indiretos deste trabalho meus sinceros agradecimentos. 


\section{RESUMO}

Novaes VLSS. Relação do estado nutricional, niveis séricos de colesterol, frações e triglicérides com o consumo alimentar de gorduras e fibras em idosos. São Paulo;2003.[Tese de Doutorado- Faculdade de Saúde Pública da Universidade de São Paulo].

Objetivo. O presente trabalho pretendeu analisar a ingestão energética, de gorduras e fibras da dieta de idosos, correlacionando-as ao estado nutricional e parâmetros bioquímicos. Métodos. Este é um estudo transversal, observacional, analítico, com idosos atendidos em ambulatório de geriatria. A população é composta por 368 indivíduos, com idade igual ou superior a 60 anos, de ambos os sexos. Como instrumento de avaliação foi realizado inquérito alimentar pelo método recordatório de 24 horas para análise da dieta. Utilizou-se como parâmetro de adequação para energia e gorduras, as recomendações do National Research Council,1989. Para o diagnóstico nutricional foi utilizado o Índice de Massa Corpórea (IMC) expresso em $\mathrm{kg} / \mathrm{m}^{2}$. Foram utilizadas como referências para os parâmetros bioquímicos os valores recomendados pela Sociedade Brasileira de Cardiologia,2001. Na análise estatística foi empregada a regressão linear e utilizada a análise de variância (ANOVA), adotando-se nivel de $5 \%$ para a significância dos testes. Resultados. A média diária de energia para os homens foi de $2175 \mathrm{Kcal}$ e para as mulheres de $2025 \mathrm{kcal}$. O consumo de gorduras totais foi menor que $30 \%$ da energia diária da dieta e, considerado 
adequado; a gordura polinsaturada ficou aquém do esperado (menor que 1/3 da gordura total). A ingestão média de fibras foi de $17,7 \mathrm{~g}$ para ambos os sexos, quantidade considerada insuficiente, segundo a recomendação do Food and Drug Administration, 1993. O estudo mostrou que, à medida que a idade avança, diminui a ingestão de colesterol e gorduras totais. $\mathrm{O}$ aumento de peso mostrou correlação, estatisticamente significativa, com os niveis séricos de triglicérides (TG), lipoproteinas de alta densidade (HDL-c) e colesterol total (CT). Houve associação, para ambos os sexos, entre a obesidade e os niveis séricos de colesterol. Não houve associação entre a ingestão de fibras alimentares e os níveis séricos de colesterol. Conclusões. A obesidade interfere nos niveis séricos de CT, HDL-C e TG. Para ambos os sexos a inadequação calórica leva à obesidade. A ingestão fibras não interferiu nos niveis séricos de HDL-c de forma significativa na população idosa estudada.A ingestão de gorduras totais mostrou associação com os niveis séricos de HDL-C.

Descritores. Idosos. Dieta. Estado Nutricional. Ingestão de fibras. Ingestão de gorduras. 


\section{ABSTRACT}

Novaes VLSS. Relationship of nutritional condition in the elderly, blood cholesterol levels and fractions and triglycerids with food consumption of fats and fibers. São Paulo; 2003.\{ Doctoral Thesis-School of Public Health of the University of São Paulo \}.

Objective. This study sought to analyze the ingestion of calories, fats and dietary fibers of the elderly and correlate them with their nutritional state and biochemical parameters. Methods. The project is an analytical, observational, transversal study of the elderly attended to in a geriatric outpatient clinic. The population studied consists of 368 individuals of 60 years old or more of both genders. The instrument used for the assessment was a recall method related to the previous 24 hours. The recommendations of The National Research Council, 1989 were used as the parameters of adequacy regarding energy and fats. The body mass index (BMI), expressed in $\mathrm{kg} / \mathrm{m}^{2}$ was used for the nutritional diagnosis. The values recommended by the Brazilian Society of Cardiology, 2001 were used as reference values for the biochemical parameters. Linear regression and variance analysis (ANOVA) were used for the statistical analysis, $5 \%$ being adapted as level of significance of the tests. Results the daily average of calories consumption of was $2175 \mathrm{kcal}$ for the men and $2025 \mathrm{kcal}$ for the women. Total intake of fats accounted for less than $30 \%$ of daily diet, though the poly insaturated fats fell short of the amount expected (less than 1/3 of total fats). The average intake of fibers was $17,7 \mathrm{~g}$ for both sexes, classified as insufficient according to the recommendation of the Food and Drug Administration, 1993. The study showed that, as age increases, the ingestion of cholesterol and total fat diminishes. Weight increase showed a significant statistical correlation with blood levels of triglycerids, high-density lipoproteincholesterol (HDL-C). No association was found between the ingestion of dietary fibers and blood cholesterol levels. Conclusions: Obesity, both genders, affects the blood levels of cholesterol, HDL-C and triglycerids. 
Inadequate consumption of calories leads to obesity both genders. Fibers intake had no significant effect on the blood levels of HDL-c in the elderly population studied. Fat intake had significant effect on the blood levels of HDL-C.

Keywords. Elderly. Diet. Nutritional State. Consumption of Fibers. Consumption of fats. 


\section{ÍNDICE}

1. Introdução

1.1 Envelhecimento da população 1

1.2 Envelhecimento e nutrição 3

1.3 Ingestão de gorduras, fibras e hiperlipidemias 5

1.4 Estado nutricional de idosos $\quad 8$

2. Objetivos

2.1 Geral

2.2 Específicos

3. Procedimento Metodológico

3.1 Delineamento do estudo 13

3.2 População 13

3.3 Casuística 14

4. Levantamento e apuração dos dados

4.1 Inquérito alimentar 14

4.2 Diagnóstico do estado nutricional 16

4.3 Exames bioquímicos $\quad 17$

4.4 Análise estatistica dos dados. 18

5. Resultados

5.1 Caracteristicas da população estudada 20

5.2 Análise das variáveis numéricas do estudo 24

5.3 Análise das variáveis categóricas do estudo 50

6. Discussão

7. Conclusões $\quad 86$

8. Referências Bibliográficas $\quad 87$

9. Anexos

Anexo 1- Parecer do Comitê de Ética em Pesquisa 98

Anexo 2- Formulário - Pesquisa em Idosos 99 


\section{LISTA DE TABELAS}

Tabela 1 - Distribuição percentual dos idosos, segundo o gênero e faixa etária. Ambulatório do Serviço de Geriatria do HCFMUSP. São Paulo, 1988/90.

Tabela 2 - Distribuição percentual dos idosos, segundo a classificação do IMC gênero. Ambulatório do Serviço de Geriatria do HCFMUSP. São Paulo, 1988/90.

Tabela 3 - Média e desvio-padrão dos valores de IMC dos idosos, segundo gênero. Ambulatório do Serviço de Geriatria do HCFMUSP. São Paulo, 1988/90.

Tabela 4 - Média, desvio-padrão,mediana e valores máximos e mínimos das variáveis pertinentes dos idosos, segundo gênero. Ambulatório do Serviço de Geriatria do HCFMUSP. São Paulo, $1988 / 90$.

Tabela 5 - Distribuição dos idosos de ambos os gêneros, segundo a adequação dos niveis séricos de HDL-c e a adequação da porcentagem de gordura da dieta. Ambulatório do Serviço de Geriatria do HCFMUSP. São Paulo, 1988/90.

Tabela 6 - Distribuição dos idosos do gênero masculino, segundo a adequação dos niveis séricos de HDL-c e a adequação da porcentagem de gordura da dieta. Ambulatório do Serviço de Geriatria do HCFMUSP. São Paulo, 1988/90. 
Tabela 7 - Distribuição dos idosos do gênero feminino, segundo a adequação dos níveis séricos de HDL-c e a adequação da porcentagem de gordura da dieta. Ambulatório do Serviço de Geriatria do HCFMUSP. São Paulo, 1988/90.

Tabela 8 - Distribuição dos idosos ambos os gêneros, segundo a adequação dos niveis séricos de HDL-c e a adequação do estado nutricional. Ambulatório do Serviço de Geriatria do HCFMUSP. São Paulo, 1988/90.

Tabela 9 - Distribuição dos idosos do gênero masculino, segundo a adequação dos niveis séricos de HDL-c e a adequação do estado nutricional. Ambulatório do Serviço de Geriatria do HCFMUSP. São Paulo, 1988/90.

Tabela 10 - Distribuição dos idosos do gênero feminino, segundo a adequação dos níveis séricos de HDL-c e a adequação do estado nutricional. Ambulatório do Serviço de Geriatria do HCFMUSP. São Paulo, 1988/90.

Tabela 11 - Distribuição dos idosos de ambos os gêneros, segundo a adequação dos niveis séricos de HDL-c e a adequação de fibras. Ambulatório do Serviço de Geriatria do HCFMUSP. São Paulo, 1988/90.

Tabela 12 - Distribuição dos idosos do gênero masculino, segundo a adequação dos niveis séricos de HDL-c e a adequação de fibras. Ambulatório do Serviço de Geriatria do HCFMUSP. São Paulo, 1988/90. 
Tabela 13 - Distribuição dos idosos do gênero feminino, segundo a adequação dos niveis séricos de HDL-c e a adequação de fibras. Ambulatório do Serviço de Geriatria do HCFMUSP. São Paulo, 1988/90.

Tabela 14 - Distribuição dos idosos de ambos os gêneros, segundo a adequação dos niveis séricos de LDL-c e a adequação do estado nutricional. Ambulatório do Serviço de Geriatria do HCFMUSP. São Paulo, 1988/90.

Tabela 15 - Distribuição dos idosos do gênero masculino, segundo a adequação dos niveis séricos de LDL-c e a adequação do estado nutricional. Ambulatório do Serviço de Geriatria do HCFMUSP. São Paulo, 1988/90.

Tabela 16 - Distribuição dos idosos do gênero feminino, segundo a adequação dos níveis séricos de LDL-c e a adequação do estado nutricional. Ambulatório do Serviço de Geriatria do HCFMUSP. São Paulo, 1988/90.

Tabela 17 - Distribuição dos idosos de ambos os gêneros, segundo a adequação dos niveis séricos de LDL-c e a adequação da porcentagem de gordura da dieta. Ambulatório do Serviço de Geriatria do HCFMUSP. São Paulo, 1988/90.

Tabela 18 - Distribuição dos idosos do gênero masculino, segundo a adequação dos niveis séricos de LDL-c e a adequação da porcentagem de gordura da dieta. Ambulatório do Serviço de Geriatria do HCFMUSP. São Paulo, 1988/90. 
Tabela 19 - Distribuição dos idosos do gênero feminino, segundo a adequação dos niveis séricos de LDL-c e a adequação da porcentagem de gordura da dieta. Ambulatório do Serviço de Geriatria do HCFMUSP. São Paulo, 1988/90.

Tabela 20 - Distribuição dos idosos de ambos os gêneros e adequação do colesterol sérico e adequação do estado nutricional. Ambulatório do Serviço de Geriatria do HCFMUSP. São Paulo, 1988/90.

Tabela 21 - Distribuição dos idosos do gênero masculino e adequação do colesterol sérico e adequação do estado nutricional. Ambulatório do Serviço de Geriatria do HCFMUSP. São Paulo, 1988/90.

Tabela 22 - Distribuição dos idosos do gênero feminino e adequação do colesterol sérico e adequação do estado nutricional. Ambulatório do Serviço de Geriatria do HCFMUSP. São Paulo,1988/90.

Tabela 23 - Distribuição dos idosos de ambos os gêneros, segundo a adequação calórica e adequação do estado nutricional. Ambulatório do Serviço de Geriatria do HCFMUSP. São Paulo,1988/90.

Tabela 24 - Distribuição dos idosos do gênero masculino, segundo a adequação calórica e adequação do estado nutricional. Ambulatório do Serviço de Geriatria do HCFMUSP. São Paulo,1988/90.

Tabela 25 - Distribuição dos idosos do gênero feminino, segundo a adequação calórica e adequação do estado nutricional. Ambulatório do Serviço de Geriatria do HCFMUSP. São Paulo,1988/90. 


\section{LISTA DE FIGURAS}

Figura 1- Gráfico da correlação entre a idade dos idosos de ambos os gêneros e a ingestão dietética de colesterol. Ambulatório do Serviço de Geriatria do HCFMUSP. São Paulo, 1988/90.

Figura 2- Gráfico da correlação entre a idade dos idosos do gênero masculino e a ingestão dietética de colesterol. Ambulatório do Serviço de Geriatria do HCFMUSP. São Paulo, 1988/90.

Figura 3- Gráfico da correlação entre a idade dos idosos do gênero feminino e a ingestão dietética de colesterol. Ambulatório do Serviço de Geriatria do HCFMUSP. São Paulo, 1988/90.

Figura 4- Gráfico da correlação entre a idade dos idosos de ambos os gêneros e a ingestão de gorduras totais na dieta. Ambulatório do Serviço de Geriatria do HCFMUSP. São Paulo, 1988/90.

Figura 5- Gráfico da correlação entre a idade dos idosos do gênero masculino e a ingestão de gorduras totais na dieta. Ambulatório do Serviço de Geriatria do HCFMUSP. São Paulo, 1988/90.

Figura 6- Gráfico da correlação entre a idade dos idosos do gênero feminino e a ingestão de gorduras totais na dieta. Ambulatório do Serviço de Geriatria do HCFMUSP. São Paulo, 1988/90.

Figura 7- Gráfico de correlação entre os valores energéticos consumidos diariamente pelos idosos de ambos os gêneros e a ingestão de gordura polinsaturada. Ambulatório do Serviço de Geriatria do HCFMUSP. São Paulo, 1988/90. 
Figura 8- Gráfico da correlação entre os valores energéticos consumidos diariamente pelos idosos do gênero masculino e a ingestão de gordura polinsaturada. Ambulatório do Serviço de Geriatria do HCFMUSP. São Paulo, 1988/90.

Figura 9- Gráfico da correlação entre os valores energéticos consumidos diariamente pelos idosos do gênero feminino e a ingestão de gordura polinsaturada. Ambulatório do Serviço de Geriatria do HCFMUSP. São Paulo, 1988/90.

Figura 10- Gráfico da correlação entre a ingestão de fibras da dieta e o colesterol dos idosos de ambos osgêneros. Ambulatório do Serviço de Geriatria do HCFMUSP. São Paulo, 1988/90.

Figura 11- Gráfico da correlação entre a ingestão de fibras da dieta e o colesterol dos idosos do gènero masculino. Ambulatório do Serviço de Geriatria do HCFMUSP. São Paulo, 1988/90.

Figura 12- Gráfico da correlação entre a ingestão de fibras da dieta e o colesterol dos idosos do gênero feminino. Ambulatório do Serviço de Geriatria do HCFMUSP. São Paulo, 1988/90.

Figura 13- Gráfico da correlação entre o peso dos idosos de ambos os gêneros e a ingestão dietética de colesterol. Ambulatório do Serviço de Geriatria do HCFMUSP. São Paulo,1988/90.

Figura 14- Gráfico da correlação entre o peso dos idosos do gênero masculino e a ingestão dietética de colesterol. Ambulatório do Serviço de Geriatria do HCFMUSP. São Pauto, 1988/90. 
Figura 15- Gráfico da correlação entre o peso dos idosos do gênero feminino e a ingestão dietética de colesterol. Ambulatório do Serviço de Geriatria do HCFMUSP. São Paulo, 1988/90.

Figura 16- Gráfico da correlação entre o peso dos idosos de ambos os gêneros e os níveis séricos de triglicérides. Ambulatório do Serviço de Geriatria do HCFMUSP. São Paulo,1988/90.

Figura 17- Gráfico da correlação entre o peso dos idosos do gênero masculino e os niveis séricos de triglicérides. Ambulatório do Serviço de Geriatria do HCFMUSP. São Paulo,1988/90.

Figura 18- Gráfico da correlação entre o peso dos idosos do gênero feminino e os níveis séricos de triglicérides. Ambulatório do Serviço de Geriatria do HCFMUSP. São Paulo,1988/90.

Figura 19- Gráfico da correlação entre o peso dos idosos de ambos os gêneros e os niveis séricos de HDL-c. Ambulatório do Serviço de Geriatria do HCFMUSP. São Paulo,1988/90.

Figura 20- Gráfico da correlação entre o peso dos idosos do gênero masculino e os níveis séricos de triglicérides. Ambulatório do Serviço de Geriatria do HCFMUSP. São Paulo,1988/90.

Figura 21- Gráfico da correlação entre o peso dos idosos do gênero feminino e os níveis séricos de triglicérides. Ambulatório do Serviço de Geriatria do HCFMUSP. São Paulo,1988/90. 


\section{LISTA DE QUADROS}

Quadro 1 - Implicações do envelhecimento sobre a ingestão e as necessidades de nutrientes.

Quadro 2 - Inter-relação entre estado nutricional, ingestão dietética e mudanças nos níveis de nutrientes nos tecidos e plasma.

Quadro 3 - Pontos de corte propostos como critério diagnóstico do estado nutricional, a partir da antropometria.em idosos.

Quadro 4 - Valores de referência de CT, LDL-C, HDL-c e TG em indivíduos com idade igual ou maior de 20 anos.

Quadro 5 - Acreditação para os idosos de ambos os gêneros quanto à adequação do colesterol sérico (C1), estado nutricional (C2), ingestão de gordura na dieta (C3) e suficiência de fibra dietética (C4). 


\section{INTRODUÇÃO}

\subsection{Envelhecimento da População}

O envelhecimento é um processo caracterizado por alterações morfológicas, fisiológicas, bioquímicas e psicológicas que levam a uma diminuição da capacidade de adaptação do indivíduo ao meio ambiente e maior incidência de processos patológicos, que terminam por levá-lo à morte (Carvalho Filho e Alencar 1994; Moriguti, Lucif Jr, Ferrioli 1998). Apesar de ser um fenômeno universal e comum a quase todos os seres animais, o envelhecimento teve seu estudo negligenciado durante muito tempo, além de ainda permanecerem obscuros os mecanismos envolvidos na sua gênese (Papaléo Netto e Ponte 1997).

O Brasil vivencia o processo de envelhecimento de sua população, à semelhança dos demais países latino-americanos. Esse processo caracteriza-se por um envelhecimento rápido e intenso, mostrando aumento proporcional de pessoas idosas em relação à população total. Traduzindo em números, as pessoas com mais de 60 anos representam $8,56 \%$ da população com uma expectativa de vida, para esta idade, de 17,9 anos (IBGE a 2000).

A expectativa de vida, ou a extensão do tempo que se pode esperar que uma pessoa viva, está sujeita às influências ambientais, melhoria nos cuidados médicos e nos padrões de vida da população, além de uma nutrição adequada e o controle de doenças (Schlenker 1998).

Segundo o IBGE (2000), a população idosa brasileira aumentou em quase 4 milhões, em números absolutos, ao longo da década. As estimativas são de que em 2020 haverá 30 milhões de pessoas com 60 anos 
ou mais no Brasil, correspondendo a $13 \%$ da população e que a esperança de vida chegue a 70,3 anos.

O aumento da longevidade, considerado um ganho no acesso à informação e a processos tecnológicos, não significa necessariamente um aumento na qualidade de vida das pessoas.

Considerando-se a variação individual, o chegar a uma idade avançada pode transcorrer de maneira harmoniosa, sendo responsável por uma etapa feliz e digna da vida do indivíduo, ou pode transcorrer de maneira desastrosa, onde, apesar da longevidade, o prazer de viver é perdido pelo caminho (Campos et al 1994).

A sociedade nem sempre tem propiciado, ao idoso, condições para uma velhice feliz, pois, por vezes, ele sente-se isolado, improdutivo, sem mobilidade e com renda minguada que sequer the permite suprir as mínimas necessidades.

A questão do idoso no Brasil é complexa e não ímpar em relação a outros grupos populacionais, pois convergem para problemas sociais, onde nem sempre é viável uma convivência justa e harmoniosa.

É claro que o envelhecimento é uma aspiração natural de qualquer indivíduo, mas esta deve estar associada a condições de vida adequada. Hoje, mais do que nunca, busca-se identificar os fatores que levam a uma velhice sadia, mas já se reconhece a alimentação como prioritária para as pessoas que desejam uma velhice saudável.

Viver por mais tempo não significa necessariamente viver bem. $A$ relação com a qualidade de vida neste processo de envelhecer é um dos desafios em que a área da nutrição pode dar valiosas contribuições (OPAS 1999). 


\subsection{Envelhecimento e Nutrição}

0 envelhecimento, apesar de ser um processo natural, submete 0 organismo a diversas alterações anatômicas e funcionais, com repercussões nas condições de saúde e nutrição do idoso (Quintero - Molina 1993).

As funções orgânicas decaem como um todo, variando em intensidade segundo o órgão ou o sistema em questão. A habilidade para responder aos hormônios está reduzida, assim como a capacidade para sintetizar ou degradar proteínas. O colágeno se torna mais fibroso e menos elástico. O tecido conectivo pode repor a perda do tecido de alguns órgãos, determinando uma perda funcional do órgão, maior que a ponderal (Moriguti, Lucif Jr, Ferrioli 1998).

Devido ao envelhecimento, o individuo apresenta alterações funcionais e estruturais em vários órgãos do aparelho digestivo (Mahan e Stump 2002; Pereira e Cervato 1997).

Essas modificaçōes iniciam-se na boca, pela diminuição salivar, que tem como conseqüência a alteração do paladar, dificuldade de mastigação e deglutição, contribuindo para a má digestão e aceleração da deterioração dos dentes (Alencar et al. 1991; Mahan e Stump 2002).As disfunções de paladar e olfato tendem a se iniciar ao redor dos 60 anos de idade e se tornam mais graves nas pessoas acima de 70 anos (Schiffman 1994).

O envelhecimento traz modificações na mucosa intestinal, com perda da elasticidade e dos movimentos peristálticos, levando a uma diminuição da motilidade intestinal com conseqüente obstipação, sendo esse quadro uma das queixas mais freqüentes em idosos (Duffy et al 1995) Além disso, os 
processos digestivos ficam comprometidos por diminuição das secreçōes gástricas (Ribeiro e Tirapegui 2001).

O envelhecimento leva, ainda, à diminuição das massas óssea e muscular, com acréscimo na gordura corporal. Essa gordura colabora, também, para a diminuição do consumo de oxigênio, o que diminui a taxa metabólica basal e, conseqüentemente, a demanda de energia para o idoso (Schlenker 2000).

Efeitos do envelhecimento sobre o binômio: ingestão / necessidades de energia, gorduras e fibras dietéticas, podem ser verificados no Quadro 1. que mostra conseqüências fisiológicas do organismo humano, que provocam modificações sobre idoso e que devem ser consideradas ao se avaliar sua alimentação e nutrição. 
Quadro 1: Implicações do envelhecimento sobre a ingestão $e$ as necessidades de nutrientes

\begin{tabular}{|c|c|}
\hline Energia $>$ Nutrientes & Efeitos do Envelhecimento \\
\hline Energia & Necessidades diminuídas \\
\hline Gorduras & $\begin{array}{c}\text { Diminuição da ingestão de gorduras } \\
\text { saturadas }\end{array}$ \\
\hline Fibras Dietéticas & $\begin{array}{c}\text { Importantes para a diminuição dos efeitos } \\
\text { da obstipação e níveis séricos de } \\
\text { colesterol }\end{array}$ \\
\hline
\end{tabular}

Adaptado : Whitney et al 1998.

Todas essas alterações provocadas pelo envelhecimento alertam para o cuidado com a dieta dos indivíduos deste grupo, principalmente no que se refere à ingestão de gorduras e fibras, tema especifico a ser tratado neste estudo.

\subsection{Ingestão de gorduras, fibras e hiperlipidemias}

Diversos compostos químicos nos alimentos e no organismo são classificados como lipídios, entre eles: ácidos graxos, triglicerídios e fosfolipídios. O colesterol, considerado geralmente um lipidio, é um álcool monohídrico não saturado, da classe dos esteróides. Os triglicérides são utilizados no organismo principalmente para fornecer energia nos diferentes processos metabólicos; sendo esta função compartilhada com os carboidratos (Guyton 1997). 
Para a circulação no sangue, os lipidios ligam-se às proteinas, dando origem a cinco classes principais de lipoproteinas: os quilomicrons, as lipoproteinas de densidade muito baixa (VLDL-c), as lipoproteinas de densidade intermediária (IDL-C), as lipoproteinas de baixa densidade (LDL-C) e as de alta densidade (HDL-C).

As hiperlipidemias podem ser primárias ou secundárias. As primárias, são principalmente de origem genética e as secundárias podem ser causadas por obesidade, dieta inadequada, abuso de álcool e outras drogas como diuréticos e, ainda, por doenças como síndrome nefrótica e insuficiência renal (Torres et al 2000).

Estudos clínicos recentes de prevenção primária e secundária sugerem que a redução expressiva do LDL-c, em idosos, diminui significativamente a morbidade e a mortalidade por doença arterial coronariana (SBC 2001).

O conceito de que no idoso o controle de fatores de risco, em particular as hiperlipidemias, não seria fundamental, foi modificado. Tendo a doença arterial alta freqüência após os 60 anos e em ambos os sexos, qualquer intervenção tem importante repercussão na sua morbidade e mortalidade. Metanálise de seis estudos controlados de intervenção dietética e / ou medicamentosa, em 12457 homens hipercolesterolêmicos sem doenças cardiovasculares (DAC), demonstrou que a redução média de 10\% do $\mathrm{CT}$, por quatro a cinco anos, determina freqüência de eventos coronarianos $26 \%$ menor do que nos controles e esses estudos indicam que a redução de $1 \%$ de $\mathrm{CT}$ em hipercolesterolêmicos corresponde a uma redução de $2 \%$ dos eventos de DAC (SBC 1996).

A dieta habitual parece ser um elemento fundamental de análise dos determinantes da suscetibilidade para as doenças do coração. Ela assume 
um papel primordial à medida que está associada ao aumento da colesterolemia, pelo consumo de alto teor de colesterol, altas proporções de calorias lipídicas, ácidos graxos saturados e baixa ingestão de fibras alimentares (Moura e Sonati 1999).

As teorias que tentam explicar a forma como as fibras alteram o metabolismo do colesterol são muitas e ainda não totalmente conclusivas. Uma hipótese para explicar o efeito das fibras na diminuição da hipercolesterolemia refere-se a sua propriedade de reter água e formar uma matriz gelatinosa, que impede a difusão dos nutrientes no intestino, reduz a emulsificação dos lipídios, reduzindo sua absorção (Lairon 1996).

Há controvérsias sobre uma dieta com altos teores de fibras,pois, se por um lado elas estariam influenciando positivamente a questão das lipoproteínas, por outro, poderiam estar influenciando negativamente o aproveitamento de elementos minerais como cálcio e zinco. Essa discussão vem desde a década de 70 , quando houve publicação de artigo sobre carências de minerais, particularmente de cálcio e zinco, nas populações do Irã, ligando essa carência aos fitatos existentes em abundância nas altas taxas de fibras consumidas naquele país (Dutra de Oliveira e Marchini 1998).

Uma dieta pobre em gorduras e rica em fibras, pode ser benéfica para a promoção da saúde por inibir a oxidação das LDL-C, diminuindo sua aterogenicidade (SBC 2001). Alimentos como frutas, hortaliças, cereais e leguminosas, consumidos com regularidade, em porções sugeridas e adaptadas por Russel et al 1999, para individuos com mais de 70 anos, proporcionariam a quantidade de fibras necessárias ao individuo.

Existem muitas demonstrações da relação dieta/hiperlipidemias, concluindo-se que estão diretamente relacionadas à ingestão excessiva de gordura, colesterol e calorias, induzindo os individuos à obesidade. (SBC 1996). 


\subsection{Estado nutricional de idosos}

A associação entre o comprometimento do estado nutricional e o maior risco de contrair doenças é bastante conhecida. Com relação ao idoso, a manutenção do estado nutricional normal é fundamental para uma vida saudável, maior resistência às moléstias crônicas e debilitantes bem como às intercorrências. (Moriguti, Lucif Jr, Ferrioli 1998).

Para Schlenker (2000) o estado nutricional, de um indivíduo ou de um grupo populacional, pode ser determinado pela integração e interpretação de dados antropométricos, bioquímicos e dietéticos. O Quadro 2 apresenta essa idéia de inter-relação, o indivíduo ou o grupo populacional em um estado de má nutrição (nível ingestão inadequada ou excessiva de alimentos) poderá ter sua saúde comprometida pelas mudanças que ocorrem no organismo. As primeiras mudanças que podem ocorrer estão relacionadas ao estoque de nutrientes dos tecidos e do plasma; a atividade enzimática e a função fisiológica passam a ter alterações posteriores, que por fim, podem levar a sinais clínicos e lesōes. 
Quadro 2: Inter-relação entre estado nutricional, ingestão dietética e mudanças nos niveis de nutrientes nos tecidos e plasma.

\begin{tabular}{|c|c|c|c|}
\hline Estado Nutricional & \multicolumn{2}{|c|}{ Alterações dos nutrientes } & Indicador \\
\hline Ótimo & \multicolumn{2}{|c|}{$\begin{array}{c}\text { Inadequação dietética } \\
\text { (excesso ou carência): } \\
\text { Primária - alimentos } \\
\text { Secundária - doenças, drogas } \\
\Omega\end{array}$} & Dietético \\
\hline Marginal & \multicolumn{2}{|c|}{$\begin{array}{c}\text { Depleção da reserva e } \\
\text { mudanças no nivel de } \\
\text { nutrientes do plasma } \\
\Omega\end{array}$} & $\begin{array}{c}\text { Bioquímico } \\
\text { Antropométrico }\end{array}$ \\
\hline $\mathbb{B}$ & \multicolumn{2}{|c|}{$\begin{array}{l}\text { Mudança na atividade } \\
\text { enzimática ou na função } \\
\text { fisiológica do nutriente } \\
\Omega\end{array}$} & Bioquímico \\
\hline \multirow[t]{3}{*}{$\begin{array}{c}\text { Ruim } \\
\text { (desnutrição/obesidade) }\end{array}$} & 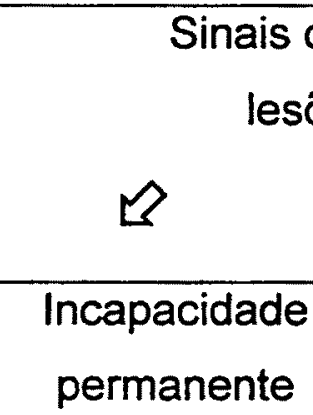 & icos & \multirow[t]{2}{*}{ Clínico } \\
\hline & \multicolumn{2}{|c|}{ S } & \\
\hline & \multicolumn{2}{|c|}{ Mortalidade } & Estatística vital \\
\hline
\end{tabular}

A monitoração do estado nutricional do idoso, a partir da antropometria, pode ser feita utilizando-se o índice de massa corpórea 
(IMC), tanto no nivel hospitalar quanto no ambulatorial, considerando tanto os erros na obtenção das medidas quanto às variações causadas pelo envelhecimento (Najas e Sachs 1997).

Pesquisas sobre nutrição e envelhecimento realizadas na Europa (EURONUT - SENECA) demonstraram valores significativamente elevados para o IMC de idosos estudados, com a prevalência de IMC maior que $30 \mathrm{~kg} / \mathrm{m}^{2}$ para 30 a $50 \%$ dos indivíduos (obesidade) em cada uma das cidades que fizeram parte da amostra.Taddei et al, em 1997, a partir de um estudo multicêntrico com idosos atendidos em ambulatório, identificaram que $36 \%$ das mulheres e $22 \%$ dos homens apresentavam obesidade. Essa tendência foi verificada tanto no meio rural, quanto no urbano, em todas as faixas etárias (Campos, Monteiro, Ornelas 2000).

A obesidade tem sido considerada a alteração nutricional mais importante do mundo atual. Vários autores evidenciam a relação entre graus de obesidade e a adiposidade com morbi - mortalidade. Bray, em um estudo de 1988 , relata que um aumento de $10 \%$ no peso corporal resulta em aumento da pressão sangüínea sistólica em $6,5 \mathrm{mmHg}$ e do colesterol plasmático em $12 \mathrm{mg} / \mathrm{dL}$.

Nos Estados Unidos, estudo do NHANESIII (Third National Health and Nutrition Examination Survey) realizado no período de 1988 a 1994, indica que a população idosa merece atenção, pois há discrepâncias no que se refere ao peso corporal e consumo de gorduras (cerca de $33 \%$ do total calórico ingerido).

Segundo Najas et al, em estudo realizado em 1994, a população idosa, residente em localidade urbana da região sudeste do Brasil, apresentou $20 \%$ de baixo peso em ambos os sexos. A obesidade estava presente em $50 \%$ das mulheres e $26 \%$ dos homens. 
A tendência do aumento da incidência da obesidade tem sido atribuída a rápidos e intensos declínios no dispêndio energético dos individuos, os quais teriam ocupações que necessitam de menor esforço físico aliado à redução da atividade física (Lessa, 1998). Igualmente importante pode ter sido o aumento no consumo de gordura e na densidade energética das dietas. A correção da obesidade reduz os niveis séricos de colesterol total e lipoproteinas de alta densidade (SBC 1996).

A correção da obesidade contribui para melhor controle da hipertensão arterial, redução dos triglicerídeos e do colesterol total, elevação do HDL-c e melhoria na tolerância à glicose (SBC 1996). Nascimento, em estudo realizado em 1999, apontou ocorrência de obesidade, porém sem hipercolesterolemia nos clientes atendidos em ambulatório de geriatria da cidade de São Paulo.

O presente trabalho pretende analisar algumas características da dieta do idoso em nosso meio, correlacionando-as ao estado nutricional e parâmetros bioquímicos.

Este estudo justifica-se face à representatividade que os idosos cada vez mais têm na sociedade e o consenso geral da importância da nutrição no processo de envelhecimento saudável, procurando ajudar na descoberta de interfaces destes dois pólos e contribuindo na melhoria da qualidade de vida dos indivíduos. Também se justifica pelo interesse em aprofundar o estudo de três indicadores importantes da nutrição do indivíduo idoso: análise da dieta, IMC e niveis séricos de colesterol e suas frações. 


\section{OBJETIVOS}

\subsection{Geral}

Comparar e analisar a ingestão energética, de gorduras e fibras da dieta de idosos, relacionando-a com o estado nutricional e parâmetros bioquímicos.

\subsection{Especificos}

Correlacionar o comportamento dos níveis séricos de colesterol, suas fraçōes (HDL-c e LDL-c) e triglicérides, com o estado nutricional e a ingestão de gordura em idosos.

Verificar a relação da adequação calórica da dieta com o estado nutricional dos idosos.

Analisar a correlação entre a ingestão de fibras dietéticas, niveis séricos de colesterol e estado nutricional do grupo em estudo. 


\section{PROCEDIMENTO METODOLÓGICO}

\subsection{Delineamento do estudo}

Trata-se de um estudo transversal, observacional analítico, que utilizou dados secundários de pesquisa, com idosos atendidos em ambulatório de geriatria (Anexo 1)

\subsection{População}

A população do presente estudo é composta por idosos com 60 anos e mais de ambos os sexos, matriculados no ambulatório do Serviço de Geriatria do Hospital das Clínicas da Faculdade de Medicina da Universidade de São Paulo (HCFMUSP), que aceitaram os procedimentos de protocolo para sua inclusão em uma pesquisa da referida instituição.

Foram incluídos na pesquisa os pacientes com consulta marcada para o periodo do levantamento dos dados, sorteando-se aqueles que, além do seu atendimento médico, passariam por avaliação nutricional e pelas demais atividades que compunham o protocolo, independentemente do seu diagnóstico.

Os sorteados deveriam atender a dois critérios: dar seu consentimento (após conhecerem os objetivos e procedimentos adotados pelo protocolo) e não estarem realizando sua primeira consulta. 0 atendimento ao paciente idoso, em primeira consulta, é bastante complexo e minucioso, o que poderia deixá-lo desestimulado, pelo cansaço, a atender a todos os procedimentos posteriores, a que seria submetido. 


\subsection{Casuística}

A casuística consta de 368 idosos com idade igual ou superior a 60 anos, sendo 102 do sexo masculino $(27,7 \%)$ e 266 do sexo feminino $(72,3 \%)$.

Os idosos que fizeram parte dessa amostra não tiveram sua dieta modificada e não utilizavam drogas hipolipidemiantes, como medicação, de tal forma que os niveis sangüíneos de colesterol e suas frações não sofreram variações por estes motivos. 


\section{LEVANTAMENTO E APURAÇÃO DOS DADOS}

Com a finalidade de identificar a população de estudo foi elaborado um formulário, a ser preenchido na primeira entrevista, com os dados pessoais dos idosos, procedência, ocupação e grau de instrução. Desse formulário foram extraídas as informações utilizadas para a elaboração do presente estudo (Anexo 2 -Parte I).

\subsection{Inquérito alimentar}

Para avaliação dietética foi escolhido um método retrospectivo denominado Recordatório de 24 Horas ( $\operatorname{Rec} 24 \mathrm{hs}$ ), que foi realizado por nutricionistas. $O$ Rec $24 \mathrm{hs}$ foi um levantamento, em medidas caseiras, dos alimentos consumidos pelos idosos no dia anterior à consulta. $\mathrm{O} \operatorname{Rec} 24 \mathrm{hs}$ é um procedimento clássico para avaliação do consumo alimentar dos indivíduos (Suitor e Hurter 1980, Kamamura et al 2002)

Os dados foram anotados, no momento da entrevista, em formulário próprio (Anexo 2 - Parte II).

Esses dados foram digitados no Programa Virtual Nutri (Philippi, Szarfarc, Latterza 1996), que contém a composição química centesimal dos alimentos "in natura", processados e de preparaçōes culinárias; a partir dos cálculos por porções, foram obtidos os valores referentes à energia total, gordura total e gordura insaturada, colesterol e fibras da dieta.

Esses dados foram trabalhados com critérios de suficiência ou adequação de acordo com as referências a seguir :

Energia Total da dieta, diferenciada por sexo, e classificada como suficiente, insuficiente e mais que suficiente pelos valores propostos pelas 
recomendações do National Research Council, USA, 1989, por meio das Recommended Dietary Allowances (RDA).Aos valores de energia recomendados, 2300kcal/dia para os homens e 1900 kcal/dia para as mulheres, estabeleceu-se uma margem de variação de $15 \%$ da energia total diária tanto para os limites superiores quanto para os inferiores (Mahan e Arlin1995).

Ingestão de gorduras, independentemente do sexo, foi considerada adequadá até $30 \%$ da Energia Total da dieta, sendo $10 \%$ de gordura polinsaturada (Food and Drug Administration-FDA-1993).

Com relação à ingestão de fibras dietéticas o critério de adequação foi independente do sexo, classificada como suficiente, insuficiente e mais que suficiente. Recomendação utilizada 20 a $30 \mathrm{~g} /$ dia a partir da média de $25 \mathrm{~g} /$ dia (FDA 1993).

\subsection{Diagnóstico do estado nutricional}

Para a avaliação antropométrica foram utilizadas as variáveis de peso e altura, segundo técnicas clássicas de mensuração (Chumlea et al 1987, Waitzberg e Ferrini 2002), colhidas da seguinte forma:

a) peso: os idosos foram pesados com vestes leves (sem casacos, paletós ou roupas grossas) e sem sapatos. Foi utilizada uma balança Filizola, com capacidade para $150 \mathrm{~kg}$ e sensibilidade de $100 \mathrm{~g}$, pertencente ao HCFMUSP.

b) altura: os idosos foram medidos em posição ereta, olhando para frente, com as costas e a parte posterior dos joelhos encostados à parede. Foi utilizada fita métrica inextensivel, afixada na parede a $0,5 \mathrm{~m}$ do piso.

Para a análise do estado nutricional foi proposto o cálculo do índice de Massa Corporal (IMC) dado pela relação: peso $(\mathrm{kg}) / \mathrm{altura}^{2}(\mathrm{~m})$. Os 
critérios utilizados para diagnóstico foram os pontos de corte propostos por Lipschitz, 1994, conforme indicado no quadro abaixo:

Quadro 3: Pontos de corte propostos como critério diagnóstico do estado nutricional, a partir da antropometria,.em idosos.

\begin{tabular}{|c|c|}
\hline IMC $\left(\mathrm{kg} / \mathrm{m}^{2}\right)$ & Diagnóstico do Estado nutricional \\
\hline menor que 22 & desnutrição \\
\hline de 22 a 27 & eutrofia (normal) \\
\hline maior que 27 & obesidade \\
\hline
\end{tabular}

\subsection{Exames bioquímicos}

As variáveis sangüineas foram: triglicérides (TG), colesterol total (CT) e suas frações: lipoproteína de alta densidade (HDL-c) e lipoproteina de baixa densidade (LDL-C).

Para colher o sangue que foi examinado pelo próprio laboratório do HCFMUSP, os idosos foram orientados a voltar em outro dia, em jejum de 12 horas, para esse procedimento.

O colesterol total e a HDL-c foram determinados por método enzimático colorimétrico em aparelho automatizado ("kit- AMES," da Miles do Brasil Ltda-Bayer). A LDL-C foi calculada pela fórmula de Friedwald. O método para determinar os triglicérides foi enzimático colorimétrico automatizado ("Laboratório Abbot").

Para o estabelecimento dos critérios de adequação e inadequação do colesterol total e suas frações, e triglicérides, foram utilizados os valores de referência propostos pelo III Consenso Brasileiro de Dislipidemia, realizado pelo Departamento de Aterosclerose da Sociedade Brasileira de Cardiologia (SBC), 2001, sendo considerados como adequados os valores que no 
Quadro 4 estão na categoria "desejáveis"; os demais valores foram considerados como inadequados.

Quadro 4: Valores de referência de CT, LDL-c, HDL-c e TG em indivíduos com idade igual ou maior de 20 anos.

\begin{tabular}{|c|c|c|c|}
\hline \multicolumn{4}{|c|}{ Valores de Referência } \\
\hline $\begin{array}{c}\text { Variáveis } \\
\text { analisadas }\end{array}$ & Desejáveis (mg/dL) & Limítrofes $(\mathrm{mg} / \mathrm{dL})$ & $\begin{array}{c}\text { Aumentados } \\
(\mathrm{mg} / \mathrm{dL})\end{array}$ \\
\hline CT & $<200$ & $200-239$ & $>=240$ \\
\hline LDL-C & $<130$ & $130-159$ & $>=160$ \\
\hline HDL-C & $>=40$ & & \\
\hline TG & $<150$ & $150-200$ & $>=200$ \\
\hline
\end{tabular}

\subsection{Análise estatística dos dados}

Para análise dos dados utilizou-se o Programa Excel (Microsoft Excel 2000). Para a estatística descritiva como: as médias e os desvios padrões das variáveis estudadas, foi utilizado o mesmo programa.

Foi empregado o instrumento da análise de regressão (regressão linear), entre o conjunto das variáveis numéricas do estudo, e utilizada a análise de variância (ANOVA.) para estabelecer a relação entre elas. Adotou-se, o nivel de $5 \%$ para significância do teste $(\alpha)$. Essas análises, foram utilizadas para verificar a relação entre idade dos pacientes e ingestão de gorduras e colesterol na dieta para ambos os sexos, peso dos pacientes e ingestão dietética de colesterol, peso dos pacientes e niveis séricos de HDL-c e TG para ambos os sexos. Foram, também, realizadas essas análises para energia da dieta e consumo de gorduras polinsaturadas, fibras e colesterol para ambos os sexos e, ainda, relação entre ingestão de fibras e colesterol da dieta. 
Para as variáveis categóricas, adequação de gordura da dieta relacionada aos níveis séricos de HDL-c e LDL-c, houve verificação da existência de associação pela prova de significância de McNemar.(Siegel 1975).

Para as demais variáveis categóricas, a existência de associação foi obtida por meio da utilização de tabelas de contingência, $2 \times 3$ e $3 \times 3$, onde se empregou o teste de associação pelo quiquadrado (Siegel 1975; Berquó et al 1980). Adotou-se nível de $5 \%$ para significância dos testes. $A$ verificação dessas associações foi para adequação do colesterol sangüineo e suas frações e adequação do estado nutricional, fibras e porcentagem de gorduras da dieta para ambos os sexos. Foi também estabelecida a relação entre adequação calórica e adequação do estado nutricional para ambos os sexos.

Foi utilizado um método de "acreditação" (adaptado de Marucci 1983), para medir um conjunto de componentes relacionados à adequação do colesterol sérico, ao estado nutricional, à ingestão de gorduras e à suficiência de fibra na dieta. Aos parâmetros em conformidade foram atribuídos sinais positivos e aos em não conformidade sinais negativos. A acreditação em si, não se destina a evidenciar fatores de qualidade de vida, nem justificar totalmente as condições da realidade do estado de saúde do idoso, mas a complementar informação sobre a adequação de critérios propostos no estudo.

A interpretação dos dados para análise foi de que, no mínimo três créditos positivos deram uma totalização positiva, indicando excelentes condições para o idoso; três créditos negativos no mínimo deram uma totalização negativa e indicaram condições ruins para o idoso. As demais combinaçōes de conformidade totalizaram um somatório nulo, indicando condições satisfatórias para o idoso. 


\section{RESULTADOS}

\subsection{Caracteristicas da população estudada}

No presente estudo foram trabalhados inicialmente os dados descritivos de 368 idosos, com idades entre 60 e 100 anos Houve predominância de mulheres $(72,3 \%$ da população) e a faixa etária com maior número de indivíduos é a de 71 a 80 anos, tanto para o sexo feminino como para o masculino. Esses dados encontram -se na Tabela 1.

Tabela 1: Distribuição percentual dos idosos estudados, segundo o gênero e faixa etária. Ambulatório do Serviço de Geriatria do HCFMUSP. São Paulo, 1988/90.

\begin{tabular}{c|c|c|c|c|c|c}
\hline \multirow{2}{*}{$\begin{array}{c}\text { Estágio } \\
\text { de vida }\end{array}$} & $\mathrm{N}$ & $\%$ & $\mathrm{~N}$ & $\%$ & $\mathrm{~N}$ & $\%$ \\
\cline { 2 - 7 }$\leq 70$ & 36 & 35,3 & 88 & 33,1 & 124 & 33,7 \\
\hline $71-80$ & 48 & 47,1 & 136 & 51,1 & 184 & 50,0 \\
\hline $81-90$ & 18 & 17,6 & 38 & 14,3 & 56 & 15,2 \\
\hline$>90$ & 0 & 0 & 4 & 1,5 & 4 & 1,1 \\
\hline Total & 102 & 100 & 266 & 100 & 368 & 100 \\
\hline
\end{tabular}


A tabela 2 indica a distribuição percentual dos idosos, segundo o IMC e gênero, sendo que em ambos predomina a normalidade para a relação pesolaltura ${ }^{2}$. A obesidade teve maior prevalência no sexo feminino $(46,6 \%)$. A média do IMC ficou dentro dos padrōes de normalidade, nos dois sexos, conforme Tabela 3.

Tabela 2: Distribuição percentual dos idosos, segundo a classificação do IMC e gênero. Ambulatório do Serviço de Geriatria do HCFMUSP. São Paulo, 1988/90.

\begin{tabular}{c|cc|cc|cc}
\hline \multirow{2}{*}{ Género } & \multicolumn{2}{|c|}{ Masculino } & \multicolumn{2}{|c|}{ Feminino } & \multicolumn{2}{|c}{ Total } \\
\cline { 2 - 7 } classes de IMc & $\mathrm{N}$ & $\%$ & $\mathrm{~N}$ & $\%$ & $\mathrm{~N}$ & $\%$ \\
\hline Desnutrido & 21 & 20,6 & 51 & 19,2 & 72 & 19,6 \\
Normal & 50 & 49,0 & 91 & 64,2 & 141 & 38,3 \\
Obeso & 31 & 30,4 & 124 & 46,6 & 155 & 42,1 \\
\hline Total & 102 & 100 & 266 & 100 & 368 & 100 \\
\hline
\end{tabular}

Tabela 3: Média e desvio-padrão $(\delta)$ dos valores de IMC dos idosos, segundo gênero. Ambulatório do Serviço de Geriatria do HCFMUSP. São Paulo, 1988/90.

\begin{tabular}{|c|c|c|}
\hline Variável & & \\
\hline Gênero & Média & $\delta$ \\
\hline Homens & 24,8 & 3,4 \\
\hline Mulheres & 26,5 & 5,1 \\
\hline Total & 26,0 & 4,8 \\
\hline
\end{tabular}

A média dos resultados dos exames com dados dos níveis séricos de triglicérides encontra-se nos valores considerados desejáveis tanto para o sexo feminino $(134,2 \mathrm{mg} / \mathrm{dL})$ como para o masculino $(127,8 / \mathrm{dL})$; já a média 
do colesterol sérico apresenta-se dentro de valores considerados limitrofes para ambos os sexos, sendo $206,1 \mathrm{mg} / \mathrm{dL}$ para os homens e $227 \mathrm{mg} / \mathrm{dL}$ para as mulheres, conforme apresentado na tabela 4.

Com relação às fraçōes de colesterol, a LDL-c, em média, quando considerados ambos os sexos está acima dos valores de referência considerados desejáveis $(153,8 \mathrm{mg} / \mathrm{dL})$, encontrando-se na categoria de limítrofes. A HDL-c tanto para homens como para mulheres encontra-se nos valores de referência adotados como "desejável" $(44,2 \mathrm{mg} / \mathrm{dL})$.

Dados os valores considerados para corte em relação ao valor energético da dieta, homens e mulheres ficaram dentro da faixa de suficiência, em média, sendo que a ingestão de gorduras totais ficou dentro do esperado, mas as gorduras polinsaturadas ficaram aquém do recomendado (menor que $1 / 3$ da gordura total)

O referencial teórico para adequação da fibra dietética $(25 \mathrm{~g} / \mathrm{dia})$, foi um parâmetro não alcançado pela média de ingestão dos idosos $(17,7 \mathrm{~g} / \mathrm{dia})$. 
Tabela 4 - Média, desvio-padrão ( $\delta$ ), mediana e valores máximo e mínimo das variáveis pertinentes dos idosos,segundo o gênero. Ambulatório do Serviço de Geriatria do HCFMUSP. São Paulo, 1988/90.

\begin{tabular}{|c|c|c|c|c|c|c|c|c|c|c|c|c|c|c|c|}
\hline \multirow[b]{2}{*}{ Variáveis } & \multicolumn{5}{|c|}{ Masculino } & \multicolumn{5}{|c|}{ Feminino } & \multicolumn{5}{|c|}{ Ambos os gêneros } \\
\hline & Média & $\delta$ & Mediana & Máximo & Minimo & Média & $\delta$ & Mediana & Máximo & Minimo & Média & $\delta$ & Mediana & Máximo & Minimo \\
\hline Idade (anos) & 74,5 & 6,6 & 74,0 & 91,0 & 61,0 & 73,8 & 7,1 & 73,0 & 100,0 & 60,0 & 74,0 & 7,0 & 73,0 & 100,0 & 60,0 \\
\hline Peso (kg) & 67,1 & 10,7 & 67,5 & 106,0 & 42,6 & 62,0 & 12,8 & 61,4 & 123,1 & 31,1 & 63,4 & 12,5 & 63,5 & 123,1 & 31,1 \\
\hline Altura (m) & 1,6 & 0,1 & 1,7 & 1,8 & 1,5 & 1,5 & 0,1 & 1,5 & 1,7 & 1,4 & 1,6 & 0,1 & 1,6 & 1,8 & 1,4 \\
\hline Triglicérides $(\mathrm{mg} / \mathrm{dL})$ & 127,8 & 52,6 & 116,5 & 297,0 & 52,0 & 134,2 & 58,3 & 121,5 & 485,0 & 50,0 & 132,4 & 56,8 & 120,0 & 485,0 & 50,0 \\
\hline Colesterol Total (mg/dL) & 206,1 & 46,2 & 200,5 & 390,0 & 112,0 & 227,0 & 42,5 & 226,0 & 351,0 & 66,0 & 221,2 & 44,5 & 218,5 & 390,0 & 66,0 \\
\hline LDL-c (mg/dL) & 149,7 & 82,6 & 137,0 & 850,0 & 48,0 & 155,4 & 42,8 & 151,0 & 468,0 & 16,0 & 153,8 & 56,6 & 148,0 & 850,0 & 16,0 \\
\hline HDL-c (mg/dL) & 39,7 & 10,8 & 38,0 & 65,0 & 18,0 & 45,9 & 11,9 & 44,0 & 99,0 & 18,0 & 44,2 & 11,9 & 44,0 & 99,0 & 18,0 \\
\hline Energia da dieta (kcal) & 2175,0 & 1072,1 & 1983,2 & 6830,9 & 684,4 & 2025,2 & 824,9 & 1966,7 & 5737,9 & 603,8 & 2066,7 & 901,2 & 1970,8 & 6830,9 & 603,8 \\
\hline Gordura total da dieta (g) & 87,7 & 55,7 & 70,9 & 376,2 & 20,9 & 83,1 & 45,4 & 75,3 & 315,0 & 11,0 & 84,4 & 48,4 & 74,9 & 376,2 & 11,0 \\
\hline Gordura insaturada da dieta $(g)$ & 20,2 & 13,1 & 18,2 & 93,4 & 3,3 & 18,8 & 16,0 & 16,6 & 229,7 & 0,8 & 19,2 & 15,3 & 17,4 & 229,7 & 0,8 \\
\hline Fibras da dieta (g) & 18,4 & 9,8 & 16,6 & 54,8 & 1,4 & 17,5 & 7,9 & 16,9 & 60,0 & 1,3 & 17,7 & 8,5 & 16,8 & 60,0 & 1,3 \\
\hline Colesterol da dieta $(\mathrm{mg})$ & 480,1 & 337,0 & 395,7 & 1818,3 & 28,3 & 460,6 & 304,8 & 425,0 & 2316,1 & 27,9 & 466,0 & 313,7 & 419,8 & 2316,1 & 27,9 \\
\hline
\end{tabular}




\subsection{Análise das variáveis numéricas do estudo}

As primeiras correlações apresentadas referem-se à idade dos pacientes e ingestão de colesterol e gorduras dietéticas.

As Figuras 1,2 e 3 apresentam a correlação entre a idade dos pacientes por gênero e a ingestão dietética de colesterol. Identificou-se uma correlação negativa entre as variáveis estudadas, demonstrando a curva que: quanto maior a idade do paciente, menor é sua ingestão dietética de colesterol.

As Figuras 4,5,6 apresentam a correlação entre a idade dos pacientes por sexo e a ingestão de gorduras totais na dieta. Identificou-se, da mesma forma, uma correlação negativa entre as variáveis estudadas, demonstrando a curva essa associação. Isto identifica que quanto maior a idade, menor a ingestão de gorduras dietéticas. 
Figura 1- Gráfico da correlação entre a idade dos idosos de ambos os gêneros e a ingestão dietética de colesterol. Ambulatório do Serviço de Geriatria do HCFMUSP. São Paulo, 1988/90.

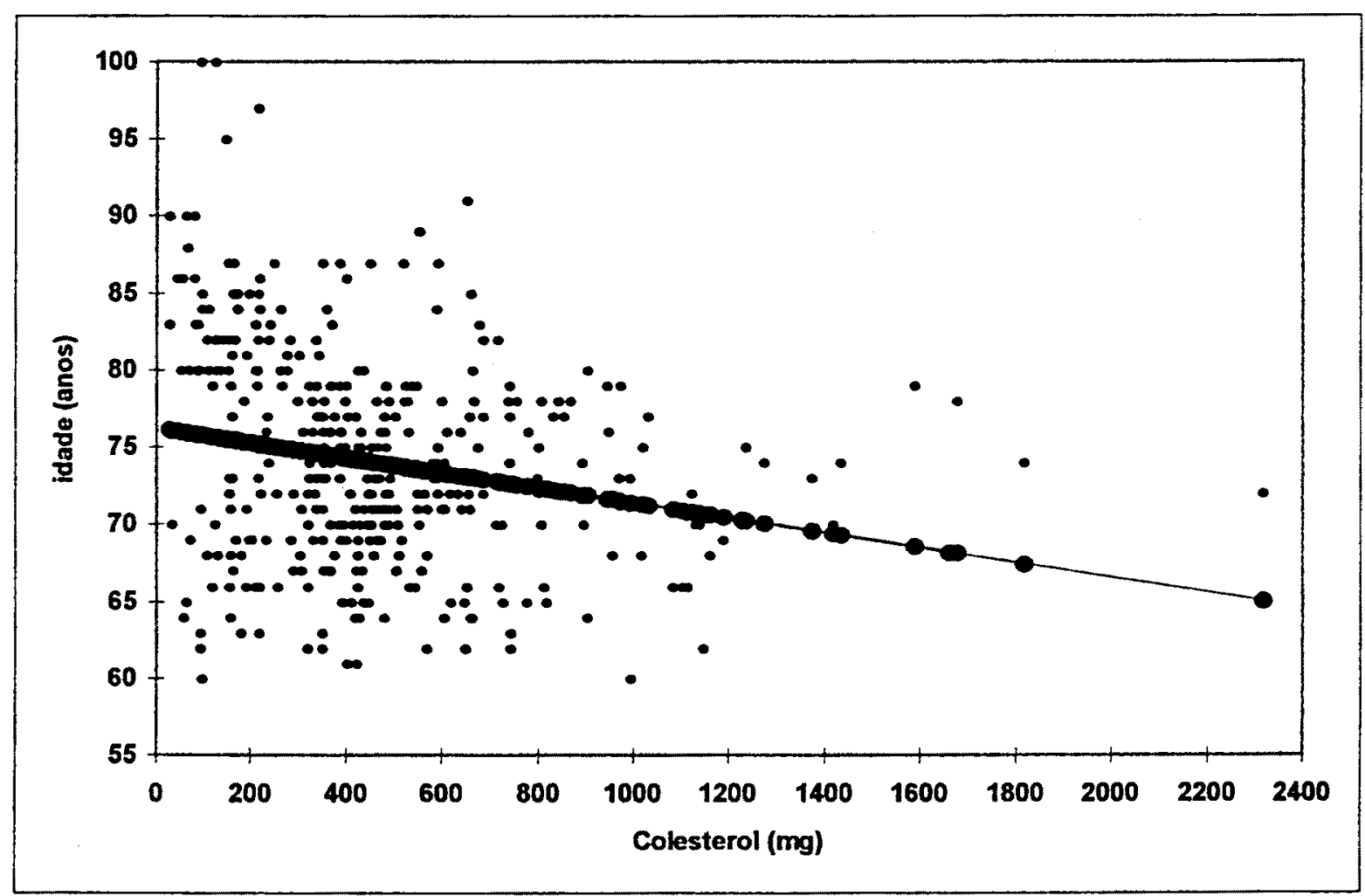

RESUMO DOS RESULTADOS

\begin{tabular}{lc}
\hline \multicolumn{2}{c}{ Estatistica de regressáo } \\
\hline R mültiplo & 0,2167 \\
R-Quadrado & 0,0469 \\
R-quadrado ajustado & 0,0443 \\
Erro padrăo & 6,85 \\
Observações & 368 \\
\hline
\end{tabular}

ANOVA

\begin{tabular}{lccccc}
\hline & GI & SQ & QM & $F$ & F de significaçăo \\
\hline Regressåo & 1 & 847,6 & 847,6 & 18,0 & $2,7 E-05$ \\
Resíduo & 366 & 17198,1 & 46,9 & & \\
Total & 367 & 18045,8 & & & \\
\hline
\end{tabular}

\begin{tabular}{lcccccccc}
\hline & Coeficientes & Erro padrăo & Stat t & valor-P & $\begin{array}{c}95 \% \\
\text { inferiores }\end{array}$ & $\begin{array}{c}95 \% \\
\text { superiores }\end{array}$ & $\begin{array}{c}\text { Inferior } \\
95,0 \%\end{array}$ & $\begin{array}{c}\text { Superior } \\
95,0 \%\end{array}$ \\
\hline Interseçåo & 76,27 & 0,6405 & 119,08 & $\mathbf{8 , 9 E - 2 9 5}$ & 75,01 & 77,53 & 75,01 & 77,53 \\
Colesterol & $-0,0048$ & 0,0011 & $-4,24$ & $2,7 E-05$ & $-0,0070$ & $-0,0026$ & $-0,0070$ & $-0,0026$ \\
\hline
\end{tabular}


Figura 2- Gráfico da Correlação entre a idade dos idosos do gênero masculino e a ingestão dietética de colesterol. Ambulatório do Serviço de Geriatria do HCFMUSP. São Paulo, 1988/90.

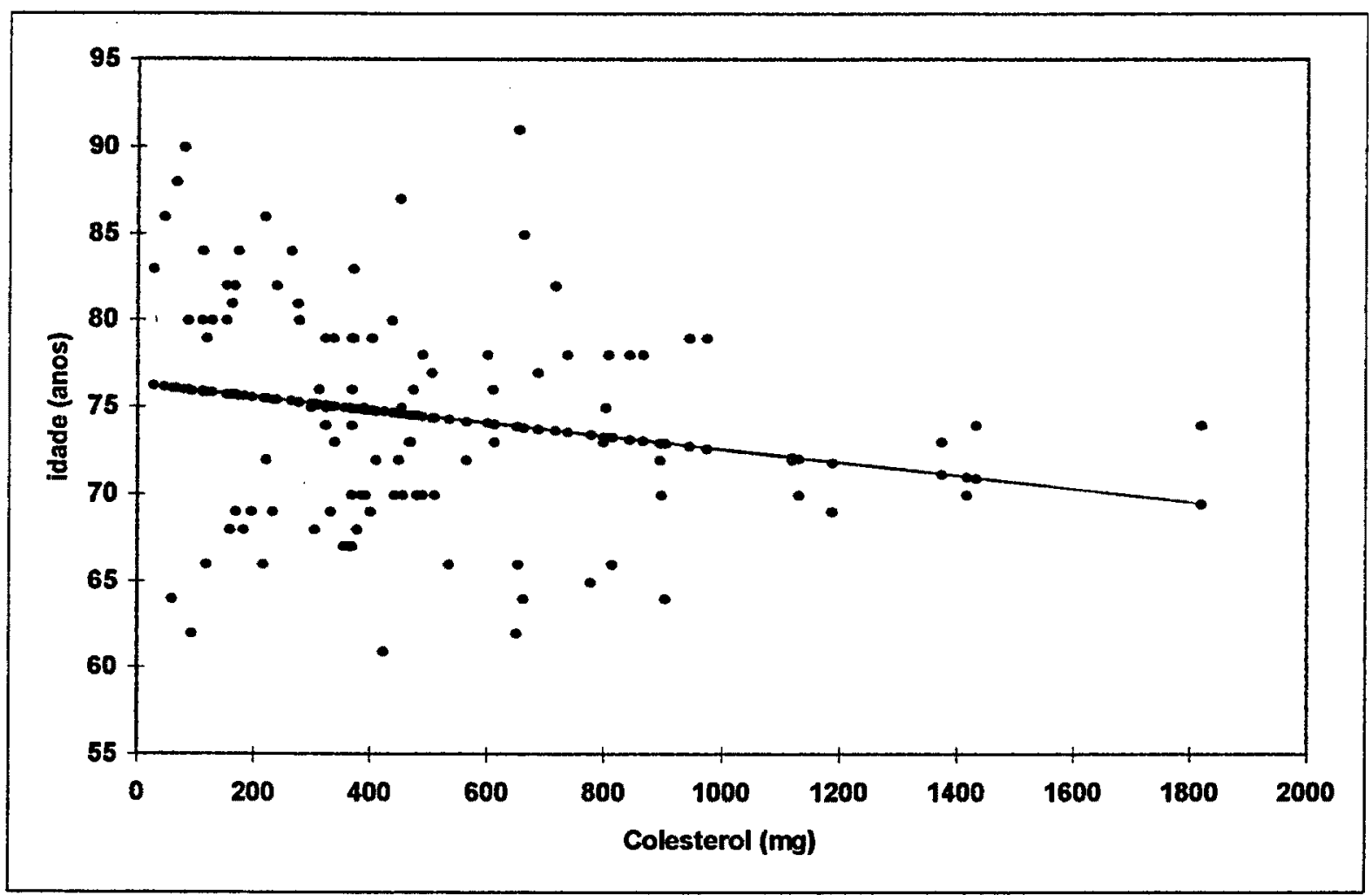

RESUMO DOS RESULTADOS

\begin{tabular}{lc}
\hline \multicolumn{2}{c}{ Estatistica de regressåo } \\
\hline R múltiplo & 0,1911 \\
R-Quadrado & 0,0365 \\
R-quadrado ajustado & 0,0268 \\
Erro padrăo & 6,55 \\
Observacőes & 102 \\
\hline
\end{tabular}

ANOVA

\begin{tabular}{lccccc}
\hline & $g l$ & $S Q$ & $Q M$ & $F$ & F de significação \\
\hline Regressåo & 1 & 163,0 & 163,0 & 3,7 & 0,054 \\
Residuo & 100 & 4300,3 & 43,0 & & \\
Total & 101 & 4463,4 & & & \\
\hline
\end{tabular}

\begin{tabular}{lcccccccc}
\hline & Coeficientes & Erro padrăo & Stat t & valor-P & $\begin{array}{c}95 \% \\
\text { inferiores }\end{array}$ & $\begin{array}{c}95 \% \\
\text { superiores }\end{array}$ & $\begin{array}{c}\text { Inferior } \\
95,0 \%\end{array}$ & $\begin{array}{c}\text { Superior } \\
95,0 \%\end{array}$ \\
\hline Interseçăo & 76,33 & 1,1339 & 67,31 & $4,1 E-85$ & 74,08 & 78,58 & 74,08 & 78,58 \\
Colesterol & $-0,0037$ & 0,0019 & $-1,94$ & 0,0543 & $-0,0076$ & $7,1-05$ & $-0,0076$ & $7,1 E-05$ \\
\hline
\end{tabular}


Figura 3- Gráfico da correlação entre a idade dos idosos do gênero feminino e a ingestão dietética de colesterol. Ambulatório do Serviço de Geriatria do HCFMUSP. São Paulo, 1988/90.

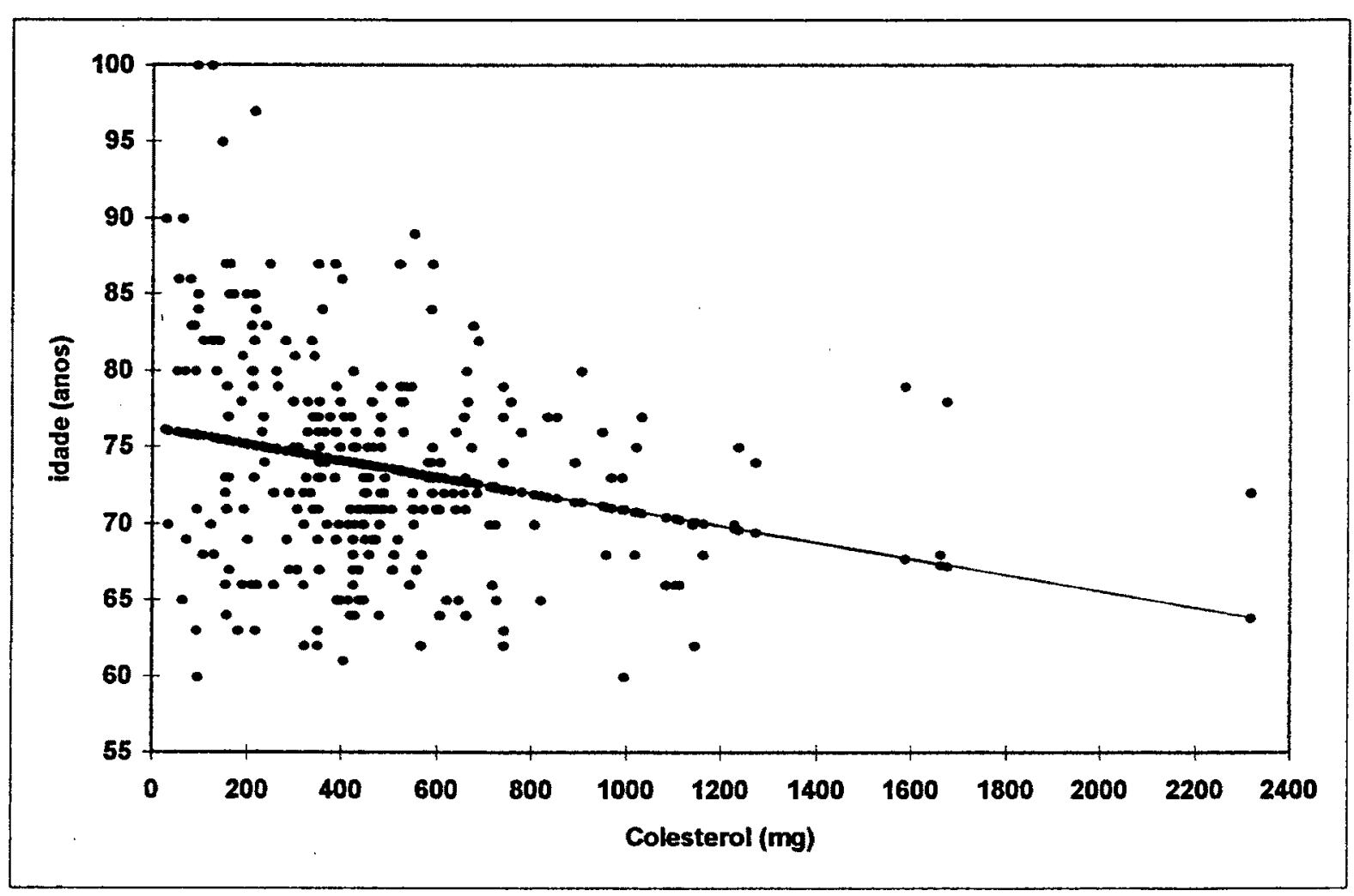

RESUMO DOS RESULTADOS

\begin{tabular}{lc}
\hline \multicolumn{2}{c}{ Estatistica de regressão } \\
\hline$R$ múltiplo & 0,2298 \\
R-Quadrado & 0,0528 \\
R-quadrado ajustado & 0,0492 \\
Erro padrão & 6,97 \\
Observaçöes & 266 \\
\hline
\end{tabular}

ANOVA

\begin{tabular}{lccccc}
\hline & $g l$ & $S Q$ & $Q M$ & $F$ & $F$ de significação \\
\hline Regressão & 1 & 715,7 & 715,7 & 14,7 & $1,5 \mathrm{E}-04$ \\
Residuo & 264 & 12830,2 & 48,5 & & \\
Total & 265 & 13546,0 & & & \\
\hline
\end{tabular}

\begin{tabular}{lcccccccc}
\hline & Coeficientes & Erro padrăo & Stat t & valor-P & $\begin{array}{c}95 \% \\
\text { inferiores }\end{array}$ & $\begin{array}{c}95 \% \\
\text { superiores }\end{array}$ & $\begin{array}{c}\text { Inferior } \\
\mathbf{9 5 , 0 \%}\end{array}$ & $\begin{array}{c}\text { Superior } \\
95,0 \%\end{array}$ \\
\hline Interseçăo & $\mathbf{7 6 , 3 1}$ & $\mathbf{0 , 7 7 5 6}$ & $\mathbf{9 8 , 3 8}$ & $\mathbf{4 , 7 E - 2 1 0}$ & $\mathbf{7 4 , 7 8}$ & $\mathbf{7 7 , 8 3}$ & $\mathbf{7 4 , 7 8}$ & $\mathbf{7 7 , 8 3}$ \\
Colesterol & $-0,0053$ & $\mathbf{0 , 0 0 1 4}$ & $\mathbf{- 3 , 8 3}$ & $\mathbf{1 , 5 E 0 4}$ & $-0,0081$ & $-0,0026$ & $-0,0081$ & $-0,0026$ \\
\hline
\end{tabular}


Figura 4- Gráfico da correlação entre a idade dos idosos de ambos os gêneros e a ingestão de gorduras totais na dieta. Ambulatório do Serviço de Geriatria do HCFMUSP. São Paulo, 1988/90.

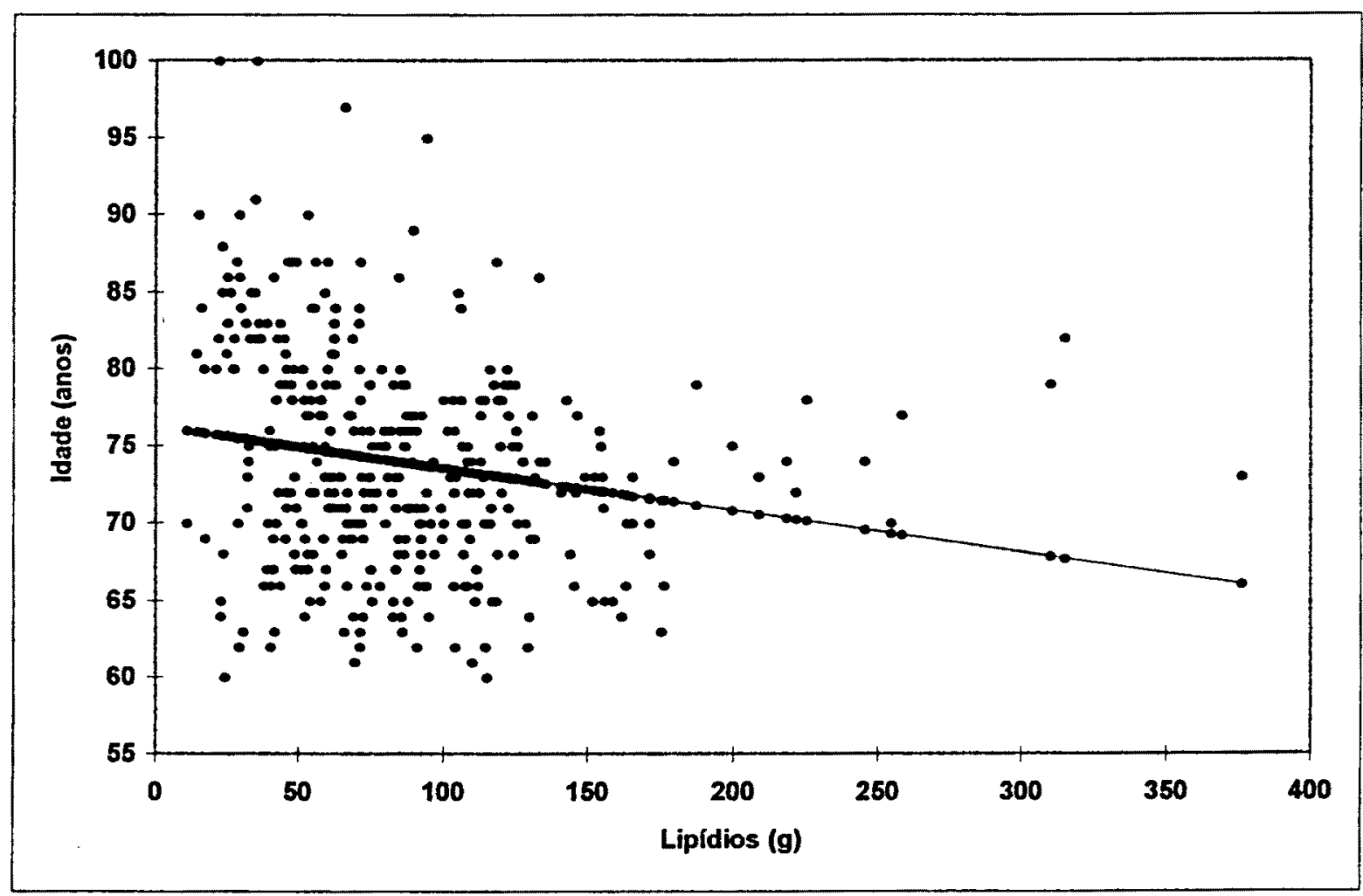

RESUMO DOS RESULTADOS

\begin{tabular}{lc}
\hline \multicolumn{2}{c}{ Estatistica de regressåo } \\
\hline R multiplo & 0,1884 \\
R-Quadrado & 0,0354 \\
R-quadrado ajustado & 0,0328 \\
Erro padråo & 6,89 \\
Observacð̃es & 368 \\
\hline
\end{tabular}

ANOVA

\begin{tabular}{|c|c|c|c|c|c|}
\hline & $g l$ & $S Q$ & $Q M$ & $F$ & F de significaçăo \\
\hline Regressão & 1 & 640,5 & 640,5 & 13,4 & 2,7E04 \\
\hline Residuo & 366 & 17405,2 & 47,5 & & \\
\hline Total & 367 & 18045,8 & & & \\
\hline
\end{tabular}

\begin{tabular}{ccccccccc}
\hline & Coeficientes & Erro padrăo & Stat t & valor-P & $\begin{array}{c}95 \% \\
\text { inferiores }\end{array}$ & $\begin{array}{c}95 \% \\
\text { superiores }\end{array}$ & $\begin{array}{c}\text { Inferior } \\
95,0 \%\end{array}$ & $\begin{array}{c}\text { Superior } \\
95,0 \%\end{array}$ \\
\hline Interseçåo & 76,32 & 0,7225 & 105,62 & $2,9 E-276$ & 74,90 & 77,74 & 74,90 & 77,74 \\
Lipídios & $-0,0272$ & 0,0074 & $-3,67$ & $2,7 E 04$ & $-0,0418$ & $-0,0126$ & $-0,0418$ & $-0,0126$ \\
\hline
\end{tabular}


Figura 5- Gráfico da correlação entre a idade dos idosos do gênero masculino e a ingestão de gorduras totais na dieta. Ambulatório do Serviço de Geriatria do HCFMUSP. São Paulo, 1988/90.

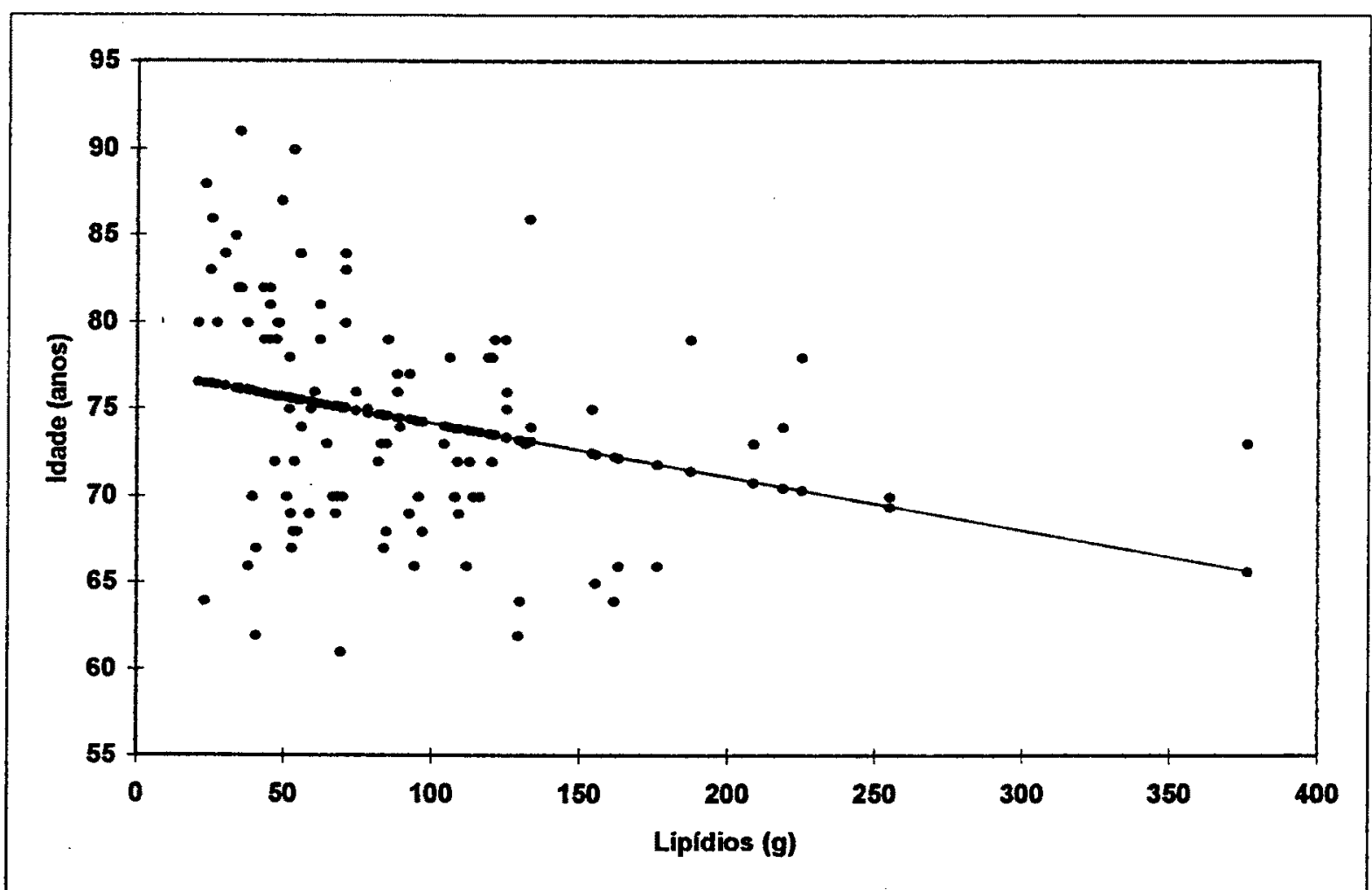

RESUMO DOS RESULTADOS

\begin{tabular}{lc}
\hline \multicolumn{2}{c}{ Estatistica de regressão } \\
\hline R múltiplo & 0,2578 \\
R-Quadrado & 0,0664 \\
R-quadrado ajustado & 0,0571 \\
Erro padrăo & 6,45 \\
Observaçøes & 102 \\
\hline
\end{tabular}

ANOVA

\begin{tabular}{lccccc}
\hline & $g l$ & SQ & QM & $F$ & F de significaçăo \\
\hline Regressăo & 1 & 296,7 & 296,7 & 7,1 & 0,0088 \\
Residuo & 100 & 4166,6 & 41,6 & & \\
Total & 101 & 4463,4 & & & \\
\hline
\end{tabular}

\begin{tabular}{ccccccccc}
\hline & Coeficientes & Erro padråo & Stat t & valor-P & $\begin{array}{c}95 \% \\
\text { inferiores }\end{array}$ & $\begin{array}{c}95 \% \\
\text { superiores }\end{array}$ & $\begin{array}{c}\text { Inferior } \\
95,0 \%\end{array}$ & $\begin{array}{c}\text { Superior } \\
95,0 \%\end{array}$ \\
\hline Interseçåo & 77,22 & 1,1956 & 64,59 & $2,3 E-83$ & 74,85 & 79,59 & 74,85 & 79,59 \\
Lipidios & $-0,0307$ & 0,0115 & $-2,66$ & 0,0088 & $-0,0536$ & $-0,0078$ & $-0,0536$ & $-0,0078$ \\
\hline
\end{tabular}


Figura 6- Gráfico da correlação entre a idade dos idosos do gênero feminino e a ingestão de gorduras totais na dieta. Ambulatório do Serviço de Geriatria do HCFMUSP. São Paulo, 1988/90.

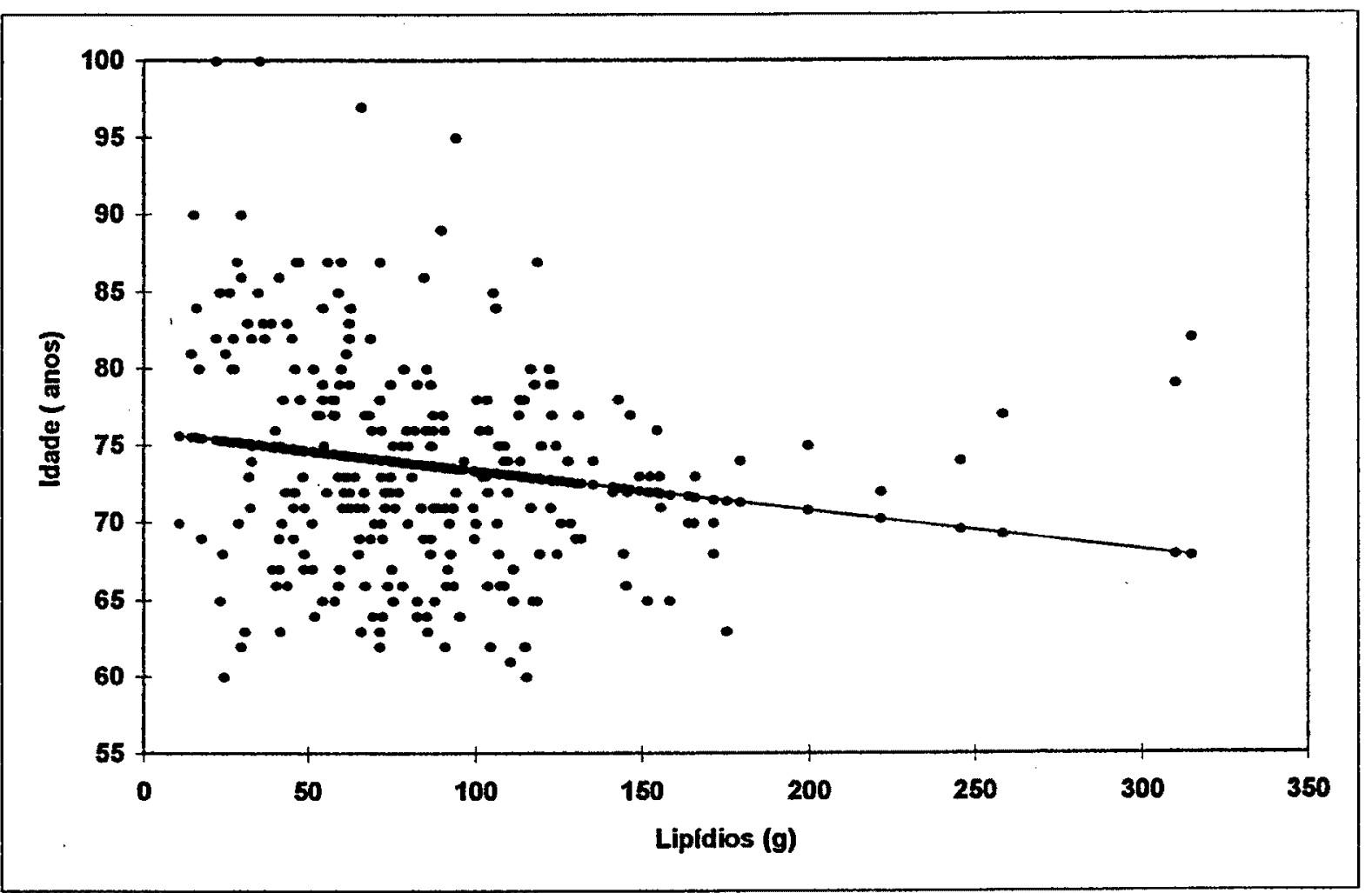

\section{RESUMO DOS RESULTADOS}

\begin{tabular}{lc}
\hline \multicolumn{2}{c}{ Estatística de regressăo } \\
\hline R múltiplo & 0,1636 \\
R-Quadrado & 0,0267 \\
R-quadrado ajustado & 0,0231 \\
Erro padrão & 7,06 \\
Observaçōes & 266 \\
\hline
\end{tabular}

\section{ANOVA}

\begin{tabular}{lccccc}
\hline & gl & SQ & QM & $F$ & F de significaçăo \\
\hline Regressåo & 1 & 362,9 & 362,9 & 7,2 & 0,0074 \\
Residuo & 264 & 13183,0 & 49,9 & & \\
Total & 265 & 13546,0 & & & \\
\hline
\end{tabular}

\begin{tabular}{ccccccccc}
\hline & Coeficientes & Erro padrăo & Stat t & valor-P & $\begin{array}{c}95 \% \\
\text { inferiores }\end{array}$ & $\begin{array}{c}95 \% \\
\text { superiores }\end{array}$ & $\begin{array}{c}\text { Inferior } \\
95,0 \%\end{array}$ & $\begin{array}{c}\text { Superior } \\
95,0 \%\end{array}$ \\
\hline Interseçåo & $\mathbf{7 5 , 9 6}$ & $\mathbf{0 , 9 0 4 9}$ & $\mathbf{8 3 , 9 4}$ & $\mathbf{2 E - 1 9 2}$ & $\mathbf{7 4 , 1 8}$ & $\mathbf{7 7 , 7 5}$ & $\mathbf{7 4 , 1 8}$ & 77,75 \\
Lipidios & $-0,0257$ & 0,0095 & $-2,69$ & 0,0074 & $-0,0446$ & $-0,0069$ & $-0,0446$ & $-0,0069$ \\
\hline
\end{tabular}


As correlações das figuras $7,8,9$, apontam para uma associação positiva entre os valores energéticos da dieta e a ingestão de gorduras polinsaturadas.Esta correlação identifica que quanto maior o consumo energético, maior a ingestão desse tipo de gorduras.As curvas apontam para a demonstração de regressão entre as variáveis ao nivel de significância do teste. 
Figura 7- Gráfico da correlação entre os valores energéticos consumidos diariamente pelos idosos de ambos os gêneros e a gordura polinsaturada. Ambulatório do Serviço de Geriatria do HCFMUSP. São Paulo, 1988/90.

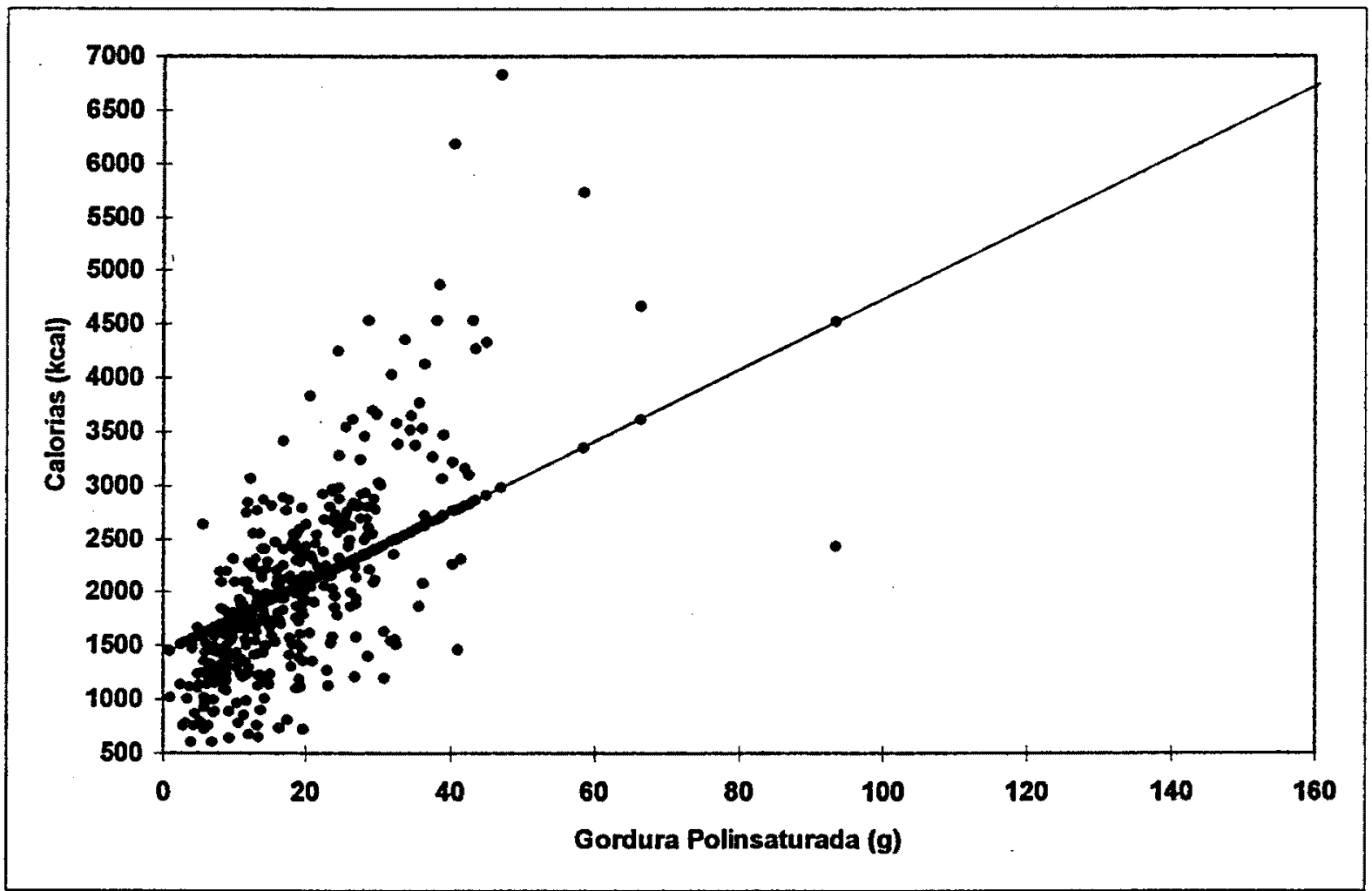

RESUMO DOS RESULTADOS

\begin{tabular}{lc}
\hline \multicolumn{2}{c}{ Estatistica de regressão } \\
\hline R múltiplo & 0,5603 \\
R-Quadrado & 0,3140 \\
R-quadrado ajustado & 0,3121 \\
Erro padråo & 747,47 \\
Observaçסes & 368 \\
\hline
\end{tabular}

ANOVA

\begin{tabular}{lccccc}
\hline & $g l$ & $S Q$ & $Q M$ & $F$ & $F$ de significaçăo \\
\hline Regressão & 1 & 93607155 & 93607155 & 167,5 & $8,2 E-32$ \\
Residuo & 366 & 204488387 & 558711,4 & & \\
Total & 367 & 298095542 & & & \\
\hline
\end{tabular}

\begin{tabular}{ccccccccc}
\hline & Coeficientes & Erro padrăo & Stat t & valor-P & $\begin{array}{c}95 \% \\
\text { inferiores }\end{array}$ & $\begin{array}{c}95 \% \\
\text { superiores }\end{array}$ & Inferior $95,0 \%$ & $\begin{array}{c}\text { Superior } \\
95,0 \%\end{array}$ \\
\hline Interseçåo & 1431,44 & 62,66 & 22,84 & $2,0 E-72$ & 1308,21 & 1554,67 & 1308,21 & 1554,67 \\
Gordura polinsaturada & 33,09 & 2,55 & 12,94 & $8,2 E-32$ & 28,06 & 38,11 & 28,06 & 38,11 \\
\hline
\end{tabular}


Figura 8- Gráfico da correlação entre os valores energéticos consumidos diariamente pelos idosos do gênero masculino e a gordura polinsaturada. Ambulatório do Serviço de Geriatria do HCFMUSP. São Paulo, 1988/90.

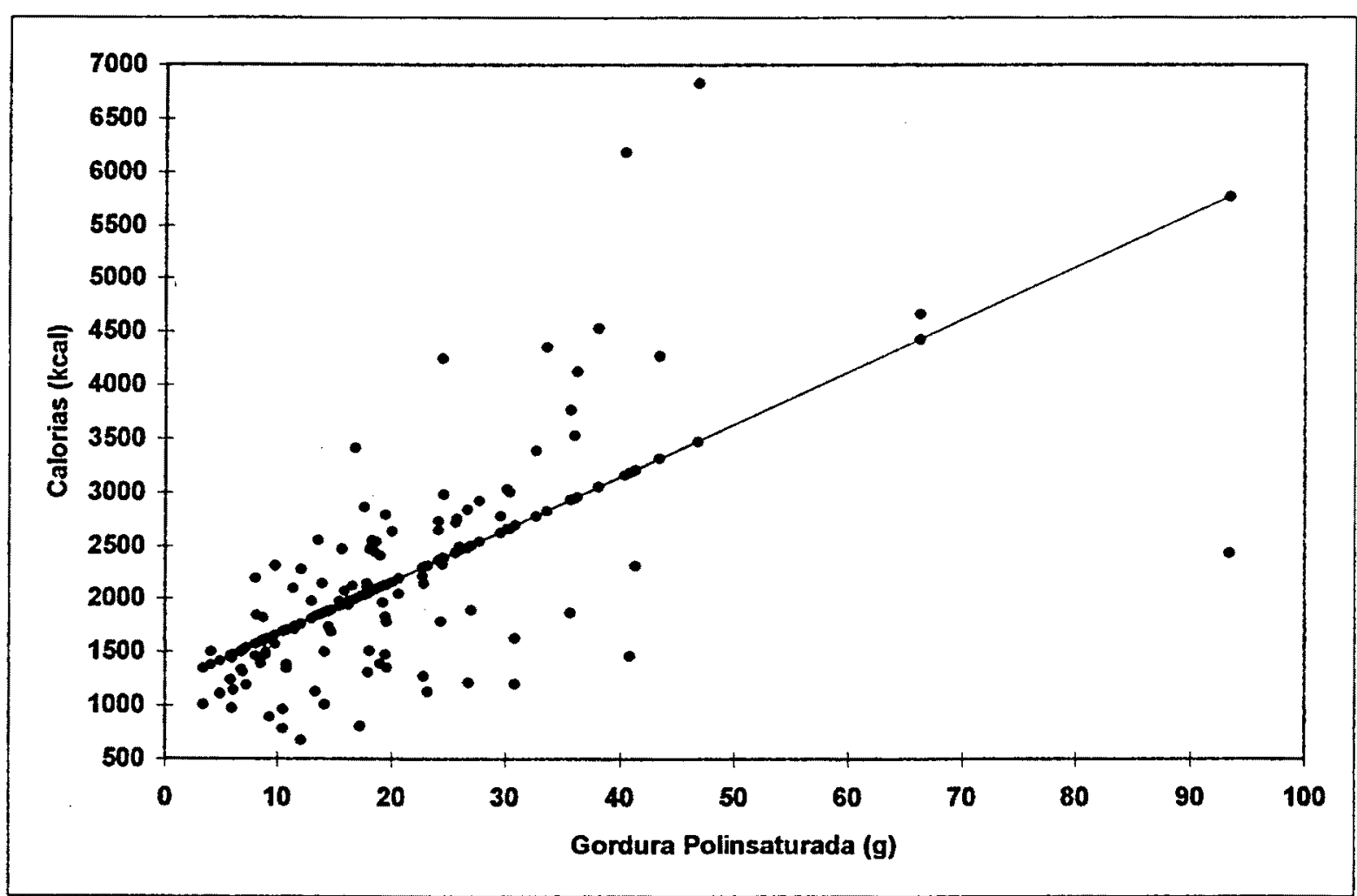

RESUMO DOS RESULTADOS

\begin{tabular}{lc}
\hline \multicolumn{2}{c}{ Estatistica de regressão } \\
\hline R múltiplo & 0,6020 \\
R-Quadrado & 0,3624 \\
R-quadrado ajustado & 0,3560 \\
Erro padrăo & 860,34 \\
Observações & 102 \\
\hline
\end{tabular}

ANOVA

\begin{tabular}{lccccc}
\hline & $g l$ & $S Q$ & $Q M$ & $F$ & F de significaçåo \\
\hline Regressåo & 1 & 42079279 & 42079279 & 56,8 & $2,1 E-11$ \\
Residuo & 100 & 74020184 & 740201,8 & & \\
Total & 101 & 116099463 & & & \\
\hline
\end{tabular}

\begin{tabular}{ccccccccc}
\hline & Coeficientes & Erro padrăo & Stat t & valor-P & $\begin{array}{c}95 \% \\
\text { inferiores }\end{array}$ & $\begin{array}{c}95 \% \\
\text { superiores }\end{array}$ & $\begin{array}{c}\text { Inferior } \\
95,0 \%\end{array}$ & $\begin{array}{c}\text { Superior } \\
95,0 \%\end{array}$ \\
\hline Interseçăo & 1179,61 & 157,11 & 7,50 & $2,5 E-11$ & 867,90 & 1491,31 & 867,90 & 1491,31 \\
Gordura polinsaturada & 49,15 & 6,51 & 7,53 & $2,1 E-11$ & 36,22 & 62,09 & 36,22 & 62,09 \\
\hline
\end{tabular}


Figura 9- Gráfico da correlação entre os valores energéticos consumidos diariamente pelos idosos do gênero feminino e a gordura polinsaturada. Ambulatório do Serviço de Geriatria do HCFMUSP. São Paulo, $1988 / 90$.

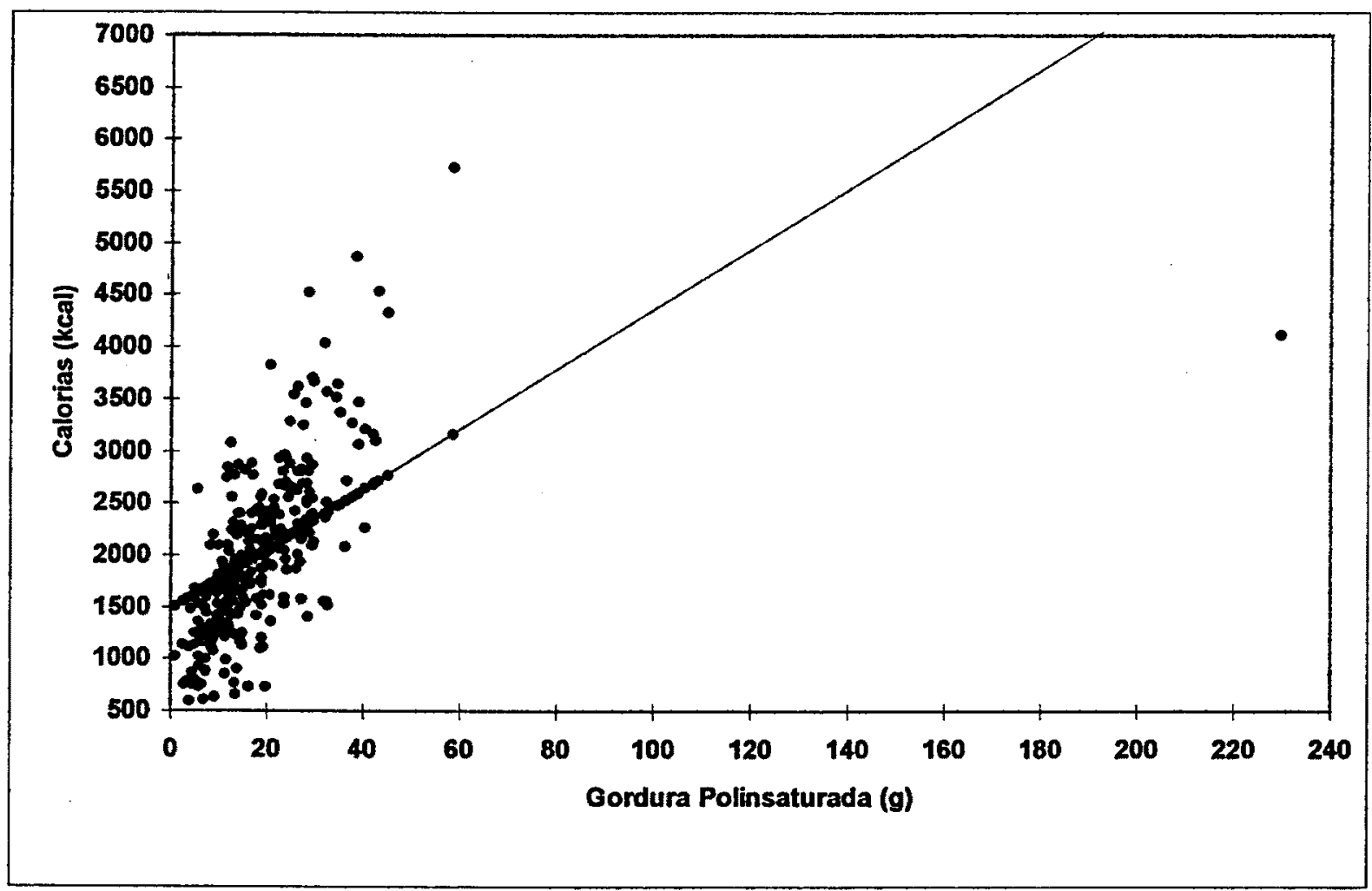

RESUMO DOS RESULTADOS

\begin{tabular}{lc}
\hline \multicolumn{2}{c}{ Estatistica de regressão } \\
\hline R múltiplo & 0,5590 \\
R-Quadrado & 0,3125 \\
R-quadrado ajustado & 0,3099 \\
Erro padråo & 685,26 \\
Observaçðes & 266 \\
\hline
\end{tabular}

ANOVA

\begin{tabular}{lccccc}
\hline & $g !$ & $S Q$ & $Q M$ & $F$ & $F$ de significaçăo \\
\hline Regressåo & 1 & 56373274 & 56373274 & 120,0 & $2,8 E-23$ \\
Resíduo & 264 & 123969594 & 469581,8 & & \\
Total & 265 & 180342868 & & & \\
\hline
\end{tabular}

\begin{tabular}{ccccccccc}
\hline & Coeficientes & Erro padråo & Stat t & valor-P & $\begin{array}{c}95 \% \\
\text { inferiores }\end{array}$ & $\begin{array}{c}95 \% \\
\text { superiores }\end{array}$ & $\begin{array}{c}\text { Inferior } \\
95,0 \%\end{array}$ & $\begin{array}{c}\text { Superior } \\
95,0 \%\end{array}$ \\
\hline Interseçåo & 1483,72 & 64,86 & 22,87 & $1,4 E-64$ & 1355,99 & 1611,44 & 1355,99 & 1611,44 \\
Gordura polinsaturada & 28,81 & 2,62 & 10,95 & $2,8 E-23$ & 23,63 & 33,99 & 23,63 & 33,99 \\
\hline
\end{tabular}


As figuras 10,11, e 12 demonstram que há regressão entre as variáveis estudadas ao nível de significância do teste; a correlação apresentada é positiva, indicando que com o aumento de consumo de fibras dietéticas, há um aumento de consumo do colesterol da dieta. 
Figura 10- Gráfico da correlação entre a ingestão de fibras da dieta e colesterol dos idosos de ambos os gêneros. Ambulatório do Serviço de Geriatria do HCFMUSP. São Paulo, 1988/90.

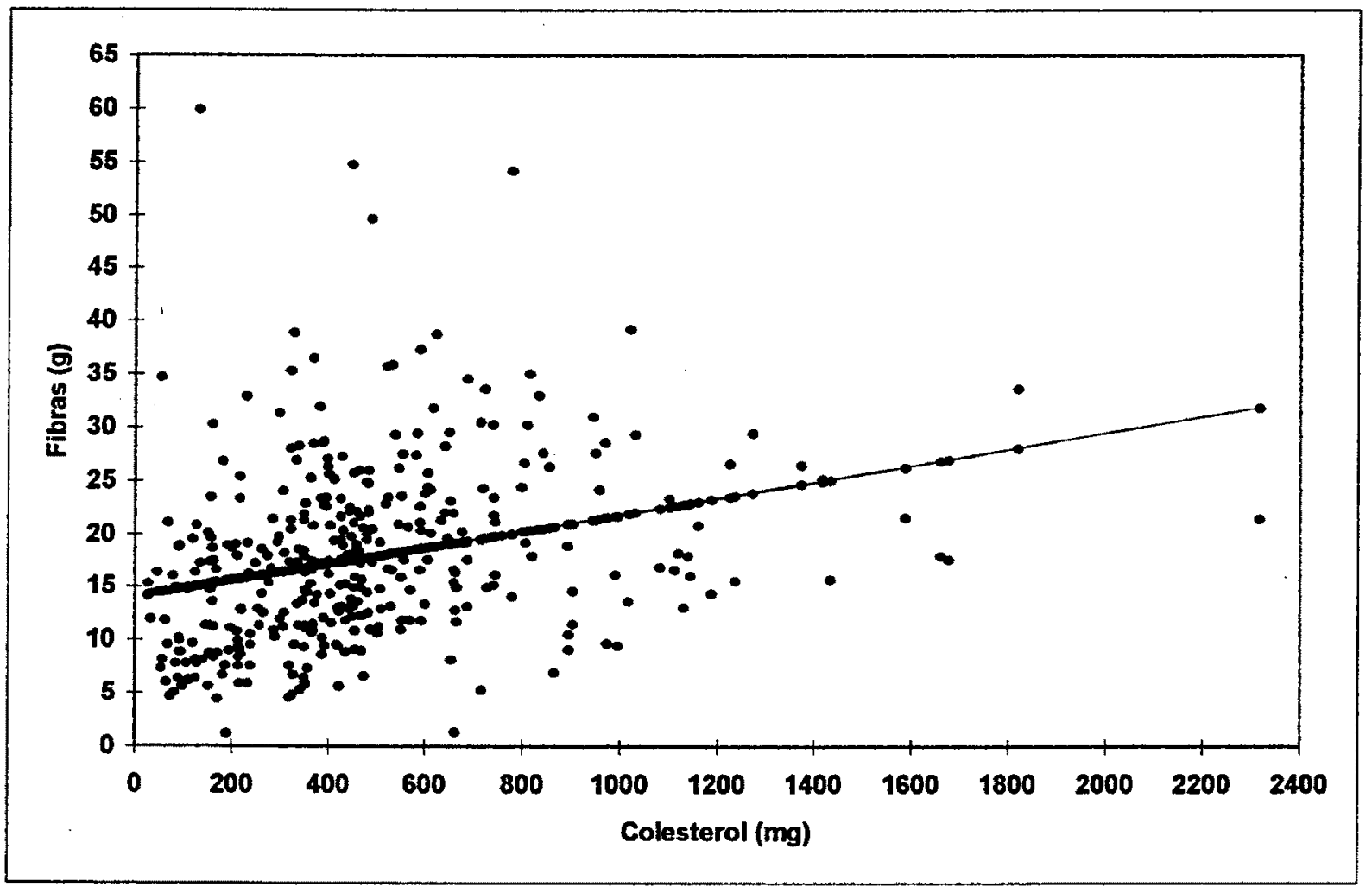

RESUMO DOS RESULTADOS

\begin{tabular}{lc}
\hline \multicolumn{2}{c}{ Estat/stica de regressåo } \\
\hline R mültiplo & 0,2837 \\
R-Quadrado & 0,0805 \\
R-quadrado ajustado & 0,0780 \\
Erro padrăo & 8,11 \\
Obsenvaç̃es & 368 \\
\hline
\end{tabular}

ANOVA

\begin{tabular}{lccccc}
\hline & gl & $S Q$ & $Q M$ & $F$ & F de significaçáo \\
\hline Regressåo & 1 & 2111,4 & 2111,4 & 32,0 & 3,0 E-08 \\
Resíduo & 366 & 24107,7 & 65,8 & & \\
Total & 367 & 26219,2 & & & \\
\hline
\end{tabular}

\begin{tabular}{lcccccccc}
\hline & Coeficientes & Erro padrão & Stat t & valor-P & $\begin{array}{c}95 \% \\
\text { inferiores }\end{array}$ & $\begin{array}{c}95 \% \\
\text { superiores }\end{array}$ & $\begin{array}{c}\text { Inferior } \\
95,0 \%\end{array}$ & $\begin{array}{c}\text { Superior } \\
95,0 \%\end{array}$ \\
\hline Interseçåo & 14,17 & 0,7583 & 18,69 & $3,1 E-55$ & 12,68 & 15,66 & 12,68 & 15,66 \\
Colesterol & 0,0076 & 0,0013 & 5,66 & $3,0 E-08$ & 0,0049 & 0,0103 & 0,0049 & 0,0103 \\
\hline
\end{tabular}


Figura 11- Gráfico da correlação entre a ingestão de fibras da dieta e colesterol dos idosos do gênero masculino. Ambulatório do Serviço de Geriatria do HCFMUSP. São Paulo, 1988/90.

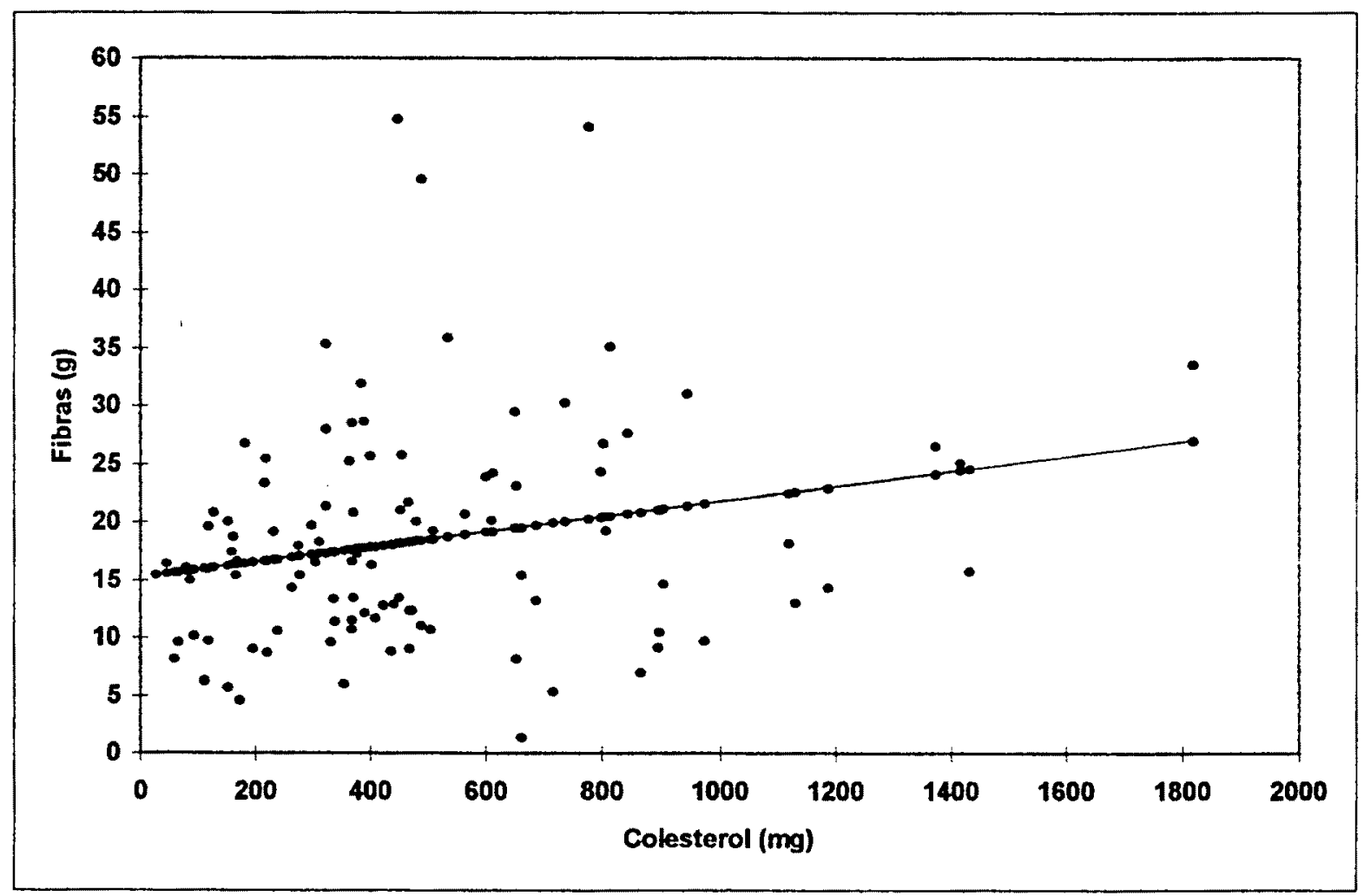

RESUMO DOS RESULTADOS

\begin{tabular}{lc}
\hline \multicolumn{2}{c}{ Estatistica de regressão } \\
\hline R múltiplo & 0,2235 \\
R-Quadrado & 0,0499 \\
R-quadrado ajustado & 0,0404 \\
Erro padråo & 9,55 \\
Observaçðes & 102 \\
\hline
\end{tabular}

ANOVA

\begin{tabular}{|c|c|c|c|c|c|c|c|c|}
\hline & & $g l$ & $S Q$ & $Q M$ & $F$ & \multicolumn{2}{|c|}{$F$ de significaçăo } & \\
\hline Regressão & & 1 & 480,3 & 480,3 & 5,2 & \multicolumn{2}{|c|}{0,0239} & \\
\hline Residuo & & 100 & 9131,7 & 91,3 & & & & \\
\hline \multirow[t]{2}{*}{ Total } & & 101 & 9612,1 & & & & & \\
\hline & Coeficientes & Erro padrão & Stat $t$ & valor-P & $\begin{array}{c}95 \% \\
\text { inferiores }\end{array}$ & $\begin{array}{c}95 \% \\
\text { superiores }\end{array}$ & $\begin{array}{l}\text { Inferior } \\
95.0 \%\end{array}$ & $\begin{array}{c}\text { Superior } \\
\mathbf{9 5 , 0 \%}\end{array}$ \\
\hline Interseçåo & 15,32 & 1,65 & 9,27 & $3,9 E-15$ & 12,04 & 18,59 & 12,04 & 18,59 \\
\hline Colesterol & 0,0064 & 0,0028 & 2,29 & 0,0239 & 0,0008 & 0,0120 & 0,0008 & 0,0120 \\
\hline
\end{tabular}


Figura 12- Gráfico da correlação entre a ingestão de fibras da dieta e colesterol dos idosos do gênero feminino. Ambulatório do Serviço de Geriatria do HCFMUSP. São Paulo, 1988/90.

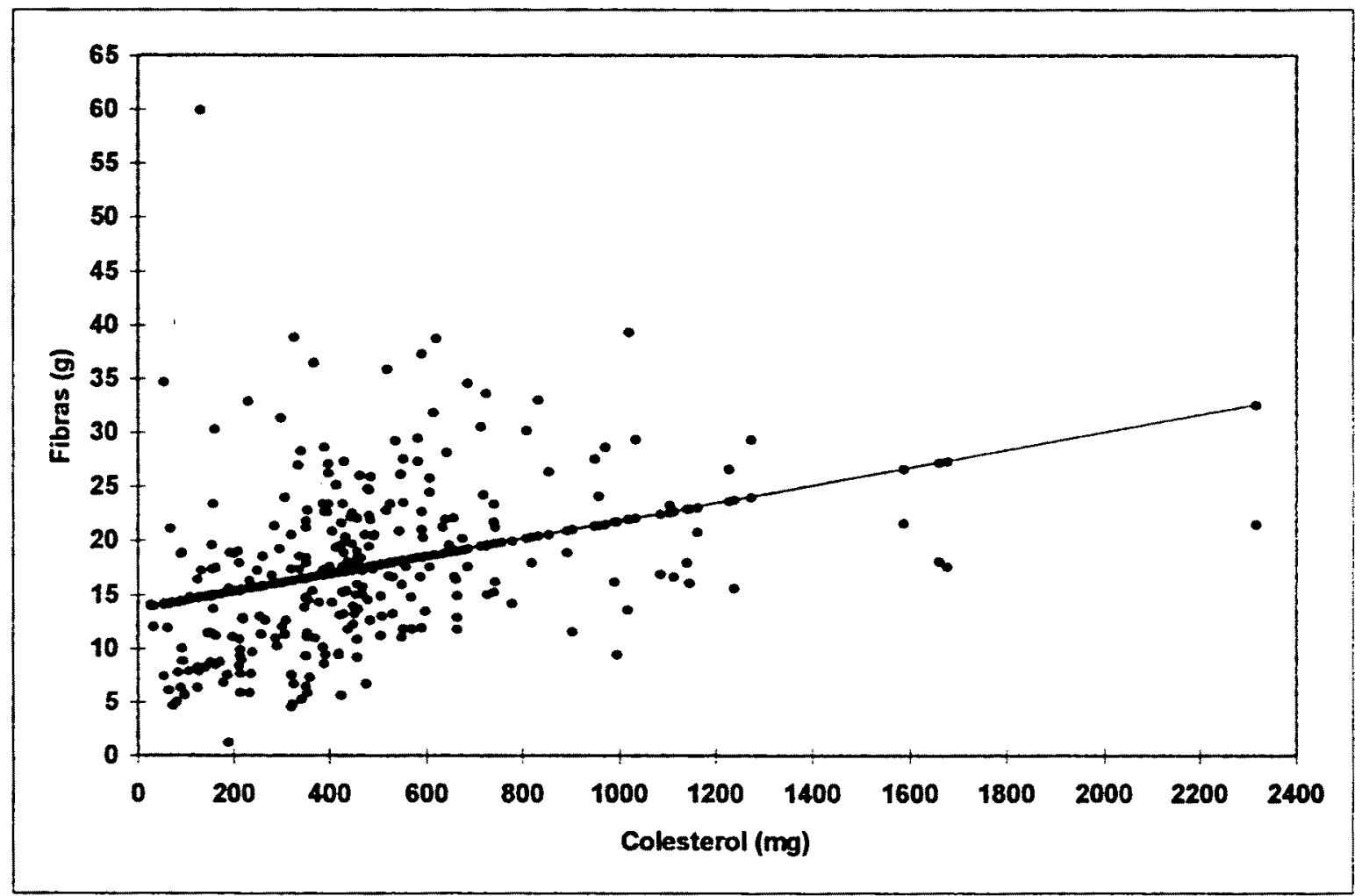

RESUMO DOS RESULTADOS

\begin{tabular}{lc}
\hline \multicolumn{2}{c}{ Estatistica de regressão } \\
\hline R múltiplo & 0,3142 \\
R-Quadrado & 0,0987 \\
R-quadrado ajustado & 0,0953 \\
Erro padrão & 7,51 \\
Observaç̋es & 266 \\
\hline
\end{tabular}

ANOVA

\begin{tabular}{lccccc}
\hline & $g l$ & $S Q$ & $Q M$ & $F$ & $F$ de significacăo \\
\hline Regressåo & 1 & 1633,8 & 1633,8 & 28,9 & $1,6 \mathrm{E}-07$ \\
Residuo & 264 & 14906,8 & 56,4 & & \\
Total & 265 & 16540,6 & & & \\
\hline
\end{tabular}

\begin{tabular}{ccccccccc}
\hline & Coeficientes & Erro padrão & Stat t & valor-P & $\begin{array}{c}95 \% \\
\text { inferiores }\end{array}$ & $\begin{array}{c}95 \% \\
\text { superiores }\end{array}$ & $\begin{array}{c}\text { Inferior } \\
95,0 \%\end{array}$ & $\begin{array}{c}\text { Superior } \\
95,0 \%\end{array}$ \\
\hline Interseçåo & 13,72 & 0,8360 & 16,41 & $3,24 E-42$ & 12,07 & 15,37 & 12,07 & 15,37 \\
Colesterol & 0,0081 & 0,0015 & 5,37 & $1,6 E-07$ & 0,0051 & 0,0111 & 0,0051 & 0,0111 \\
\hline
\end{tabular}


As figuras 13 e 15 demonstram correlação positiva entre o peso dos pacientes de ambos os sexos e do sexo feminino, respectivamente, e a ingestão dietética de colesterol,ao nivel de significância do teste. Já a figura 14 não demonstra a mesma correlação para o peso de homens e a ingestão de colesterol. 
Figura 13- Gráfico da correlação entre o peso dos idosos de ambos os gêneros e a ingestão dietética de colesterol. Ambulatório do Serviço de Geriatria do HCFMUSP. São Paulo, 1988/90.

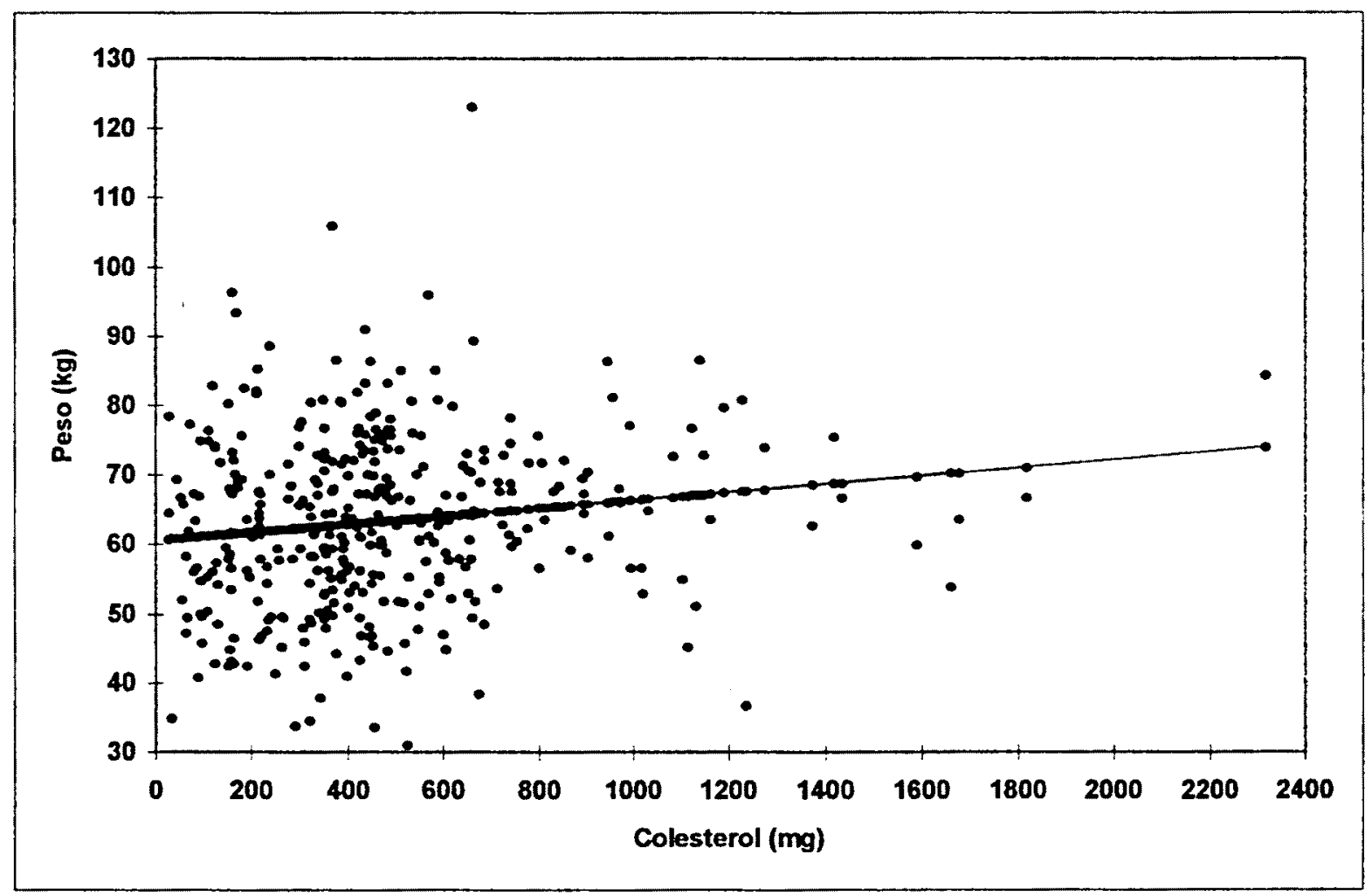

RESUMO DOS RESULTADOS

\begin{tabular}{lc}
\hline \multicolumn{2}{c}{ Estatística de regressåo } \\
\hline R múltiplo & 0,1452 \\
R-Quadrado & 0,0210 \\
R-quadrado ajustado & 0,0184 \\
Erro padråo & 12,35 \\
Observaç̃es & 368 \\
\hline
\end{tabular}

ANOVA

\begin{tabular}{lccccc}
\hline & $g l$ & $S Q$ & $Q M$ & $F$ & F de significaçăo \\
\hline Regressão & 1 & 1203,3 & 1203,3 & 7,8 & 0,0052 \\
Residuo & 366 & 55831,7 & 152,5 & & \\
Total & 367 & 57035,1 & & & \\
\hline
\end{tabular}

\begin{tabular}{ccccccccc}
\hline & Coeficientes & Erro padrão & Stat t & valor-P & $\begin{array}{c}95 \% \\
\text { inferiores }\end{array}$ & $\begin{array}{c}95 \% \\
\text { superiores }\end{array}$ & $\begin{array}{c}\text { Inferior } \\
95,0 \%\end{array}$ & $\begin{array}{c}\text { Superior } \\
95,0 \%\end{array}$ \\
\hline Interseçåo & $\mathbf{6 0 , 7 3}$ & 1,15 & 52,62 & $\mathbf{8 , 5 E - 1 7 3}$ & 58,46 & 63,00 & 58,46 & 63,00 \\
Colesterol & 0,0057 & 0,0020 & 2,80 & 0,0052 & 0,0017 & 0,0098 & 0,0017 & 0,0098 \\
\hline
\end{tabular}


Figura 14- Gráfico da correlação entre o peso dos idosos do gênero masculino e a ingestão dietética de colesterol. Ambulatório do Serviço de Geriatria do HCFMUSP. São Paulo, 1988/90.

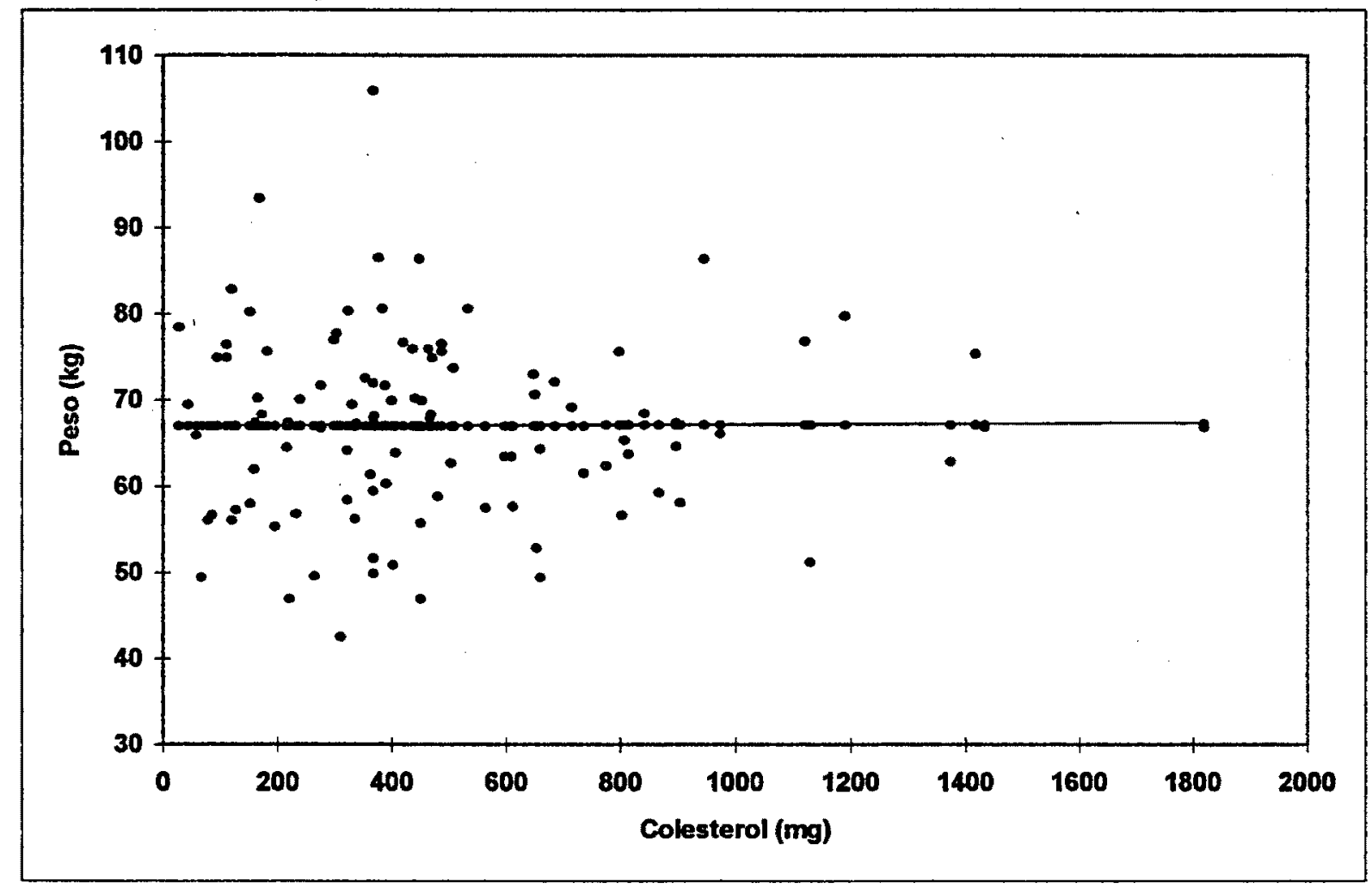

RESUMO DOS RESULTADOS

\begin{tabular}{lc}
\hline \multicolumn{2}{c}{ Estatistica de regressåo } \\
\hline$R$ múltiplo & 0,0049 \\
R-Quadrado & $2,4 E-05$ \\
R-quadrado ajustado & $-0,0099$ \\
Erro padrão & 10,75 \\
Observaçסes & 102 \\
\hline
\end{tabular}

ANOVA

\begin{tabular}{lccccc}
\hline & $g l$ & $S Q$ & $Q M$ & $F$ & $F$ de significaçáo \\
\hline Regressão & 1 & 0,2838 & 0,2838 & 0,0024 & 0,9605 \\
Residuo & 100 & 11568,8 & 115,6 & & \\
Total & 101 & 11569,1 & & & \\
\hline
\end{tabular}

\begin{tabular}{lcccccccc}
\hline & Coeficientes & Erro padrão & Stat t & valor-P & $\begin{array}{c}95 \% \\
\text { inferiores }\end{array}$ & $\begin{array}{c}95 \% \\
\text { superiores }\end{array}$ & $\begin{array}{c}\text { Inferior } \\
95,0 \%\end{array}$ & $\begin{array}{c}\text { Superior } \\
95,0 \%\end{array}$ \\
\hline Interseçåo & 67,01 & 1,85 & 36,031 & $4,3 E-59$ & 63,32 & 70,70 & 63,32 & 70,70 \\
Colesterol & $1,5 \mathrm{E} 04$ & 0,0031 & 0,0495 & 0,9605 & $-0,0061$ & 0,0064 & $-0,0061$ & 0,0064 \\
\hline
\end{tabular}


Figura 15- Gráfico da correlação entre o peso dos idosos do gênero feminino e a ingestão dietética de colesterol. Ambulatório do Serviço de Geriatria do HCFMUSP. São Paulo, 1988/90.

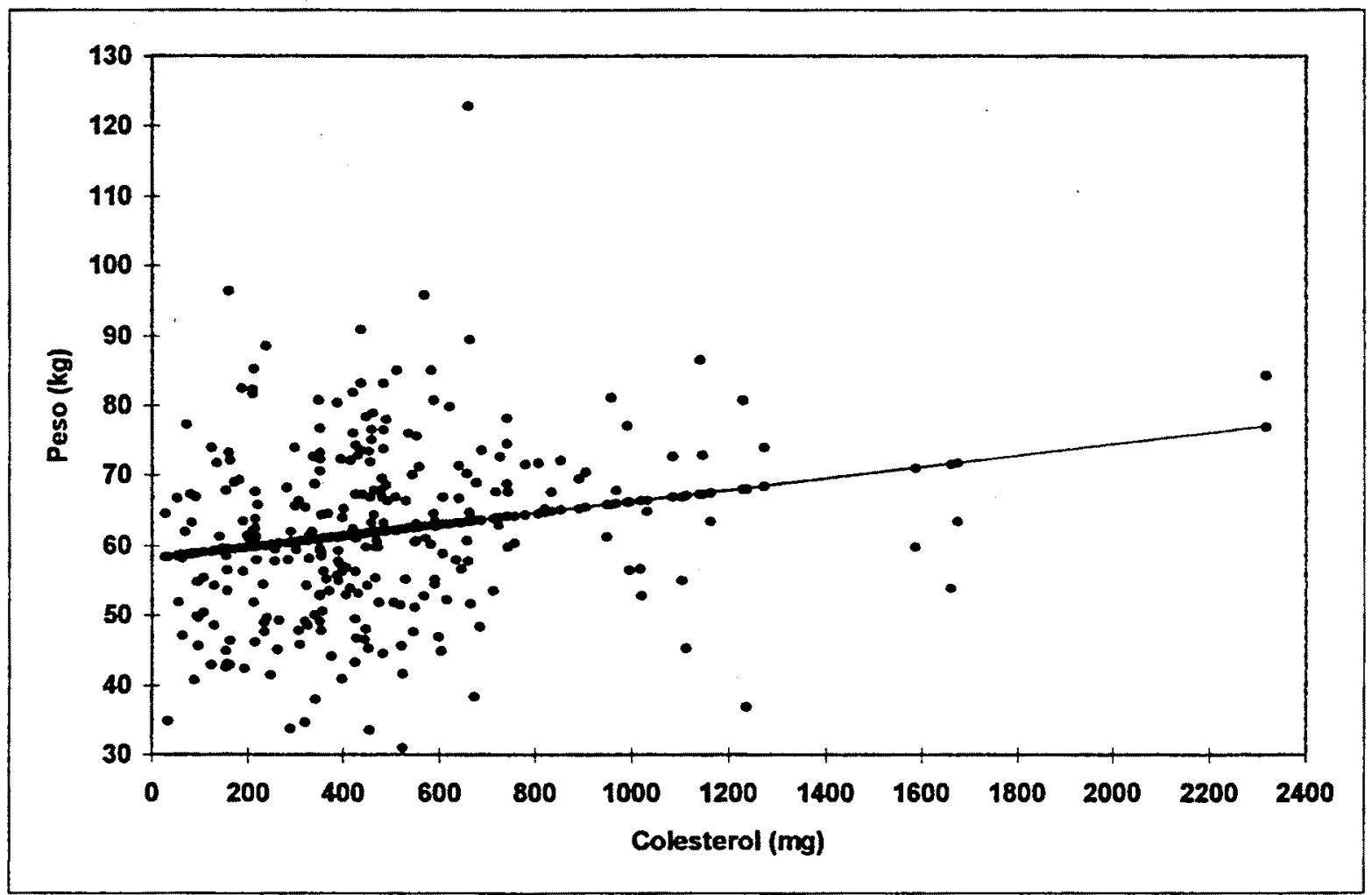

RESUMO DOS RESULTADOS

\begin{tabular}{lc}
\hline \multicolumn{2}{c}{ Estatıstica de regressáo } \\
\hline R múltiplo & 0,1925 \\
R-Quadrado & 0,0370 \\
R-quadrado ajustado & 0,0334 \\
Erro padrăo & 12,60 \\
Observaçoes & 266 \\
\hline
\end{tabular}

ANOVA

\begin{tabular}{lccccc}
\hline & gl & SQ & QM & $F$ & F de significação \\
\hline Regressåo & 1 & 1614,7 & 1614,7 & 10,1 & 0,0016 \\
Residuo & 264 & 41959,2 & 158,9 & & \\
Total & 265 & 43573,9 & & & \\
\hline
\end{tabular}

\begin{tabular}{ccccccccc}
\hline & Coeficientes & Erto padrăo & Stat t & valor-P & $\begin{array}{c}95 \% \\
\text { inferiores }\end{array}$ & $\begin{array}{c}95 \% \\
\text { superiores }\end{array}$ & $\begin{array}{c}\text { Inferior } \\
95,0 \%\end{array}$ & $\begin{array}{c}\text { Superior } \\
95,0 \%\end{array}$ \\
\hline Interseçăo & 58,29 & 1,40 & 41,55 & $7,7 E-118$ & 55,53 & 61,05 & 55,53 & 61,05 \\
Colesterol & 0,0080 & 0,0025 & 3,18 & 0,0016 & 0,0030 & 0,0131 & 0,0030 & 0,0131 \\
\hline
\end{tabular}


As figuras 16, 17, 18, 19, 20 e 21 correlacionam o peso dos pacientes por sexo e niveis séricos de triglicérides $(16,17,18)$ e HDL-c $(19,20,21)$; em todos os casos há regressão entre as variáveis ao nivel de significância do teste. Em relação aos triglicérides essa correlação é positiva, ou seja, com o aumento de peso dos pacientes, em ambos os sexos, há um aumento nas taxas de triglicérides no sangue. Vale a pena ressaltar que $o$ aumento dos níveis de triglicérides nos indivíduos, após $150 \mathrm{mg} / \mathrm{dL}$, leva a valores considerados limítrofes, fora dos indicadores considerados desejáveis.

Em relação a HDL-c essa correlação é negativa, ou seja, quanto menor o peso, maior as taxas de HDL-c no sangue. Neste caso, os valores desejáveis devem estar abaixo de $40 \mathrm{mg} / \mathrm{dL}$, o que aponta que indivíduos com pesos menores têm taxas melhores de HDL-c sangüineas. 
Figura 16- Gráfico da correlação entre o peso dos idosos de ambos os gêneros e os níveis séricos de triglicérides. Ambulatório do Serviço de Geriatria do HCFMUSP. São Paulo, 1988/90.

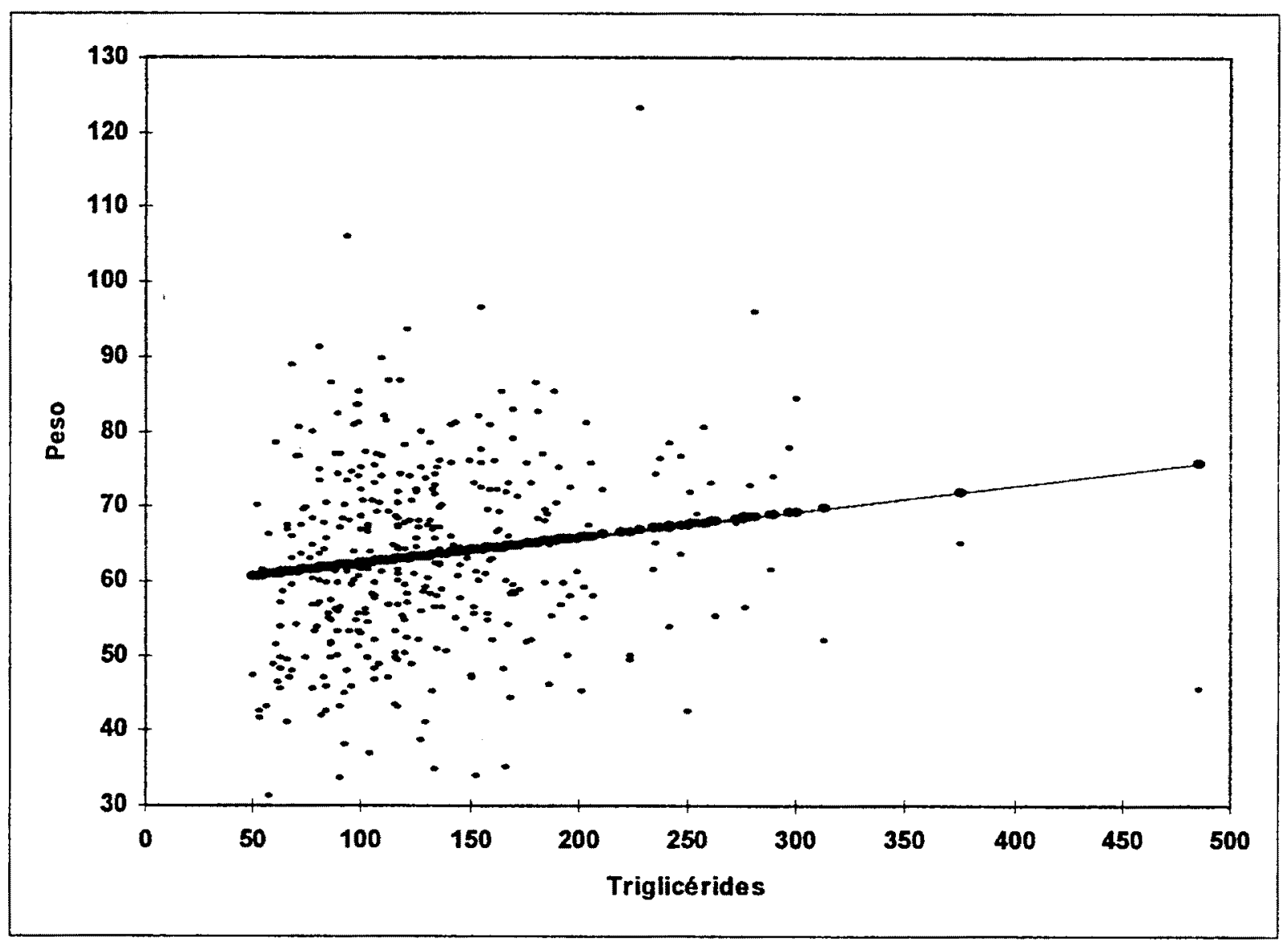

RESUMO DOS RESULTADOS

\begin{tabular}{lc}
\hline Estatistica de regressáo & \\
\hline$R$ múltiplo & 0,1588 \\
R-Quadrado & 0,0252 \\
R-quadrado ajustado & 0,0225 \\
Erro padrăo & 12,32 \\
Observaçøes & 368 \\
\hline
\end{tabular}

ANOVA

\begin{tabular}{lccccc}
\hline & $g l$ & $S Q$ & $Q M$ & $F$ & $F$ de significação \\
\hline Regressão & 1 & 1438,5 & 1438,5 & 9,4 & 0,0022 \\
Residuo & 366 & 55596,5 & 151,9 & & \\
Total & 367 & 57035,1 & & & \\
\hline
\end{tabular}

\begin{tabular}{ccccccccc}
\hline & Coeficientes & Erro padrão & Stat t & valor-P & $\begin{array}{c}95 \% \\
\text { inferiores }\end{array}$ & $\begin{array}{c}95 \% \\
\text { superiores }\end{array}$ & $\begin{array}{c}\text { Inferior } \\
95,0 \%\end{array}$ & $\begin{array}{c}\text { Superior } \\
95,0 \%\end{array}$ \\
\hline Interseção & 58,81 & 1,63 & 36,05 & $1,6 \mathrm{E}-122$ & 55,60 & 62,02 & 55,60 & 62,02 \\
Triglicérides & 0,0348 & 0,0113 & 3,07 & 0,0022 & 0,01258 & 0,0571 & 0,01258 & 0,0571 \\
\hline
\end{tabular}


Figura 17- Gráfico da correlação entre o peso dos idosos do gênero masculino e os niveis séricos de triglicérides. Ambulatório do Serviço de Geriatria do HCFMUSP. São Paulo, 1988/90.

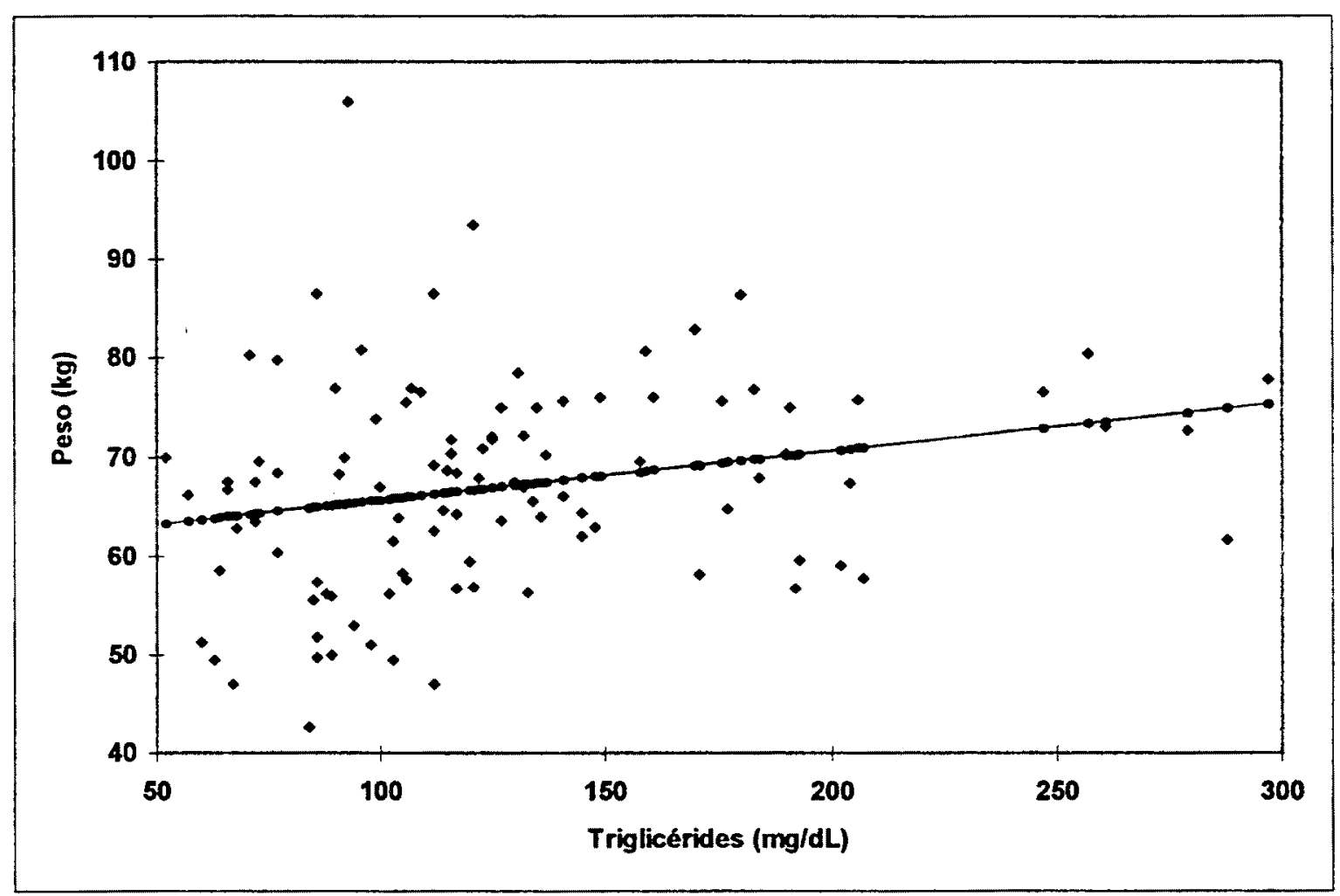

RESUMO DOS RESULTADOS

\begin{tabular}{lc}
\hline Estatlstica de regressão & \\
\hline R múltiplo & 0,2413 \\
R-Quadrado & 0,0582 \\
R-quadrado ajustado & 0,0488 \\
Erro padrão & 10,43 \\
Observaçס̋es & 102 \\
\hline
\end{tabular}

ANOVA

\begin{tabular}{lccccc}
\hline & $g l$ & $S Q$ & $Q M$ & $F$ & F de significação \\
\hline Regressåo & 1 & 673,8 & 673,8 & 6,1 & 0,01453 \\
Residuo & 100 & 10895,2 & 108,9 & & \\
Total & 101 & 11569,1 & & & \\
\hline
\end{tabular}

\begin{tabular}{ccccccccc}
\hline & Coeficientes Erro padrão & Stat t & valor-P & $\begin{array}{c}95 \% \\
\text { inferiores }\end{array}$ & $\begin{array}{c}95 \% \\
\text { superiores }\end{array}$ & $\begin{array}{c}\text { Inferior } \\
\mathbf{9 5 , 0 \%}\end{array}$ & $\begin{array}{c}\text { Superior } \\
95,0 \%\end{array}$ \\
\hline Interseçåo & $\mathbf{6 0 , 8 1}$ & 2,72 & $\mathbf{2 2 , 2 9}$ & $\mathbf{1 , 3 E - 4 0}$ & $\mathbf{5 5 , 3 9}$ & $\mathbf{6 6 , 2 2}$ & $\mathbf{5 5 , 3 9}$ & $\mathbf{6 6 , 2 2}$ \\
Triglicérides & $\mathbf{0 , 0 4 9 1}$ & $\mathbf{0 , 0 1 9 7}$ & $\mathbf{2 , 4 8}$ & $\mathbf{0 , 0 1 4 5}$ & $\mathbf{0 , 0 0 9 9}$ & $\mathbf{0 , 0 8 8 3}$ & $\mathbf{0 , 0 0 9 9}$ & 0,0883 \\
\hline
\end{tabular}


Figura 18- Gráfico da correlação entre o peso dos idosos do gênero feminino e os niveis séricos de triglicérides. Ambulatório do Serviço de Geriatria do HCFMUSP. São Paulo, 1988/90.

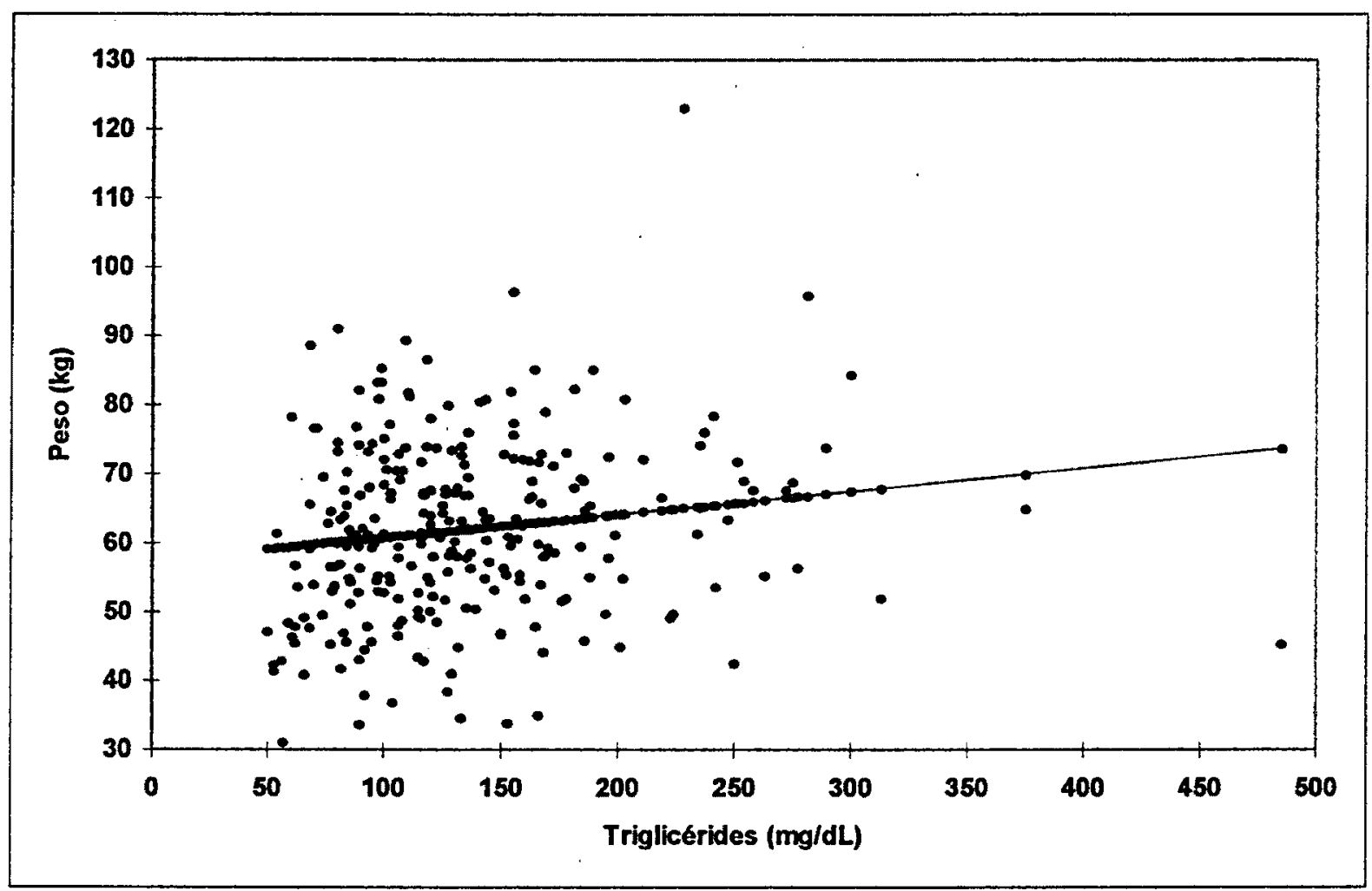

RESUMO DOS RESULTADOS

\begin{tabular}{lc}
\hline \multicolumn{2}{c}{ Estatistica de regressåo } \\
\hline$R$ múltiplo & 0,1510 \\
R-Quadrado & 0,0228 \\
R-quadrado ajustado & 0,0191 \\
Erro padrăo & 12,69 \\
Observaçoes & 266 \\
\hline
\end{tabular}

ANOVA

\begin{tabular}{lcccccc}
\hline & gl & SQ & QM & $F$ & F de significaçăo \\
\hline Regressão & 1 & 994,5 & 994,5 & 6,1 & 0,0136 \\
Residuo & 264 & 42579,3 & 161,2 & & \\
Total & 265 & 43573,9 & & & \\
\hline
\end{tabular}

\begin{tabular}{ccccccccc}
\hline & Coeficientes & Erro padrăo & Stat t & valor-P & $\begin{array}{c}\mathbf{9 5 \%} \\
\text { inferiores }\end{array}$ & $\begin{array}{c}\mathbf{9 5 \%} \\
\text { superiores }\end{array}$ & $\begin{array}{c}\text { Inferior } \\
95,0 \%\end{array}$ & $\begin{array}{c}\text { Superior } \\
95,0 \%\end{array}$ \\
\hline Interseçăo & 57,56 & 1,95 & 29,43 & $2,2 E-85$ & 53,71 & 61,42 & 53,71 & 61,42 \\
Triglicérides & 0,0332 & 0,0133 & 2,48 & 0,0136 & 0,0068 & 0,0595 & 0,0068 & 0,0595 \\
\hline
\end{tabular}


Figura 19- Gráfico da correlação entre o peso dos idosos de ambos os gêneros e os níveis séricos de HDL-c. Ambulatório do Serviço de Geriatria do HCFMUSP. São Paulo, 1988/90.

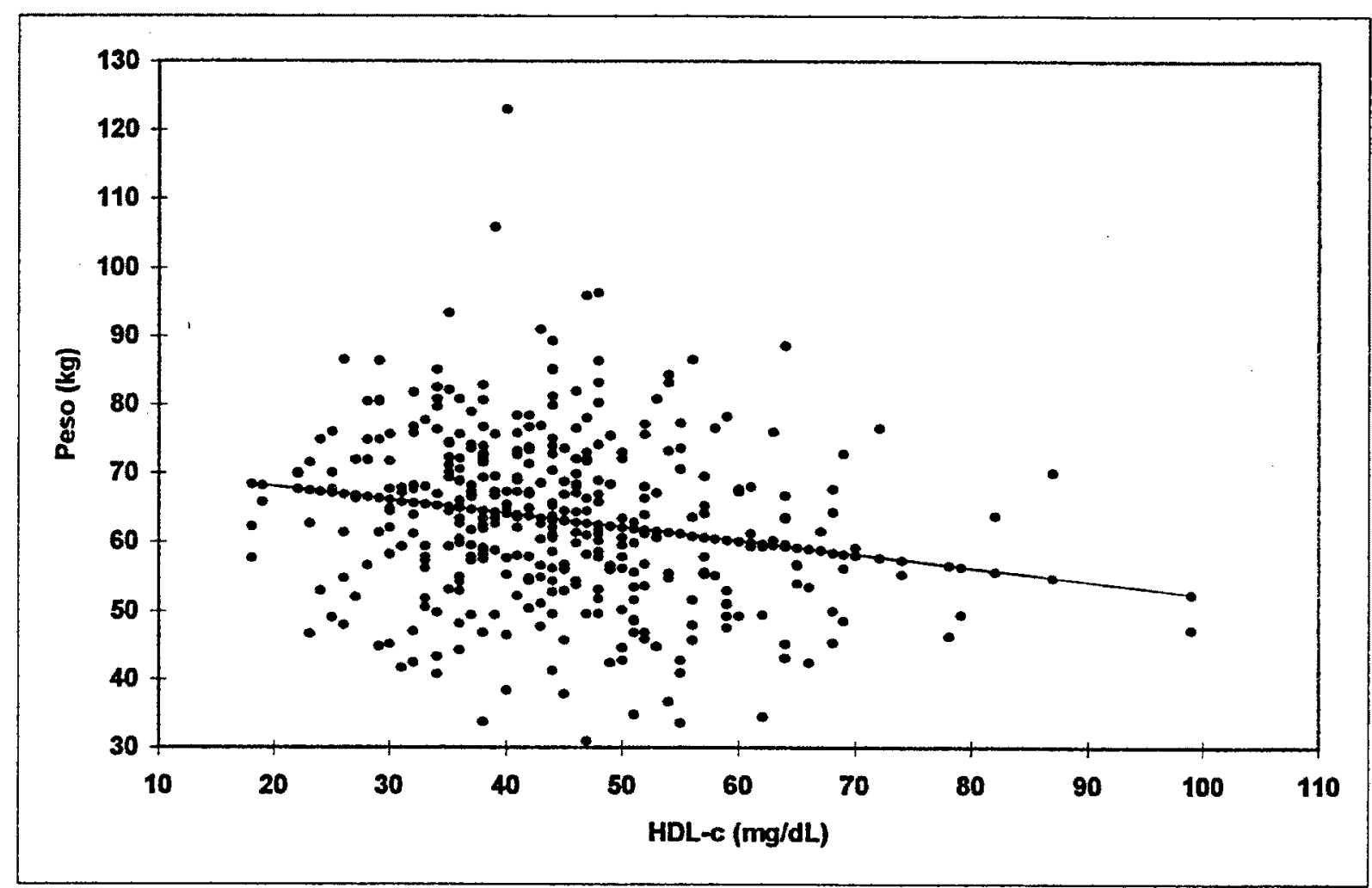

RESUMO DOS RESULTADOS

\begin{tabular}{lc}
\hline \multicolumn{2}{c}{ Estatistica de regressăo } \\
\hline R mültiplo & 0,1903 \\
R-Quadrado & 0,0362 \\
R-quadrado ajustado & 0,0336 \\
Erro padrão & 12,25 \\
Observaç̋es & 368 \\
\hline
\end{tabular}

ANOVA

\begin{tabular}{lccccc}
\hline & $g l$ & $S Q$ & $Q M$ & $F$ & F de significaçăo \\
\hline Regressão & 1 & 2067,1 & 2067,1 & 13,7 & 0,0002 \\
Residuo & 366 & 54967,9 & 150,1 & & \\
Total & 367 & 57035,1 & & & \\
\hline
\end{tabular}

\begin{tabular}{ccccccccc}
\hline & Coeficientes Erro padrăo & Stat t & valor-P & $\begin{array}{c}95 \% \\
\text { inferiores }\end{array}$ & $\begin{array}{c}95 \% \\
\text { superiores }\end{array}$ & $\begin{array}{c}\text { Inferior } \\
95,0 \%\end{array}$ & $\begin{array}{c}\text { Superior } \\
95,0 \%\end{array}$ \\
\hline Intersę̆ăo & 72,23 & 2,45 & 29,37 & $2,7 E-98$ & 67,40 & 77,07 & 67,40 & 77,07 \\
HDL-c & $-0,1993$ & 0,0537 & $-3,70$ & 0,0002 & $-0,3050$ & $-0,0936$ & $-0,3050$ & $-0,0936$ \\
\hline
\end{tabular}


Figura 20- Gráfico da correlação entre o peso dos idosos do gênero masculino e os niveis séricos de HDL-c. Ambulatório do Serviço de Geriatria do HCFMUSP. São Paulo, 1988/90.

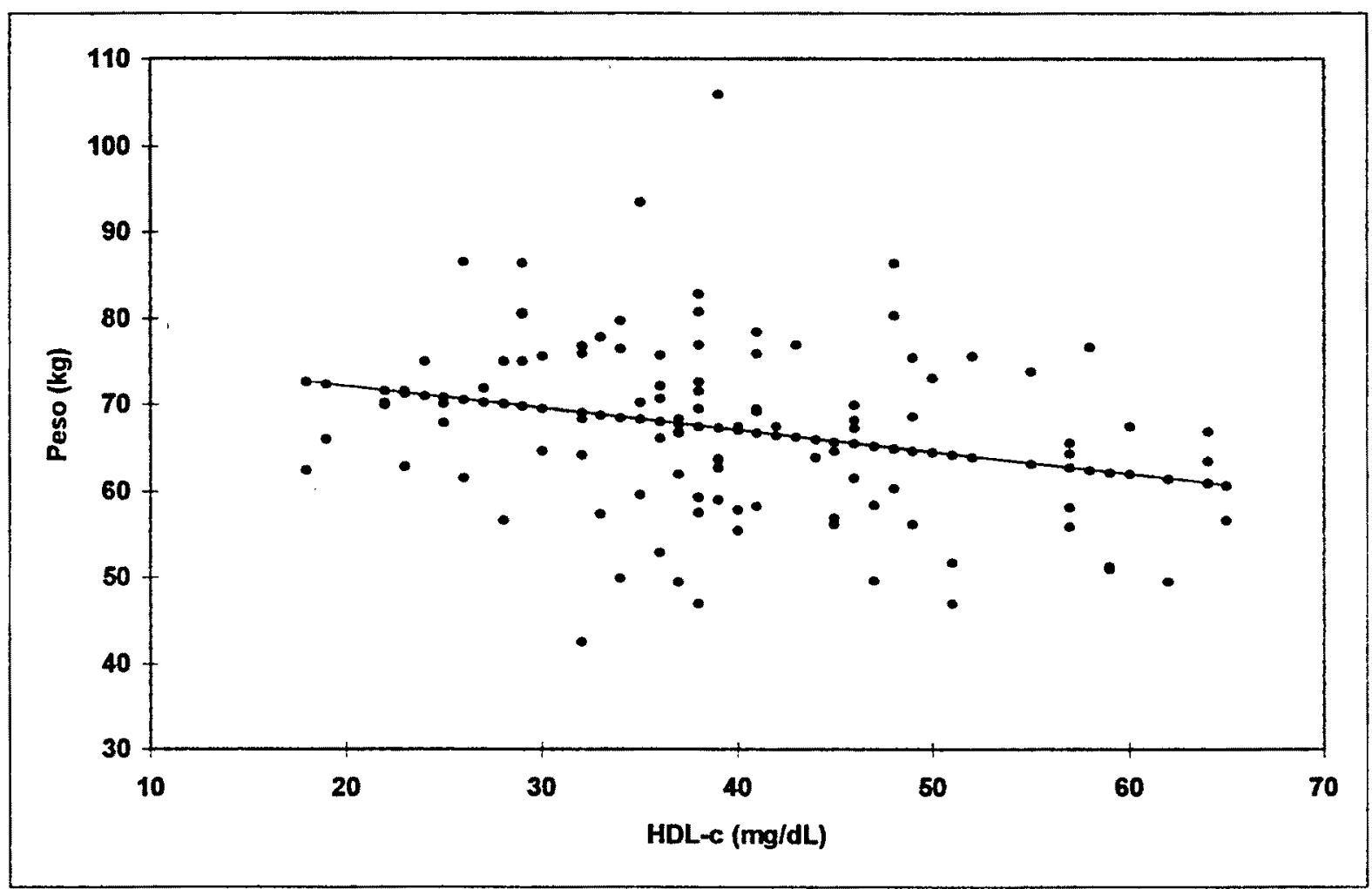

RESUMO DOS RESULTADOS

\begin{tabular}{lc}
\hline \multicolumn{2}{c}{ Estatistica de regressåo } \\
\hline$R$ múltiplo & 0,2568 \\
R-Quadrado & 0,06598 \\
R-quadrado ajustado & 0,05661 \\
Erro padrão & 10,39 \\
Observaç̋es & 102 \\
\hline
\end{tabular}

ANOVA

\begin{tabular}{lccccc}
\hline & $g l$ & $S Q$ & $Q M$ & $F$ & $F$ de significacăo \\
\hline Regressão & 1 & 763,0 & 763,0 & 7,0 & 0,0091 \\
Residuo & 100 & 10806,1 & 108,0 & & \\
Total & 101 & 11569,1 & & & \\
\hline
\end{tabular}

\begin{tabular}{ccccccccc}
\hline & Coeficientes & Erro padrão & Stat t & valor-P & $\begin{array}{c}95 \% \\
\text { inferiores }\end{array}$ & $\begin{array}{c}95 \% \\
\text { superiores }\end{array}$ & $\begin{array}{c}\text { Inferior } \\
95,0 \%\end{array}$ & $\begin{array}{c}\text { Superior } \\
95,0 \%\end{array}$ \\
\hline Interseçăo & 77,21 & 3,94 & 19,56 & $5,6 E-36$ & 69,38 & 85,03 & 69,38 & 85,03 \\
HDL-c & $-0,2547$ & 0,0958 & $-2,65$ & 0,0091 & $-0,4449$ & $-0,0645$ & $-0,4449$ & $-0,06454$ \\
\hline
\end{tabular}


Figura 21- Gráfico da correlação entre o peso dos idosos do gênero feminino e os niveis séricos de HDL-C. Ambulatório do Serviço de Geriatria do HCFMUSP. São Paulo, 1988/90.

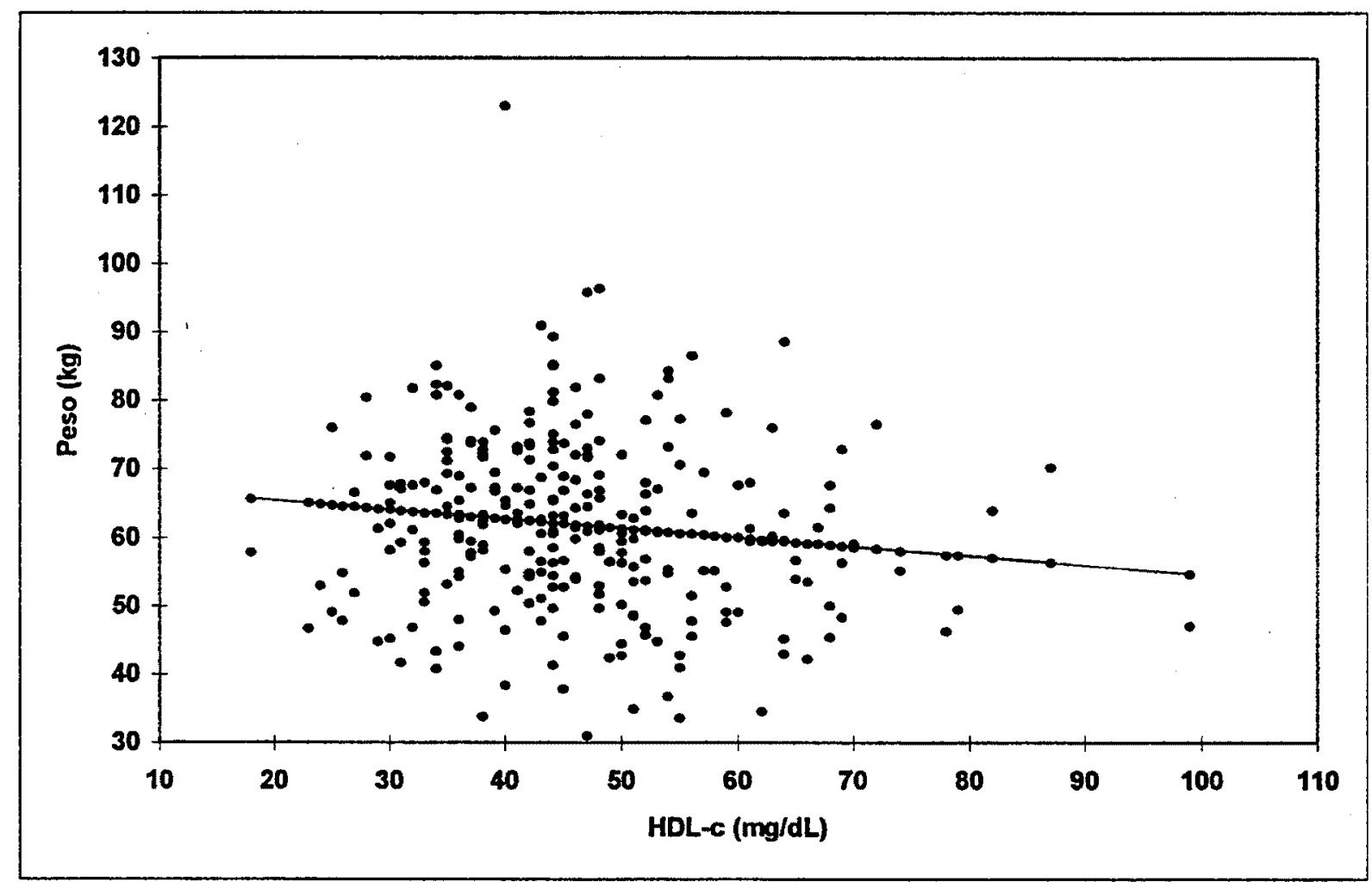

RESUMO DOS RESULTADOS

\begin{tabular}{lc}
\hline Estatistica de regressăo & \\
\hline R múltiplo & 0,1254 \\
R-Quadrado & 0,0157 \\
R-quadrado ajustado & 0,0120 \\
Erro padrăo & 12,74 \\
Observaçóes & 266 \\
\hline
\end{tabular}

ANOVA

\begin{tabular}{lccccc}
\hline & gl & SQ & QM & $F$ & F de significaçăo \\
\hline Regressão & 1 & 685,8 & 685,8 & 4,2 & 0,0408 \\
Residuo & 264 & 42888,0 & 162,4 & & \\
Total & 265 & 43573,9 & & & \\
\hline
\end{tabular}

\begin{tabular}{ccccccccc}
\hline & Coeficientes & Erro padråo & Stat t & valor-P & $\begin{array}{c}95 \% \\
\text { inferiores }\end{array}$ & $\begin{array}{c}95 \% \\
\text { superiores }\end{array}$ & $\begin{array}{c}\text { Inferior } \\
95,0 \%\end{array}$ & $\begin{array}{c}\text { Superior } \\
95,0 \%\end{array}$ \\
\hline Interseção & 68,23 & 3,12 & 21,84 & $3,9 E-61$ & 62,08 & 74,38 & 62,08 & 74,38 \\
HDL-c & $-0,1353$ & 0,0658 & $-2,05$ & 0,0408 & $-0,2650$ & $-0,0056$ & $-0,2650$ & $-0,0056$ \\
\hline
\end{tabular}




\subsection{Análise das variáveis categóricas do estudo}

Para as variáveis categóricas, conforme descrito na metodologia, formulou-se a hipótese de nulidade da independência entre elas. Com base nos valores obtidos, foi verificado se houve associação entre as variáveis estudadas, ao nível de significância do teste.

As Tabelas 5, 6 e 7 mostram a distribuição dos pacientes, segundo a adequação dos niveis séricos de HDL-c e a adequação de gordura da dieta; apresentam, também, o resumo dos resultados da Prova de McNemar, apontando que há associação entre essas variáveis, para ambos os gêneros, para o masculino e também para o feminino.

Tabela 5: Distribuição dos idosos de ambos os gêneros segundo a adequação dos níveis séricos de HDL-c e a adequação da porcentagem de gordura da dieta. Ambulatório do Serviço de Geriatria do HCFMUSP. São Paulo, 1988/90.

\begin{tabular}{c|cc|c}
\hline \% Gordura & Adequado & Inadequado & Total \\
\hline Adequado & 62 & 166 & 228 \\
Inadequado & 34 & 106 & 140 \\
\hline Total & 96 & 272 & 268 \\
\hline
\end{tabular}

Resumo dos resultados do teste de independéncia para a tabela acima-Prova de McNemar

\begin{tabular}{l|c}
\hline Graus de Liberdade & 1 \\
Qui-quadrado calculado & 85,8050 \\
Qui-quadrado critico & 3,841 \\
Nivel de significancia & $5 \%$ \\
\hline
\end{tabular}


Tabela 6: Distribuição dos idosos do gênero masculino segundo a adequação dos niveis séricos de HDL-c e a adequação da porcentagem de gordura da dieta. Ambulatório do Serviço de Geriatria do HCFMUSP. São Paulo, 1988/90.

\begin{tabular}{c|cc|c}
\hline \% Gordura & Adequado & Inadequado & Total \\
\hline Adequado & 11 & 33 & 44 \\
inadequado & 17 & 41 & 58 \\
\hline Total & 28 & 74 & 102 \\
\hline
\end{tabular}

Resumo dos resultados do teste de independência para a tabela acima-Prova de McNemar

\begin{tabular}{l|c}
\hline Graus de Liberdade & 1 \\
Qui-quadrado calculado & 4,500 \\
Qui-quadrado crítico & 3,841 \\
Nivel de significancia & $5 \%$ \\
\hline
\end{tabular}


Tabela 7: Distribuição dos idosos do gênero feminino segundo a adequação dos niveis séricos de HDL-C e a adequação da porcentagem de gordura da dieta. Ambulatório do Serviço de Geriatria do HCFMUSP. São Paulo, 1988/90.

\begin{tabular}{c|cc|c}
\hline \% Gordura & Adequado & Inadequado & Total \\
\hline Adequado & 51 & 133 & 184 \\
Inadequado & 17 & 65 & 82 \\
\hline Total & 68 & 198 & 266 \\
\hline
\end{tabular}

Resumo dos resultados do teste de independència para a tabela acima - Prova de McNemar

\begin{tabular}{l|c}
\hline Graus de Liberdade & 1 \\
Qui-quadrado calculado & 88,1667 \\
Quj-quadrado crltico & 3,841 \\
Nivel de significancia & $5 \%$ \\
\hline
\end{tabular}


As Tabelas 8,9 e 10 mostram a distribuição dos pacientes, segundo a adequação dos niveis séricos de HDL-c e a adequação do estado nutricional; apresentam também o resumo dos resultados do teste de associação pelo quiquadrado, apontando associação entre as variáveis para ambos os gêneros e gênero masculino e não associação para o feminino.

Tabela 8: Distribuição dos idosos de ambos os gêneros, segundo a adequação dos níveis séricos de HDL-c e adequação do estado nutricional. Ambulatório do Serviço de Geriatria do HCFMUSP. São Paulo, 1988/90.

\begin{tabular}{c|ccc|c}
\hline $\begin{array}{r}\text { Estado } \\
\text { Nutricional }\end{array}$ & Desnutrido & Normal & Obeso & Total \\
\hline Adequado & 54 & 85 & 89 & 228 \\
Inadequado & 18 & 56 & 66 & 140 \\
\hline Total & 72 & 141 & 155 & 368 \\
\hline
\end{tabular}

Resumo dos resultados do teste de independência para a tabela acima

\begin{tabular}{l|c}
\hline Graus de Liberdade & 2 \\
Qui-quadrado calculado & 6,7181 \\
Qui-quadrado crítico & 5,991 \\
Nivel de significåncia & $5 \%$ \\
\hline
\end{tabular}


Tabela 9: Distribuição dos idosos do gênero masculino, segundo a adequação dos niveis séricos de $\mathrm{HDL}-\mathrm{C}$ e adequação do estado nutricional. Ambulatório do Serviço de Geriatria do HCFMUSP. São Paulo, 1988/90.

\begin{tabular}{c|ccc|c}
\hline $\begin{array}{r}\text { Estado } \\
\text { Nutricional }\end{array}$ & Desnutrido & Normal & Obeso & Total \\
\hline Adequado & 14 & 21 & 9 & 44 \\
Inadequado & 7 & 29 & 22 & 58 \\
\hline Total & 21 & 50 & 31 & 102 \\
\hline
\end{tabular}

Resumo dos resultados do teste de independência para a tabela acima

\begin{tabular}{l|c}
\hline Graus de Liberdade & 2 \\
Qui-quadrado calculado & 7,2805 \\
Qui-quadrado crítico & 5,991 \\
Nivel de significáncia & $5 \%$ \\
\hline
\end{tabular}


Tabela 10: Distribuição dos idosos do gênero feminino segundo a adequação dos níveis séricos de HDL-c e adequação do estado nutricional. Ambulatório do Serviço de Geriatria do HCFMUSP. São Paulo, 1988/90.

\begin{tabular}{c|ccc|c}
\hline $\begin{array}{r}\text { Estado } \\
\text { Nutricional }\end{array}$ & Desnutrido & Normal & Obeso & Total \\
\hline Adequado & 40 & 64 & 80 & 184 \\
Inadequado & 11 & 27 & 44 & 82 \\
\hline Total & 51 & 91 & 124 & 266 \\
\hline
\end{tabular}

Resumo dos resultados do teste de independência para a tabela acima

\begin{tabular}{l|c}
\hline Graus de Liberdade & 2 \\
Qui-quadrado calculado & 3,3682 \\
Qui-quadrado crítico & 5,991 \\
Nivel de significáncia & $5 \%$ \\
\hline
\end{tabular}


Os resultados apontados nas Tabelas 11,12 e 13 permitem concluir que não há associação entre a adequação dos niveis séricos de colesterol e a ingestão suficiente de fibras na dieta dos idosos estudados, pois, tanto para os homens como para as mulheres os valores obtidos mostraram independência entre as variáveis.

Tabela 11: Distribuição dos idosos de ambos os gêneros, segundo a adequação dos níveis séricos de HDL-c e adequação de fibras. Ambulatório do Serviço de Geriatria do HCFMUSP. São Paulo, $1988 / 90$.

\begin{tabular}{c|ccc|c}
\hline Fibras & Insuficiente & Suficiente & + Suficiente & Total \\
\hline Adequado & 154 & 59 & 15 & 228 \\
Inadequado & 91 & 37 & 12 & 140 \\
\hline Total & 245 & 96 & 27 & 368 \\
\hline
\end{tabular}

Resumo dos resultados do teste de independência para a tabela acima

\begin{tabular}{l|c}
\hline Graus de Liberdade & 2 \\
Qui-quadrado calculado & 0,5637 \\
Qui-quadrado crítico & 5,991 \\
Nivel de significåncia & $5 \%$ \\
\hline
\end{tabular}


Tabela 12: Distribuição dos idosos do gênero masculino segundo a adequação dos níveis séricos de HDL-c e adequação de fibras. Ambulatório do Serviço de Geriatria do HCFMUSP. São Paulo, 1988/90.

\begin{tabular}{c|ccc|c}
\hline Fibras & Insuficiente & Suficiente & + Suficiente & Total \\
\hline Adequado & 26 & 15 & 3 & 44 \\
Inadequado & 39 & 12 & 7 & 58 \\
\hline Total & 65 & 27 & 10 & 102 \\
\hline
\end{tabular}

Resumo dos resultados do teste de independência para a tabela acima

\begin{tabular}{l|c}
\hline Graus de Liberdade & 2 \\
Qui-quadrado calculado & 2,6619 \\
Qui-quadrado critico & 5,991 \\
Nivel de significåncia & $5 \%$ \\
\hline
\end{tabular}


Tabela 13: Distribuição dos idosos do gênero feminino segundo a adequação dos niveis séricos de HDL-c e adequação de fibras. Ambulatório do Serviço de Geriatria do HCFMUSP. São Paulo, 1988/90.

\begin{tabular}{c|ccc|c}
\hline Fibras & Insuficiente & Suficiente & + Suficiente & Total \\
\hline Adequado & 128 & 44 & 12 & 184 \\
Inadequado & 52 & 25 & 5 & 82 \\
\hline Total & 180 & 69 & 17 & 266 \\
\hline
\end{tabular}

Resumo dos resultados do teste de independência para a tabela acima

\begin{tabular}{l|c}
\hline Graus de Liberdade & 2 \\
Qui-quadrado calculado & 1,2783 \\
Qui-quadrado crltico & 5,991 \\
Nivel de significáncia & $5 \%$ \\
\hline
\end{tabular}


As Tabelas 14 e 16 mostram a não associação entre os niveis séricos de LDL-c dos pacientes estudados e o estado nutricional, para ambos os gêneros e para o gênero feminino. Por sua vez, a tabela 15 mostra associação dessas variáveis para os pacientes do gênero masculino.

As tabelas 17, 18 e 19 mostram a não associação entre a adequação dos niveis séricos de LDL-c e a adequação da porcentagem de gordura da dieta, para ambos os gêneros, para o masculino e para o feminino.

Tabela 14: Distribuição dos idosos de ambos os gêneros segundo a adequação dos níveis séricos de LDL-c e adequação do estado nutricional. Ambulatório do Serviço de Geriatria do HCFMUSP. São Paulo, 1988/90.

\begin{tabular}{c|ccc|c}
\hline $\begin{array}{r}\text { Estado } \\
\text { LDLtricional }\end{array}$ & Desnutrido & Normal & Obeso & Total \\
\hline Adequado & 27 & 42 & 36 & 106 \\
Inadequado & 45 & 99 & 119 & 262 \\
\hline Total & 72 & 141 & 155 & 368 \\
\hline
\end{tabular}

Resumo dos resultados do teste de independência para a tabela acima

\begin{tabular}{l|c}
\hline Graus de Liberdade & 2 \\
Qui-quadrado calculado & 5,0888 \\
Qui-quadrado critico & 5,991 \\
Nivel de significáncia & $5 \%$ \\
\hline
\end{tabular}


Tabela 15: Distribuição dos idosos do gênero masculino, segundo a adequação dos níveis séricos de $L D L-c$ e adequação do estado nutricional. Ambulatório do Serviço de Geriatria do HCFMUSP. São Paulo, 1988/90.

\begin{tabular}{c|ccc|c}
\hline $\begin{array}{r}\text { Estado } \\
\text { LDLutricional }\end{array}$ & Desnutrido & Normal & Obeso & Total \\
\hline Adequado & 11 & 22 & 6 & 40 \\
Inadequado & 10 & 28 & 25 & 62 \\
\hline Total & 21 & 50 & 31 & 102 \\
\hline
\end{tabular}

Resumo dos resultados do teste de independencia para a tabela acima

\begin{tabular}{l|c}
\hline Graus de Liberdade & 2 \\
Qui-quadrado calculado & 7,1622 \\
Qui-quadrado critico & 5,991 \\
Nivel de significáncia & $5 \%$ \\
\hline
\end{tabular}


Tabela 16: Distribuição dos idosos do gênero feminino, segundo a adequação dos niveis séricos de LDL-c e adequação do estado nutricional. Ambulatório do Serviço de Geriatria do HCFMUSP. São Paulo, 1988/90.

\begin{tabular}{c|ccc|c}
\hline $\begin{array}{r}\text { Estado } \\
\text { Nutricional }\end{array}$ & Desnutrido & Normal & Obeso & Total \\
\hline Adequado & 16 & 20 & 30 & 66 \\
Inadequado & 35 & 71 & 94 & 200 \\
\hline Total & 51 & 91 & 124 & 266 \\
\hline
\end{tabular}

Resumo dos resultados do teste de independência para a tabela acima

\begin{tabular}{l|c}
\hline Graus de Liberdade & 2 \\
Qui-quadrado calculado & 1,5938 \\
Qui-quadrado critico & 5,991 \\
Nivel de significáncia & $5 \%$ \\
\hline
\end{tabular}


Tabela 17: Distribuição dos idosos de ambos os gêneros, segundo a adequação dos niveis séricos de LDL-c e a adequação da porcentagem de gordura da dieta. Ambulatório do Serviço de Geriatria do HCFMUSP. São Paulo, 1988/90.

\begin{tabular}{c|cc|c}
\hline LD Gordura & Adequado & Inadequado & Total \\
\hline Adequado & 34 & 72 & 106 \\
Inadequado & 62 & 200 & 262 \\
\hline Total & 96 & 272 & 368 \\
\hline
\end{tabular}

Resumo dos resultados do teste de independência para a tabela acima- Prova de McNemar

\begin{tabular}{l|c}
\hline Graus de Liberdade & 1 \\
Qui-quadrado calculado & 0,6045 \\
Qui-quadrado critico & 3,841 \\
Nivel de significancia & $5 \%$ \\
\hline
\end{tabular}


Tabela 18: Distribuição dos idosos do gênero masculino, segundo a adequação dos niveis séricos de LDL-C e a adequação da porcentagem de gordura da dieta. Ambulatório do Serviço de Geriatria do HCFMUSP. São Paulo, 1988/90.

\begin{tabular}{c|cc|c}
\hline LD Gordura & Adequado & Inadequado & Total \\
\hline Adequado & 10 & 30 & 40 \\
Inadequado & 18 & 44 & 62 \\
\hline Total & 28 & 74 & 102 \\
\hline
\end{tabular}

Resumo dos resultados do teste de independéncia para a tabela acima- Prova de McNemar

\begin{tabular}{l|c}
\hline Graus de Liberdade & 1 \\
Qui-quadrado calculado & 2,5208 \\
Qui-quadrado critico & 3,841 \\
Nivel de significáncia & $5 \%$ \\
\hline
\end{tabular}


Tabela 19: Distribuição dos idosos do gênero feminino, segundo a adequação dos níveis séricos de LDL-c e a adequação da porcentagem de gordura da dieta. Ambulatório do Serviço de Geriatria do HCFMUSP. São Paulo, 1988/90.

\begin{tabular}{c|cc|c}
\hline LD Gordura & Adequado & Inadequado & Total \\
\hline Adequado & 24 & 42 & 66 \\
Inadequado & 44 & 156 & 200 \\
\hline Total & 68 & 198 & 266 \\
\hline
\end{tabular}

Resumo dos resultados do teste de independência para a tabela acima- Prova de McNemar

\begin{tabular}{l|c}
\hline Graus de Liberdade & 1 \\
Qui-quadrado calculado & 0,0116 \\
Qui-quadrado critico & 3,841 \\
Nivel de significáncia & $5 \%$ \\
\hline
\end{tabular}


Os resultados das Tabelas 20 e 21 mostram que há associação entre adequação dos níveis séricos de colesterol e adequação do estado nutricional para ambos os sexos e para os homens estudados, para as mulheres (Tabela 22) não há esta associação.

A Tabela 23 aponta para uma associação entre adequação calórica e o estado nutricional; quando os indivíduos são separados por gênero (Tabelas 24 e 25) esta associação não fica demonstrada, pois os valores obtidos não permitem inferir dependência entre as variáveis em estudo.

Tabela 20: Distribuição dos idosos de ambos os gêneros e adequação do colesterol sérico e adequação do estado nutricional. Ambulatório do Serviço de Geriatria do HCFMUSP. São Paulo, 1988/90.

\begin{tabular}{c|ccc|c}
\hline $\begin{array}{r}\text { Estado } \\
\text { Nutricional } \\
\text { Colesterol }\end{array}$ & Desnutrido & Normal & Obeso & Total \\
\hline Adequado & 34 & 46 & 67 & 117 \\
Inadequado & 38 & 95 & 118 & 251 \\
\hline Total & 72 & 141 & 155 & 368 \\
\hline
\end{tabular}

Resumo dos resultados do teste de independência para a tabela acima

\begin{tabular}{l|c}
\hline Graus de Liberdade & 2 \\
Qui-quadrado calculado & 12,43 \\
Qui-quadrado critico & 5,991 \\
Nivel de significáncia & $5 \%$ \\
\hline
\end{tabular}


Tabela 21: Distribuição dos idosos do gênero masculino e adequação do colesterol sérico e adequação do estado nutricional. Ambulatório do Serviço de Geriatria do HCFMUSP. São Paulo, 1988/90.

\begin{tabular}{c|ccc|c}
\hline $\begin{array}{r}\text { Estado } \\
\text { Nutricional }\end{array}$ & Desnutrido & Normal & Obeso & Total \\
\hline $\begin{array}{c}\text { Sérico } \\
\text { Adequado }\end{array}$ & 15 & 25 & 11 & 51 \\
\hline Inadequado & 6 & 25 & 20 & 51 \\
\hline Total & 21 & 50 & 31 & 102 \\
\hline
\end{tabular}

Resumo dos resultados do teste de independência para a tabela acima

\begin{tabular}{l|c}
\hline Graus de Liberdade & 2 \\
Qui-quadrado calculado & 6,47 \\
Qui-quadrado crítico & 5,991 \\
Nivel de significância & $5 \%$ \\
\hline
\end{tabular}


Tabela 22: Distribuição dos idosos do gênero feminino e adequação do colesterol sérico e adequação do estado nutricional. Ambulatório do Serviço de Geriatria do HCFMUSP. São Paulo, $1988 / 90$.

\begin{tabular}{c|ccc|c}
\hline $\begin{array}{r}\text { Estado } \\
\text { Nutricional }\end{array}$ & Nesnutrido & Normal & Obeso & Total \\
$\begin{array}{c}\text { Colesterol } \\
\text { sérico }\end{array}$ & 19 & 21 & 26 & 66 \\
\hline Adequado & 32 & 70 & 98 & 200 \\
\hline Inadequado & 51 & 91 & 124 & 266 \\
\hline Total & & &
\end{tabular}

Resumo dos resultados do teste de independência para a tabela acima

\begin{tabular}{l|c}
\hline Graus de Liberdade & 2 \\
Qui-quadrado calculado & 5,36 \\
Qui-quadrado critico & 5,991 \\
Nivel de significância & $5 \%$ \\
\hline
\end{tabular}


Tabela 23: Distribuição dos idosos de ambos os gêneros segundo a adequação calórica e adequação do estado nutricional. Ambulatório do Serviço de Geriatria do HCFMUSP. São Paulo, 1988/90.

\begin{tabular}{c|ccc|c}
\hline $\begin{array}{r}\text { Estado } \\
\text { Adequaçáa } \\
\text { calórica }\end{array}$ & Desnutrido & Normal & Obeso & Total \\
\hline Insuficiente & 32 & 46 & 43 & 121 \\
Suficiente & 23 & 50 & 47 & 120 \\
+ Suficiente & 17 & 45 & 65 & 127 \\
\hline Total & 72 & 141 & 155 & 368 \\
\hline
\end{tabular}

Resumo dos resultados do teste de independência para a tabela acima

\begin{tabular}{l|c}
\hline Graus de Liberdade & 4 \\
Qui-quadrado calculado & 10,01 \\
Qui-quadrado crítico & 9,488 \\
Nivel de significáncia & $5 \%$ \\
\hline
\end{tabular}


Tabela 24: Distribuição dos idosos do gênero masculino, segundo a adequação calórica e adequação do estado nutricional. Ambulatório do Serviço de Geriatria do HCFMUSP. São Paulo, $1988 / 90$.

\begin{tabular}{c|ccc|c}
\hline $\begin{array}{r}\text { Estado } \\
\text { Adequaçăà } \\
\text { calórica }\end{array}$ & Desnutrido & Normal & Obeso & Total \\
\hline Insuficiente & 14 & 21 & 13 & 48 \\
Suficiente & 6 & 16 & 7 & 29 \\
+ Suficiente & 1 & 13 & 11 & 25 \\
\hline Total & 21 & 50 & 31 & 102 \\
\hline
\end{tabular}

Resumo dos resultados do teste de independência para a tabela acima

\begin{tabular}{l|c}
\hline Graus de Liberdade & 4 \\
Qui-quadrado calculado & 7,66 \\
Qui-quadrado critico & 9,488 \\
Nivel de significancia & $5 \%$ \\
\hline
\end{tabular}


Tabela 25: Distribuição dos idosos do gênero feminino, segundo a adequação calórica e adequação do estado nutricional. Ambulatório do Serviço de Geriatria do HCFMUSP. São Paulo, 1988/90.

\begin{tabular}{c|ccc|c}
\hline $\begin{array}{r}\text { Estado } \\
\text { Nutricional }\end{array}$ & Desnutrido & Normal & Obeso & Total \\
\hline $\begin{array}{c}\text { Adequaçăo } \\
\text { calórica }\end{array}$ & 18 & 25 & 30 & 73 \\
\hline Insuficiente & 17 & 34 & 40 & 91 \\
+ Suficiente & 16 & 32 & 54 & 102 \\
\hline Total & 51 & 91 & 124 & 266 \\
\hline
\end{tabular}

Resumo dos resultados do teste de independência para a tabela acima

\begin{tabular}{l|c}
\hline Graus de Liberdade & 4 \\
Qui-quadrado calculado & 3,79 \\
Qui-quadrado critico & 9,488 \\
Nivel de significáncia & $5 \%$ \\
\hline
\end{tabular}


Aplicando-se os critérios de acreditação propostos na metodologia, para quatro variáveis descritas, foram obtidos os resultados apresentados no Quadro 5. Destes resultados destaca-se que $46,1 \%$ dos idosos do sexo masculino encontraram-se em condições excelentes e satisfatórias.para os quesitos cruzados. Esse valor, para as mulheres, foi de $31,3 \%$. Aproximadamente $10 \%$ dos idosos estudados apresentaram condições excelentes para a acreditação proposta. 
Quadro 5: Acreditação para os idosos de ambos os gêneros quanto à adequação do colesterol sérico (C1), estado nutricional (C2), ingestão de gordura na dieta (C3) e suficiência de fibra dietética (C4).

\begin{tabular}{|c|c|c|c|c|c|c|c|c|c|c|c|}
\hline Combinações & C1 & $\mathrm{C} 2$ & C3 & C4 & Crédito & Masculino & $\%$ & Feminino & $\%$ & Total & $\%$ \\
\hline 1 & + & + & + & + & + & 3 & 2,9 & 2 & 0,8 & 5 & 1,4 \\
\hline 2 & + & + & + & - & + & 5 & 4,9 & 2 & 0,8 & 7 & 1,9 \\
\hline 3 & + & + & - & + & + & 6 & 5,9 & 4 & 1,5 & 10 & 2,7 \\
\hline 4 & + & + & - & - & 0 & 11 & 10,8 & 13 & 4,9 & 24 & 6,5 \\
\hline 5 & + & - & + & + & + & 3 & 2,9 & 3 & 1,1 & 6 & 1,6 \\
\hline 6 & + & - & + & - & 0 & 2 & 2,0 & 8 & 3,0 & 10 & 2,7 \\
\hline 7 & + & - & - & + & 0 & 4 & 3,9 & 11 & 4,1 & 15 & 4,1 \\
\hline 8 & + & - & - & - & - & 17 & 16,7 & 23 & 8,6 & 40 & 10,9 \\
\hline 9 & - & + & + & + & + & 0 & 0,0 & 5 & 1,9 & 5 & 1,4 \\
\hline 10 & - & + & + & - & 0 & 6 & 5,9 & 19 & 7,1 & 25 & 6,8 \\
\hline 11 & - & + & - & + & 0 & 5 & 4,9 & 10 & 3,8 & 15 & 4,1 \\
\hline 12 & - & + & - & - & - & 16 & 15,7 & 37 & 13,9 & 53 & 14,4 \\
\hline 13 & - & $\cdot$ & + & + & 0 & 2 & 2,0 & 6 & 2,3 & 8 & 2,2 \\
\hline 14 & - & $\cdot$ & + & - & - & 6 & 5,9 & 24 & 9,0 & 30 & 8,2 \\
\hline 15 & - & - & - & + & - & 5 & 4,9 & 27 & 10,2 & 32 & 8,7 \\
\hline \multirow[t]{2}{*}{16} & - & - & - & - & - & 11 & 10,8 & 72 & 27,1 & 83 & 22,6 \\
\hline & & & & & & 102 & 100 & 266 & 100 & 368 & 100 \\
\hline
\end{tabular}




\section{DISCUSSÃO}

Os dados obtidos neste estudo referem-se a uma população idosa específica estudada, que tem características próprias e que devem ser consideradas, pois são pacientes que procuraram o Ambulatório de Geriatria de forma espontânea e apresentavam diferentes níveis sociais, cuja classificação não faz parte dos objetivos deste estudo. O levantamento dos dados desta pesquisa já contribuiu para a elaboração de outros trabalhos (Garcia, 2001; Novaes, 1997; Alencar, 1994 e Marucci, 1992).

Nos últimos anos, profissionais da área de saúde, no Brasil, têm voltado a atenção para o estudo da população mais idosa; isto está diretamente relacionado ao aumento da expectativa de vida do brasileiro. Dados publicados pelo Instituto Brasileiro de Geografia e Estatística (IBGE a e IBGE b) mostram que essa expectativa aumentou 2,6 anos entre 1991 e 2000 , passando de 66 anos para 68,6 anos; entre as mulheres a expectativa de vida é de 72,6 anos e, entre os homens é de 64,8 anos. Este estudo mostra uma predominância de mulheres na amostra, com maior número de indivíduos entre 71 e 80 anos. A média de idade para homens e mulheres (ambos os gêneros) foi de 74 anos com desvio-padrão de 7 anos.

A média do consumo energético diário para o sexo feminino (2025kcal) apresentou-se acima do padrão de referência da RDA,1989. Vale a pena ressaltar 0 alto valor do desvio padrão $(824,9 \mathrm{kcal})$, que sugere variações bastante relevantes, na alimentação das idosas. Para o sexo masculino, a média do consumo energético diário foi de $2175 \mathrm{kcal}$, dentro da margem de referência, com um desvio padrão de 1072,1 kcal. A mediana é de $1983 \mathrm{kcal}$ para o gênero masculino e $1966 \mathrm{kcal}$ para o gênero feminino. 
Ortega et al, em 1995, estudando idosos, não encontraram diferenças significativas entre pacientes obesos e normais para o peso e a quantidade de energia de suas dietas, mas identificaram que foi a composição delas que levou ao aparecimento da obesidade.

Em um estudo realizado por Garcia et al (2003), com idosos institucionalizados, encontrou-se que tanto os homens quanto às mulheres consumiam uma quantidade de energia maior que a recomendada. Trabalhos realizados com indivíduos institucionalizados tendem a ter um controle maior sobre o consumo alimentar efetivo de cada pessoa. Van Staveren et al (1994) demonstraram que quando o dado dietético é obtido por entrevista alimentar com pessoas idosas podem surgir problemas contornáveis, mas que podem e precisam sempre de um direcionamento por parte do entrevistador.

O método de entrevista alimentar, no caso deste estudo, Rec 24 hs apresenta vantagens e desvantagens. Como vantagens podem ser apontadas: facilidade e rapidez na entrevista, baixo custo, inalteração da dieta usual e obtenção de dados que propiciem estimar o valor energético total da dieta e a ingestão de macronutrientes (Kamimura et al 2002). Como desvantagens podem ser citadas: a dependência da memória do entrevistado, a retratação de uma ingestão atípica dos alimentos (fim de semana), podendo ocorrer, assim, imprecisões quantitativas sobre a dieta referida (Kamimura et al 2002). No entanto esta metodologia, escolhida neste trabalho para colheita dos dados dietéticos dos idosos, no final da década de 80 , ainda hoje, é uma das mais utilizadas para avaliar consumo alimentar de indivíduos e grupos.

A referência proposta para avaliação da ingestão energética da dieta dos idosos, RDA (1989), foi parâmetro nos últimos 20 anos para análise do aporte calórico e de nutrientes das dietas, nos diferentes estágios de vida 
dos indivíduos. Vale ressaltar que, hoje, em fase preliminar de publicação pelo The National Academies Press, estão as DRIs 2002 (Dietary Reference Intake), que ampliam o conceito das recomendações, pois propõem niveis médios de ingestão de nutrientes e tolerância máxima permitida, propiciando uma melhor avaliação, quer da dieta individual quer da grupal de uma população; no entanto, as DRIs, em seu texto, referem que em relação à energia da dieta, há necessidade de se aprofundar mais os estudos para adotá-la, pois, ainda há que se incluir nos novos requisitos nutricionais, preliminarmente propostos, elementos importantes que influenciam a energia total a ser consumida por um individuo ou grupo, a saber: digestibilidade da dieta, viscosidade e densidade da energia e dos nutrientes.

Quanto aos resultados dos exames, que mostram os valores dos níveis séricos de triglicérides, estes se encontram nos valores de referência considerados desejáveis tanto para o sexo feminino como para o masculino. Já a média do colesterol sérico apresenta-se dentro dos valores considerados limitrofes para ambos os sexos. Os resultados para o colesterol se tornam preocupantes, uma vez que, vários estudos demonstram relação entre a concentração lipídica sérica e agravos à saúde, principalmente de ordem cardiovascular (Oomen et al 2001; Shikany e White 2000; Toeller et al 1999; Campbell et al 1998).

Segundo estudo realizado por Campbell et al (1998), com individuos americanos e chineses de área rural, a concentração média de colesterol sérico foi de $203 \mathrm{mg} / \mathrm{dL}$ e $127 \mathrm{mg} / \mathrm{dL}$ respectivamente. Esses pesquisadores associaram inversamente a taxa de mortalidade por doença coronariana dos chineses, com a freqüente ingestão de vegetais verdes e um adequado perfil lipídico de ácidos graxos monoinsaturados plasmáticos. Em países desenvolvidos a dieta relaciona-se direta ou indiretamente a uma maior prevalência de doenças crônicas; sendo assim, a ingestão de gorduras monoinsaturadas e fibras (hortaliças, frutas e grãos de cereais integrais) deve ser promovida e, por outro lado, o consumo de gorduras saturadas e 
polinsaturadas modificadas, que têm alteração de sua estrutura química por processo tecnológico (isômero trans), deve ser minimizado (Shikany e White, 2000).

Posner (1986) comprova, por estudos baseados em intervenção comunitária, que modificações dietéticas podem reduzir $10 \%$ a $15 \%$ do colesterol plasmático. Estudo realizado por Cervato et al (1997), encontrou resultados para a ingestão do colesterol acima do recomendado, mostrando que $25 \%$ da população estudada ingeriam mais de $334 \mathrm{mg}$ de colesterol por dia.

A ingestão dietética média de colesterol, deste estudo, tanto para homens como para as mulheres, está muito acima do recomendado pelo FDA (Food and Drug Administration) que é de $300 \mathrm{mg} /$ dia. A ingestão dietética média de colesterol para os homens foi de $480,1 \mathrm{mg}$ e para as mulheres de 460,6, o que pode sugerir alterações sangüíneas para a população em estudo.

As médias sangüíneas de HDL-c em mulheres encontram-se em concentrações séricas melhores do que nos homens, sendo 45,9 e $39,7 \mathrm{mg} / \mathrm{dL}$, respectivamente. Os valores de referência desejáveis estão acima de $40 \mathrm{mg} / \mathrm{dL}$.Com relação a LDL-c, tanto os homens quanto as mulheres, apresentam-se nos valores limítrofes recomendados, sendo que, para as mulheres, estes valores encontram-se mais próximos dos considerados aumentados pela SBC (2001).A literatura mostra maior prevalência de doença coronariana na pós-menopausa, provavelmente devido à redução dos níveis do hormônio estrogênio e, conseqüentemente, de seus efeitos protetores. Na pós-menopausa o perfil lipídico das mulheres tende a sofrer modificações nas suas concentrações em relação ao HDL-c e LDL-c, pois a diminuição da taxa de estrogênio favorece esse quadro (Grodstein et al, 1997). 
Neste estudo, na amostra de idosos, $42,1 \%$ foram classificados como obesos, sendo que no sexo feminino a prevalência de obesidade é maior do que no sexo masculino( $46,6 \%$ e $30,4 \%$, respectivamente). Coitinho et al (1991) mostraram resultado semelhante, em seu estudo com indivíduos adultos, a obesidade no Brasil afeta proporcionalmente mais mulheres que homens, sendo esses valores de $38 \%$ e $27 \%$, respectivamente.

Dados do estudo realizado por Cabrera \& Jacob Filho (2001), identificaram a prevalência de obesidade em $9,3 \%$ dos homens estudados e em $23,8 \%$ das mulheres, sendo menor entre os idosos de 80 anos e mais. Esses autores discutem que entre as mulheres há maior tolerância à obesidade, o que poderia explicar as diferenças nos índices de prevalência de obesidade entre os sexos; no entanto a WHO, aponta que o peso corpóreo aumenta com a idade, mas não está claro porque as mulheres são mais predispostas ao rápido ganho de peso. A hipótese de que a menopausa predisporia à obesidade, não é comprovado. pois o término do ciclo menstrual não afeta o consumo de alimentos e a taxa metabólica basal diminui de forma não significativa.O sedentarismo que acompanha, nas sociedades industrializadas, o envelhecimento, poderia, em parte, explicar o ganho de peso neste período da vida.

O estado nutricional pode afetar positivamente a expectativa de vida. O consumo nutricional adequado e o controle de doenças aumentaram claramente o número de pessoas na população que atingem faixas etárias cada vez maiores.Ledikwe et al (2003) verificaram em estudo com 179 idosos de uma população rural que, em mulheres, o IMC foi diretamente associado com indicadores de risco nutricional como: ingestão de gordura total e gordura saturada. Para esse estudo $44 \%$ dos indivíduos apresentavam sobrepeso (IMC 25-29,9) e 35\% obesidade (IMC maior que 30). O sobrepeso e a obesidade em mulheres podem, principalmente, nas que vivem sozinhas, ser um risco nutricional maior que em homens. $O$ peso 
em mulheres teve uma associação inversa à ingestão de carboidratos e fibras.

A intervenção dietética na hipercolesterolemia é a retirada de produtos de origem animal, especialmente aqueles com gorduras saturadas, como as carnes vermelhas e seus substitutos, a pele de todos animais, carne de porco, gema de ovo, vísceras, leite integral e seus substitutos, além de pescados, como o camarão e a lagosta. Os ácidos graxos saturados elevam a colesterolemia por reduzirem receptores celulares, inibindo a remoção plasmática das partículas de LDL-c. Segundo as DRIs 2002, um guia dietético deve propor a minimização da ingestão de colesterol, e a uma dieta nutricionalmente adequada deve-se viabilizar $\circ$ controle desse nutriente, e isso depende de orientação, adequada e preferencialmente especializada, para a mudança no consumo de alimentos que são fontes de colesterol.

Neste estudo os valores médios de LDL-c para ambos os sexos ficaram na categoria "limítrofes".Segundo Mahan e Stump (2002), o envelhecimento leva ao aumento do $C T$ e da LDL-C; entre a faixa etária de 20 anos a 65 anos, o CT em homens aumenta ao redor de $13 \%$ e em mulheres, durante o mesmo periodo, o aumento é de $21 \%$.

Frank e Soares (2002), chamam a atenção para o fato da gordura saturada elevar a LDL-c plasmática e a insaturada auxiliar no aumento da HDL-c sem, no entanto, justificar uma dieta com elevado teor de gorduras insaturadas, pois dependendo do grau de aquecimento, as gorduras insaturadas tornam-se saturadas; daí ressalta-se a importância de se evitar - consumo de frituras. Neste estudo não foi possível demonstrar a associação entre a gordura total dietética e os níveis séricos de LDL-C.

Os ácidos graxos monoinsaturados também têm sido estudados como coadjuvantes em relação à diminuição da LDL-c e manutenção das 
concentraçōes de HDL-c. Pogozheva et al, em 2000, observaram os efeitos dos ácidos graxos monoinsaturados presentes no óleo de oliva, quando adicionados à dieta, e concluiram que há benefícios associados à melhora da imunidade celular em pacientes cardiopatas.

Os dados, deste estudo, demonstraram uma correlação negativa entre idade do paciente, ingestão dietética de colesterol e gordura total, mostrando que, à medida que se envelhece, há uma preocupação com a ingestão de determinados tipos de alimentos, principalmente no que se refere às gorduras, talvez por influência do que é amplamente divulgado pela mídia.

Isto se evidencia em outros resultados encontrados neste estudo, como a associação positiva entre ingestão energética e de gorduras polinsaturadas. Já Schelenker (1994), encontrou dados que apontaram para um consumo de gorduras totais e saturadas superiores aos valores recomendados para os idosos. Pesquisadores ressaltam a importância das modificações na dieta, principalmente em mulheres menopausadas, quanto ao consumo quantitativo e qualitativo de lipídios para a prevenção de doenças cardiovasculares (Schwab 2000; Toobert et al 2000).

O consumo de gordura polinsaturada pelos idosos, deste estudo ficou aquém do esperado ( $1 / 3$ da gordura total ou $10 \%$ ), no entanto, se 0 parâmetro fosse as ${ }^{1} \mathrm{DR}$ ls 2002 , este consumo seria superior ao recomendado, uma vez que a orientação de ingestão para polinsaturado, (ácido linolênico) é de $12 \mathrm{~g}$ a $17 \mathrm{~g}$ e $9 \mathrm{~g}$ a $11 \mathrm{~g}$ para homens e mulheres, respectivamente. Os resultados encontrados neste estudo, para a ingestão de gordura polinsaturada foi de $20,2 \mathrm{~g}$ para homens e $18,8 \mathrm{~g}$ para as mulheres

\footnotetext{
${ }^{1}$ A recomendação DRI 2002 para gordura polinsaturada está baseada no consumo de ácido linolênico, que corresponde à aproximadamente $90 \%$ do consumo desse tipo de nutriente.
} 
Uma dieta rica em fibras implica, muitas vezes, numa redução do consumo energético diário por substituir alimentos de maior densidade calórica, além de promover maior saciedade e apresentar menor palatabilidade (Duarte e Resende e Costa 1999); no entanto, este estudo mostra que o aumento das fibras dietéticas teve uma associação positiva com o colesterol dietético e este, por sua vez, está correlacionado positivamente com o peso, tanto em mulheres, como para ambos os sexos.

Há que se ressaltar que autores que apontam essa possibilidade para o aumento de fibras, discutem-na nos patamares de adequação, o que não aconteceu com os dados deste estudo pois, em média, o consumo de fibras foi bem menor que o recomendado ( $25 \mathrm{~g} / \mathrm{dia})$.

O aumento no consumo das fibras teria um papel no controle do peso, e diminuição nos níveis séricos de colesterol. Neste estudo, não se encontrou associação entre essas duas variáveis com base nos valores dos testes, frisando que não houve incremento da ingestão de fibras nem controle deste quesito. Talvez se as fibras dietéticas estivessem na dieta em maior quantidade e houvesse possibilidade de classificação destas em solúveis e insolúveis (Tabelas de composição de alimentos e programas nacionais não trazem, normalmente, estes dados), os efeitos fisiológicos e suas respostas pudessem ser melhor controlados e apontarem alguma associação entre elas.

Esse consumo diminuído de fibras, presente em todas as faixas etárias e também neste grupo de idosos, reflete a alimentação pós-avanço tecnológico, que colaborou para que as fibras alimentares fossem excluídas "ad dieta", uma vez que o hábito alimentar dos indivíduos, de uma maneira geral, substituiu o consumo de produtos integrais pelos refinados (Frank e Soares 2002). 
Esses resultados, que apontam o baixo consumo de fibras, vão ao encontro dos levantados por Federmann (1994), que identificou em $92 \%$ dos individuos investigados, um consumo desse nutriente abaixo da recomendação.Mattos \& Martins (2000), também, encontraram em seu estudo dados semelhantes para o consumo de fibras alimentares em população adulta: houve baixo consumo de fibras alimentares, sendo que a insolúvel era mais consumida que a solúvel. Van Rossun et al, em 2000, analisando variações na ingestão alimentar de idosos, constataram que, aqueles que têm menor escolaridade, ingerem menor quantidade de fibras na dieta.

Anderson et al (2000) conduziram uma pesquisa, para definir os efeitos lipidêmicos de uma fibra (psilio) associada à dieta com baixo teor de gordura. A conclusão obtida foi que a suplementação com a fibra reduziu significativamente as concentrações séricas de colesterol total e LDL-c. Jenkins et al, em dois artigos publicados em 2002, ratificam a vantagem da suplementação da dieta com fibras, e acrescenta que, em seus estudos, os indivíduos não relataram alteração na palatabilidade, nem sintomas gastrointestinais que pudessem estar relacionados com a modificação dietética proposta.

Estudos apontam que uma dieta com alto consumo de fibras, frutas e hortaliças e quantidade reduzida de gorduras são importantes e afetam beneficamente as concentrações plasmáticas lipídicas, reduzindo o risco de doenças (kumanyike et al 2000; Toeller et al 1999).

Neste estudo, realizado com idosos, não houve associação estatisticamente significativa entre a ingestão de fibras e a adequação dos niveis séricos deHDL-c; no entanto, a quantidade de fibras alimentares ingeridas pelos idosos ficou aquém da recomendação, diferentemente de estudos que a suplementam $e$, dessa forma, podem apontar os efeitos 
benéficos desse nutriente em relação às concentrações plasmáticas de lipidios.

O controle da obesidade e do colesterol da dieta pressupõe algumas restrições, que podem ter pontos em comum, ou seja, redução de alguns alimentos como leite integral e seus substitutos (queijo, manteiga, creme de leite), biscoitos amanteigados, croissants, folhados, sorvetes cremosos, embutidos (lingüiça, salsicha), frios (presunto, salame, mortadela), torresmo bacon, pele de aves, frutos de mar e gema de ovo. A diminuição da ingestão destes alimentos corrige imediatamente a ingestão do colesterol dietético e pode contribuir para diminuir a obesidade.

No estudo em questão encontrou-se correlação entre o peso dos pacientes e a ingestão dietética de colesterol, quando considerados ambos os gêneros ou o gênero feminino. A obesidade é decorrência da alta ingestão de alimentos associada à falta de exercícios físicos, onde a adesão a uma dieta é fundamental, mas muitas vezes deve ser precedida de técnicas comportamentais.

Cordero et al (2000) avaliaram o impacto de um programa de redução de peso corporal de nove meses nos lipídios plasmáticos, ingestão dietética e gordura abdominal em mulheres pós menopausadas obesas e concluiram que a perda de peso e as modificações dietéticas tais como: redução do consumo de energia, colesterol, gorduras totais e gorduras saturadas estão associados com a melhora de lipídios plasmáticos (redução CT, LDL-c,TG e aumento da HDL-C).

Outro estudo feito por Ryan et al, em 2000, apontou que a perda de peso e gordura corporal por meio de modificações na dieta e exercícios em mulheres obesas pós-menopausa, reduziu o tecido adiposo, bem como melhoraram o perfil lipidico delas (houve redução dos triglicérides e aumento de HDL-C). 
Segundo Beynen \& Katon (1985), o colesterol possui menor efeito sobre a colesterolemia, quando comparado às gorduras saturadas. $O$ colesterol alimentar influencia diferentemente os níveis plasmáticos de colesterol; a maioria da população é hipo-responsiva e uma minoria é hiperresponsiva, isto, provavelmente, atribuido ao fenótipo.

Estudo descrito por Pereira e Cervato analisou comparativamente 10 mulheres idosas, com média etária de 93 anos, e 10 mulheres jovens, com faixa etária de 36 anos, mostrando que nas mulheres idosas houve uma pequena elevação dos triglicérides plasmáticos, com aumento nas concentrações de lipoproteínas de alta densidade e colesterol; foi feito o controle da ingestão dietética das mulheres estudadas, sendo verificada que aquela era rica em gorduras. Assim, assume particular importância, após os 50 ou 60 anos, o controle do peso, dos níveis séricos de lipoproteínas de baixa densidade, de colesterol, de triglicérides, da glicose e da pressão arterial Portanto, paralelamente àquelas medidas que visam normalizar estas variáveis, é fundamental a redução do peso.

Neste estudo, os resultados mostraram uma correlação estatisticamente significativa entre 0 peso dos idosos e os valores de referência para triglicérides sangüíneos, sendo essa inversamente proporcional à HDL-c sangüínea, para ambos os sexos. Fica demonstrado que, no grupo estudado, a obesidade leva a hipertrigliceridemia, hipercolesterolemia e diminui as concentrações de HDL-C, o que pode aumentar o risco das doenças cardiovasculares. Neste estudo foi, ainda, possivel demonstrar associação estatisticamente significativa, entre o estado nutricional e os valores de referência para HDL-c sangüínea, para ambos os gêneros e para o gênero masculino, ou seja, nestes casos, indivíduos normais para o peso têm adequação dos niveis séricos de HDL-c. 
Estudos epidemiológicos, submetidos à análise multivariada, demonstraram que a hipertrigliceridemia varia na razão direta do valor da LDL-c e na razão inversa do HDL-c, sendo também influenciada pela condição clínica associada, na presença de hiperlipidemia familiar (SBC 1996).

Estudo realizado por Franco (1998), nos EUA, com mulheres entre 20 e 74 anos, mostrou que um quarto delas, apresentava excesso de peso, e que mais de um quarto eram sedentárias e hipercolesterolêmicas. No Brasil, um estudo de prevalência encontrou $41 \%$ de hipercolesterolemia em idosos (Guimarães et al 1998) .

Judelson (1994) e Wenger (1995) demonstraram que o nivel de HDLc é o melhor preditor de mortalidade para doenças ateroscleróticas (DAC) em mulheres, enquanto o nivel de LDL-c é o melhor preditor para os homens. Neste estudo foi encontrado, em relação á LDL-c e estado nutricional associação, somente, para o gênero feminino.

O presente estudo apontou associação entre a adequação de colesterol sérico e obesidade, ou seja, à medida que o valor energético aumenta tende-se à obesidade e as taxas sangüíneas de colesterol tornamse inadequadas, sendo isto verificado para ambos os gêneros e para o masculino. O excesso de peso (IMC) leva, geralmente os indivíduos, a triglicérides elevados e HDL-c baixo (Clevidence et al 1992; Lichtenstein et al 1994); este estudo vem ao encontro dessa afirmação, através das correlações apresentadas.

Neste estudo houve associação entre estado nutricional e adequação nos niveis sangüíneos de HDL-c, para ambos os gêneros e para o masculino; houve também associação entre ingestão de gorduras totais e HDL-C; outros estudos relacionam o elevado consumo de gorduras, e as altas concentrações plasmáticas de lipidios, excetuando-se os ácidos graxos ômega 3 (Loktionov et al, 2000; Person,2000). 
O presente trabalho não teve como objetivo fazer a correlação dos niveis séricos de CT, suas frações e triglicérides e as doenças apresentadas pelos idosos ou o risco delas ocorrerem, exceto a obesidade, produto dos dados do diagnóstico nutricional; o estudo pretendeu correlacionar os níveis bioquímicos dos exames propostos com a ingestão desses idosos. 


\section{CONCLUSÕES}

Os resultados obtidos neste estudo permitem as seguintes conclusões:

- Para ambos os sexos, a inadequação calórica levou à obesidade, porém a participação percentual de gordura total na dieta do grupo estudado mostrou-se adequada (menor que $30 \%$ ).

- A obesidade, presente em $42,1 \%$ dos idosos estudados, apresentou, para ambos os sexos, correlação estatisticamente significativa com os niveis séricos de triglicérides (TG), lipoproteina de alta densidade (HDL-C) e colesterol total (CT). Este resultado permite inferir que o aumento do peso corporal é fator predisponente ao aumento desses parâmetros bioquímicos apresentados. Este fato permite sugerir a correção da obesidade para o controle das hiperlipidemias.

- A ingestão fibras alimentares, que se mostrou menor do que a recomendada, não interferiu nos niveis séricos de HDL-c de forma significativa na população idosa estudada.

- Apesar da alta prevalência de obesidade nos indivíduos estudados, e da inadequação calórica da dieta, em ambos os sexos; o estudo mostrou correlação negativa entre a idade, consumo de gordura total e colesterol, sugerindo que possa existir uma preocupação dos idosos em compor a alimentação com menor quantidade desses nutrientes.

- A ingestão dietética de gorduras mostrou associação com os niveis séricos de HDL-c, que pode sugerir necessidade de controle deste nutriente na dieta dos idosos, no sentido de prevenir complicações que venham interferir na qualidade de vida dos idosos. 


\section{REFERÊNCIAS BIBLIOGRAFICAS}

Alencar YMG. Níveis de 25-hidróxi vitamina $D$ em indivíduos idosos. São Paulo;1994.[Dissertação de Mestrado - Faculdade de Medicina - USP].

Alencar YMG, Roncada MJ..Correa NC; Alencar IA., Baxter YC., Louette SC., Carvalho Filho ET., Wilson D. Problemas odontológicos e seus efeitos sobre os hábitos alimentares do idoso. In: Congresso Brasileiro de Geriatria e Gerontologia, 9․, São Paulo, 1991. Resumo. São Paulo, Sociedade Brasileira de Geriatria e Gerontologia, 1991. Tema Livre $n^{0} 10$.

Anderson JW et al,. Cholesterol-lowering effects of psylluim intake adjunctive to diet therapy in men and women with hypercholesterolemic: meta-analysis of 8 controlled trials. Am J Clin Nutr.2000; 71(2): 472-479.

Berquó ES, Souza JMP, Gotllieb SLD. Bioestatística.São Paulo: Editora Pedagógica e Universitária, 1980.

Beynen AC, Katan MB. Reproducibility of the variations between humans in response of serum cholesterol to cessation of eggs consumption. Arterosclerosis 1985;57:19-31.

Bray GA, Gray DS. Obesity: Pathogenesis. West J Med 1988;149(4):429441.

Cabrera AS,Jacob Filho W.Obesidade em idosos: Prevalência, distribuição e associação com hábitos e co-morbidade.Arq Bras Endocrinol Met 2001;45(5):494-501.

Campbell et al,. Diet, lifestyle, and the etiology of coronary artery disease: the Cornell China Study. Am J Cardiol.1998;82(10B):18Y-21T. 
Campos CM, Menezes T, Baechet T.Prevenção em Geriatria. In: Caminhos do Envelhecer. Sociedade Brasileira de Geriatria e Gerontologia. São Paulo:Ed. Revinter, 1994:p.39-43.

Campos MTFS, Monteiro JBR, Ornelas AB.C. Fatores que afetam o consumo alimentar e a nutrição do idoso. Rev Nutr 2000;13(3):157-165.

Carvalho Filho ET, Alencar YMG. Teorias do envelhecimento. In: Carvalho Filho ET, Papaléo Netto M. Geriatria: fundamentos, clínica e terapêutica. São Paulo:Ed. Atheneu; 1994.

Cervato AM, Mazzilli RN, Martins IS, Marucci MFN. Dieta habitual e fatores de risco para doenças cardiovasculares.Rev Saúde Públ 1997;31(3):227235.

Chumlea WC et al. Nutritional assessment of the elderly though antropometry. Ohio: Columbus; 1987.

Clevidence BA et al.Plasma lipid and lipoprotein concentrations of men consuming a low-fat, high-fiber diet. Am J Clin Nutr.1992;55:689-694.

Coitinho $\mathrm{D}$ et al,. Condições nutricionais da população brasileira: adultos e idosos.Brasília.INAN;1991.

Cordero $\mathrm{M}$ et al,. Weight loss is correlated with an improved lipoprotein profile in obese postmenopausal women. Am J Clin Nutr 2000;10(2):275284.

Duarte HS, Resende JB, Costa MMB. Efeito de uma sopa rica em fibras sobre a ingestão alimentar, peso e composição corporal. Rev Bras Nutr Clín $1999 ; 14: 228-236$. 
Duffy $V$ et al,. Olfactory dysfunction and related nutritional risk in freeliving, ederly women. J Am Diet Assoc 1995;95:89-93.

Dutra de Oliveira JE, Marchini JS. Ciências Nutricionais. São Paulo,Sarvier: 1998.

Federmann M. Conhecimentos e práticas alimentares de individuos diabéticos não insulino dependentes. São Paulo, 1994 [Dissertação de Mestrado-Faculdade de Saúde Pública da USP].

Food and Drug Administration FDA - Focus and food tabeling.Washington.DC;1993:42.

Frank AA, Soares EA. Nutrição no envelhecer. São Paulo, Atheneu: 2002.

Franco LJ. Epidemiologia das doenças crônicas não transmissíveis. Hucitec/Abrasco, 1998:123-137.

Garcia AMT et al,. Daily intake of macronutrients in a group of institucionalized elderly people in Leon.Spain. Nutr Hosp. 2003;18(2):87-90.

Garcia YM. Sinais clínicos, níveis bioquímicos e consumo alimentar de vitamina $A$ em idosos atendidos em ambulatório geriátrico. São Paulo, 2001 [ Tese de Doutorado- Faculdade de Saúde Pública da USP ]

Grodstein F et al,. Post menopausal hormone therapy and mortality. N England J Med.1997;25(1):769-775.

Guimarães AC, Lima A,Mota E,Lima JC, Martinez T, Conti AF. The cholesterol level of a selected Brazilian salaried population: biological and socioeconomic influences. CVD Prevention 1998,1:306-317. 
Guyton AC.,Hall JE. Tratado de fisiologia médica. Rio de Janeiro. $9^{a} \mathrm{Ed}$ Guanabara-Koogan:1997.

IBGE a -Instituto Brasileiro de Geografia e Estatístca. Estatística da população brasileira.

http://www.ibge.gov.br/home/estatistica/populacao,2000

IBGE b' -Instituto Brasileiro de Geografia e Estatística. Mulheres vivem 7,8 anos que homens no Brasil. http:llwww.ibge.gov.br, 2001.

Jenkins JAD et al,. Soluble fiber intake at a dose approved by the US Food and Drug Administration for a clain of health benefits: serum lipid risk factors for cardiovascular disease assesed in a randomized controlled crossover trial. Am J Clin Nutr. 2002; 75:834-839. (a)

Jenkins JAD et al,. A dietary portfolio approach to cholesterol reduction combined effects of plant sterols vegetable proteins, and viscous fibers in hypercholesterolemia. Metabolism.2002;51(12):1596 -1604.(b)

Judelson DR. Coronary heart disease in women : risk factors and prevention. J Am Med Assoc 1994; 49:186-187.

kamimura AM et al.Avaliação Nutricional. In: Cuppari L. Nutrição Clínica no Adulto. são Paulo: Manole,2002.

Kumanyike SK et al,. Maintenance of dietary behavior change. Health Psycho.2000;19(S): 42-56.

Lairon D.Review -Dietary fibers: effects on lipid metabolism and mechanisms of action. Eur J Clin Nutr 1996; 50:125-133. 
Ledikwe $\mathrm{JH}$ et al,. Nutritional risk assessment and obesity in rural older adults: a sex difference. Am J Clin Nutr .2003;77 (3): 551-558.

Lessa I. $O$ adulto brasileiro e as doenças da modernidade. Epidemiologia das doenças crônicas não transmissíveis 1998 Hucitec-Abrasco.

Lichtenstein $\mathrm{AH}$ et al.Short-term consumption of a low-fat diet beneficially affects plasma lipid concentrations only when accompanied by weight loss. Aterioscler Thromb.1994;14: 1751-1760.

Lipschitz DA. Screening for nutritional status in the elderly. Primary care.1994;21 (1): 55-67.

Lisette CPEM et al. Nutrition and Health of elderly people in Europe:EURONUT-SENECA study. Nutrition Reviews.1992;7:185-194.

Loktionov $A$ et al. Gene-nutrient interactions: dietary behavior associated with high coronary heart disease risk particularly affects serum LDL cholesterol in apolipoprotein e epsilon 4-carrying free-living individuals. $\mathrm{Br} \mathrm{J}$ Nutr 2000; 84(6):885-890.

Mahan LK, Arlin MT. Krause: Alimentos, nutrição e dietoterapia. $8^{\text {a }}$ ed São Paulo. Roca:1995

Mahan LK, Stump SE. Krause: Alimentos, nutrição e dietoterapia. $10^{\mathrm{a}}$ ed São Paulo. Roca: 2002.

Marucci MFN, coordenador. Grupo de Trabalho da Área Materno Infantil. In: Gandra YR, coodernador. Avaliação de Serviços de Nutrição e Alimentação. São Paulo: Sarvier; 1983. 
Marucci MFN Aspectos nutricionais e hábitos alimentares de idosos, matriculados em ambulatório geriátrico. São Paulo, 1992. [ Tese de doutorado - Faculdade de Saúde Pública - USP. ]

Microsoft Excel 2000 Versão (9.0.2812). N Y: 1998.

Moriguti CJ, Lucif JrN.; Ferrioli E. Nutrição do idoso. In: Dutra de Oliveira JE,Marchini SJ. Ciências nutricionais. São Paulo. Sarvier: 1998.

Moura EC, Sonati JG. Perfil lipídico e sua relação com os niveis de colesterolemia em escolares de uma escola pública de Campinas, São Paulo,Brasil. Rev Nutr. 1999;11(1):69-75.

Najas MS et al. Padrão alimentar de idosos de diferentes estratos sócioeconômicos residentes em localidade urbana da região sudeste, Brasil. Rev.Saúde Públ. 1994;28(3):187-91.

Najas MS, Sachs A Avaliação nutricional do idoso. In: Papaléo Netto M. Gerontologia. São Paulo. Atheneu, 1997.

Nascimento ML. Relação cintura/quadril, níveis séricos de colesterol e fraçōes e doenças crônico degenerativas em adultos, 1999 [ Dissertação de mestrado-Faculdade de Saúde Pública - USP ].

National Health and Nutrition Examination Survey (NHANES), III. 19881994.NHANES III.CD- ROM,Series $11, n^{\circ} 1 ; 1997$.

National Research Council: Recommended Dietary Allowances, $10^{\mathrm{a} e d}$. Washington, D.C., National Academy Press, 1989. (NRC).

Novaes VLSS. Padrão dietético de idosos de $\mathbf{8 0}$ anos e mais, atendidos em ambulatório de geriatria na capital de São Paulo, 1997 [ Dissertação de Mestrado FCF/FEAJFSP - Universidade de São Paulo ]. 
Oomen $\mathrm{CM}$ et al. Association between trans fatty acid intake and 10 years risk of coronary heart disease in the zutphen Elderly Study: a prospective population-based study. Lancet.2001;357(9258): 746-751.

Ortega RM et al,. Energy balance and caloric profile in the elderly obese or in those with overweight compared to those of normal weight. Med Clin. 1995;104(14): 526-529.

OPAS - Organização Panamericana Da Saúde - Ano Internacional das Pessoas Idosas. Envelhecimento: mitos na berlinda:1999.

Papaléo Netto M, Ponte JR. Envelhecimento:desafio na transição do século. In: Papaléo Netto M .Gerontologia. São Paulo. Atheneu:1997.

Pereira EAI, Cervato AM. Recomendações nutricionais. In: Papaléo Netto M. Gerontologia. São Paulo. Atheneu:1997.

Person TA. The undertreatment of LDL-cholesterol: addressing the challenge. Int J Cardiol.2000;74(1): 23S-28S.

Philippi ST,Szarfarc SC,Latterza AR. Virtual Nutri for windows [software] Versão 1,0. São Paulo: Departamento de Nutrição, Faculdade de Saúde Pública, USP, 1996.

Pogozheva AV et al,. Clinical metabolic evaluation of the effectiveness of the olive oil use in patients with cardiovascular disease. Vopr Pitan.2000;69(12):41-43.

Posner $\mathrm{BM}$ et al.. Preventive nutrition intervention in coronary hearty disease: risk assessment and formulating dietary goals. J Am Diet Assoc 1986;86:1395-1401. 
Quintero - Molina R. Nutricion en los ancianos. Geriatrika 1993; 9(1):14-18.

Ribeiro SML; Tirapegui J. Nutrição e envelhecimento. In: Tirapegui J. Nutrição fundamentos e aspectos atuais. São Paulo. Atheneu: 2001.

Ryan AS, Nicklas BJ, Berman DM, Dennis KE. Dietary restrition and walking reduce fat deposition in the midthigh in obese older women. Am J Clin Nutr 2000;72(3): 708-713.

Russel et al,. Modified food guide pyramid for people over seventy years of age. J Nutr.1999;129:751-753.

SBC - Sociedade Brasileira De Cardiologia. II Consenso sobre dislipidemia: detecção, avaliação e tratamento. Arq Bras Cardio 1996;67:109-128.

SBC - Sociedade Brasileira De Cardiologia. III Consenso. Diretrizes brasileiras sobre dislipidemias e diretriz de prevenção da aterosclerose. Arquivo Brasileiro de Cardiologia 2001;77:4-44.

Schiffman SS. Changes in taste and smell: Drug interactions and food preferences. Nutr Reviews1994;52:11S-17S.

Schlenker ED. Nutrition en el envejecimento. Morby/Doyma Libros:1994.

Schlenker ED. Who are the aging? In: Malinee $V$. Nutriton in aging, $3^{\text {rd }}$ ed, Boston. Mc Graw Hill: 1998.

Schlenker ED. Nutrition in aging, $3^{\mathrm{a}}$ Ed., Boston. Mc Graw- Hill: 2000. 
Schwab ND. Risk of coronary heart disease, dietary fat modification, stages of change, and self efficacy in surgically and naturally postmenopausal women. J Women Health Gen Based Med.2000;9(10): 1089-1099.

Shikany JM, White GLJr. Dietary Guidelines for cronic disease prevention. South Med J.2000;93(12): 1138-1151.

Siegel S..Estatística não-paramétrica. Trad Farias AA São Paulo. McGraw-Hill: 1975.

Suitor C, Hurter M. Nutrition Principles and applications in Health promotion. PHiladelphia: J B.Lippincott. Company: 1980.

Taddei CFG et al,. Estudo multicêntrico de idosos atendidos em ambulatório de cardiologia e geriatria de instituições brasileiras. Arq Bras Cardiol.1997;69(5):327-333.

The National Academies Press. Dietary Reference intake (DRI) - energy, carbohydrate, Fiber, Fat, faty Acids, Cholesterol, Protein, and Amino Acids. Institute of Medicine: 2002 part 1.

Toeller $\mathrm{N}$ et al,.Associations of fat and cholesterol intake with serum lipid levels and cardiovascular disease : the Eurodiab IDDM Complications Study. Expert Clin Endocrinol Diabetes. 1999;107(8): 512-521.

Torres IC, Mira L, Ornelas CP, Melim A. Study of the dietary fish intake on serum lipids and lipoprotein in two populations with different dietary habits. Br J Nutr 2000;83(4):371-379.

Toobert DJ et al. Physiologic and related behavioral outcomes from the women's lifestyle heart trial. Ann Beh Med 2000;22(1):1-9. 
Van Rossun CT et al,.Education and nutrient intake in Duch elderly people. The Rotterdam Study. Eur J Clin Nutr.2000;54(2): 159-165.

Van Staveren WA et al,. Assessing diets of elderly people: problems and approachs. Am J Clin Nutr.1994;59(S): 221-223.

Waitzberg DL, Feirini MT. Exame Físico e Antropometria. In: Waitzberg DL. Nutrição Oral, Enteral e Parenteral na Prática Clínica. $3^{a}$ ed. São Paulo: Atheneu; 2002.v1.

Wenger $\mathrm{Kn}$. Hypertension and other cardiovascular risk factors in women. Am J Hypertens 1995;8: 94S-99S.

Whitney EN, Cataldo CD, Rolfes SR. Understanding normal and clinical nutrition. Belmont. Wadsworth: 1998.

WHO, World Health Organization. Obesity : Preventing and Managing the global Epidemic (Report of a WHO Consultation on Obesity). Geneve : world Health Organization. 2000 (WHO_technical Report Series, 894). 
9. Anexos 
Anexo 1

\author{
Universidade de São Paulo \\ Faculdade de Saúde Pública \\ COMITÉ DE ÉTICA EM PESQUISA-COEP
}

Av. Dr. Arnaldo, 715 - CEP $01246-904$ - São Paulo - Brasil

Telefones: (55-11) 3066- 7779 fone/fax (55-11) 3064-7314 e-mail mdgracas a usp br

Of. $\operatorname{COEP} / 28 / 02$

08 de fevereiro de 2002

Pelo presente, informo que o Comitê de Ética em Pesquisa da Faculdade de Saúde Pública da Universidade de São Paulo-COEP, analisou e aprovou "adreferendum", de acordo com os requisitos da Resolução CNS/196/96, o protocolo de Pesquisa n. ${ }^{\circ}$ 631, intitulado: "PRATICA ALIMENTAR DE IDOSOS: INGESTÃO DE GORDURAS E FIBRAS, SUA RELAÇÃO COM O ESTADO NUTRICIONAL E PARÂMETROS BIOQUIMICOS", apresentado pela pesquisadora Vera Lúcia Sampar de Souza Novaes, que se propõe a utilizar dados secundários de sujeitos de pesquisa.

Atenciosamente,

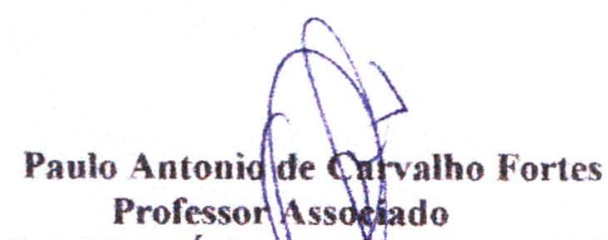

Coordenador do Comitê de Ética em Pẹquisa da FSP-COEP 


\section{Anexo 2}

FORMULÁRIO - PESQUISA IDOSOS

(Parte do formulário utilizado na pesquisa geral)

Identificação

Paciente $\mathrm{n}^{\circ}$

$R G n^{0}$

Data

Nome

Data de nascimento

sexo

cor

Naturalidade

Procedência atual

Procedência remota

Endereço

quanto tempo

Telefone

Ocupação

Instrução

\section{Parte I - Investigação Nutricional}

1 - Tem dificuldades ou dores quando mastiga os alimentos?

() $\operatorname{sim} \quad$ () não

2 - Mudou a forma de preparar os alimentos por causa disto ?

() $\operatorname{sim}$ () não

3 - Quais alimentos ?

4 - Tem algum alimento que não come ?

() $\operatorname{sim}$ () não Qual ?

5 - Por que?

() faz mal

() não tolera

() dificuldades financeiras

() dificuldades no preparo

() dificuldades para mastigar

() outros 


\section{Anexo 2}

\section{Parte II - Anamnese alimentar (recordatório de 24 horas)}

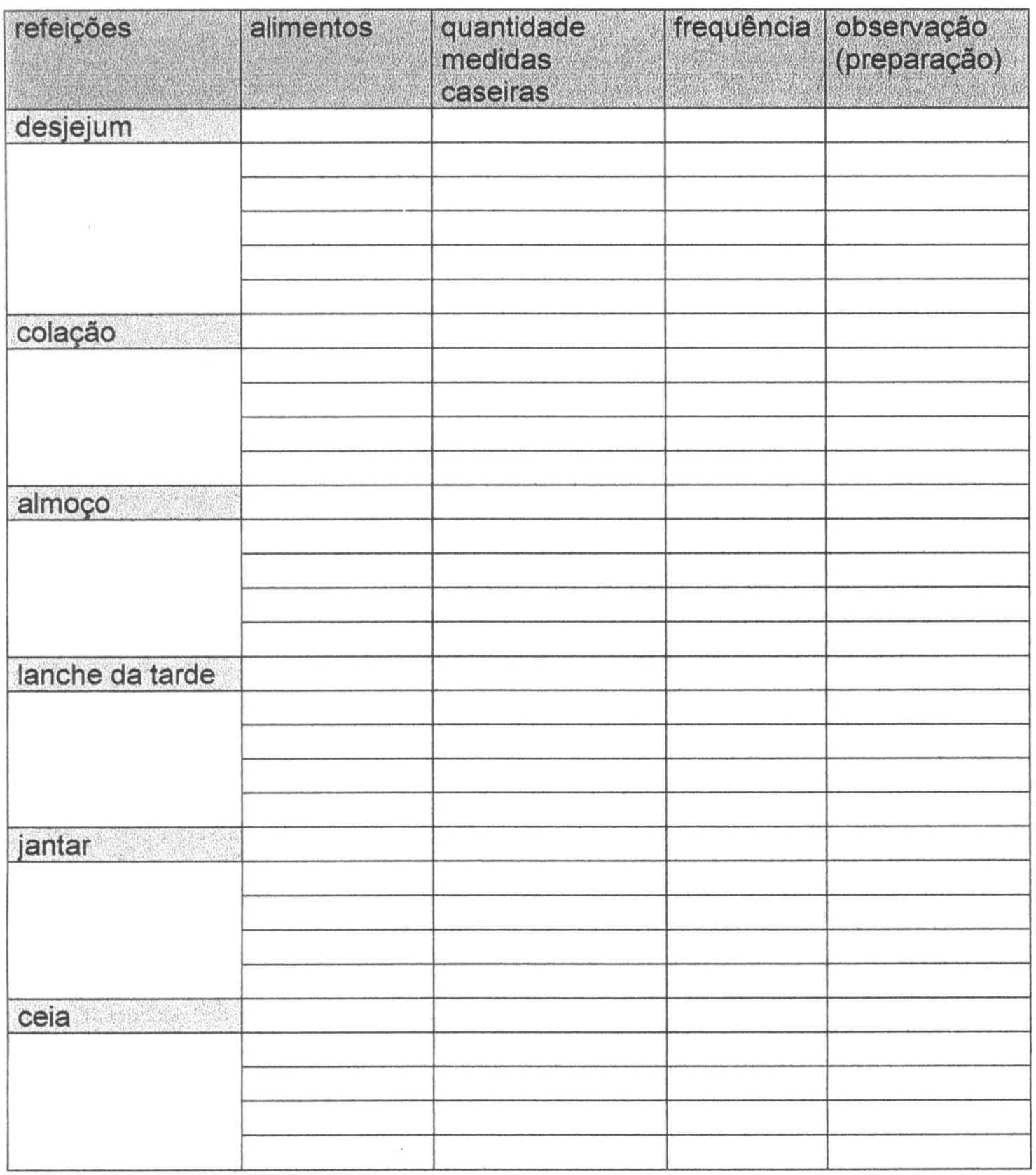

necessidades

calóricas:

necessidades

proteicas:

classificação

nutricional:

nutricionista 